\title{
Optimizing infectious disease control
}

Citation for published version (APA):

Heil, J. (2018). Optimizing infectious disease control: how to detect hidden infections? [Doctoral Thesis, Maastricht University]. Boekenplan. https://doi.org/10.26481/dis.20181025jh

Document status and date:

Published: 01/01/2018

DOI:

10.26481/dis.20181025jh

Document Version:

Publisher's PDF, also known as Version of record

\section{Please check the document version of this publication:}

- A submitted manuscript is the version of the article upon submission and before peer-review. There can be important differences between the submitted version and the official published version of record.

People interested in the research are advised to contact the author for the final version of the publication, or visit the DOI to the publisher's website.

- The final author version and the galley proof are versions of the publication after peer review.

- The final published version features the final layout of the paper including the volume, issue and page numbers.

Link to publication

\footnotetext{
General rights rights.

- You may freely distribute the URL identifying the publication in the public portal. please follow below link for the End User Agreement:

www.umlib.nl/taverne-license

Take down policy

If you believe that this document breaches copyright please contact us at:

repository@maastrichtuniversity.nl

providing details and we will investigate your claim.
}

Copyright and moral rights for the publications made accessible in the public portal are retained by the authors and/or other copyright owners and it is a condition of accessing publications that users recognise and abide by the legal requirements associated with these

- Users may download and print one copy of any publication from the public portal for the purpose of private study or research.

- You may not further distribute the material or use it for any profit-making activity or commercial gain

If the publication is distributed under the terms of Article $25 \mathrm{fa}$ of the Dutch Copyright Act, indicated by the "Taverne" license above, 
Academische Werkplaats

Publieke Gezondheid Limburg

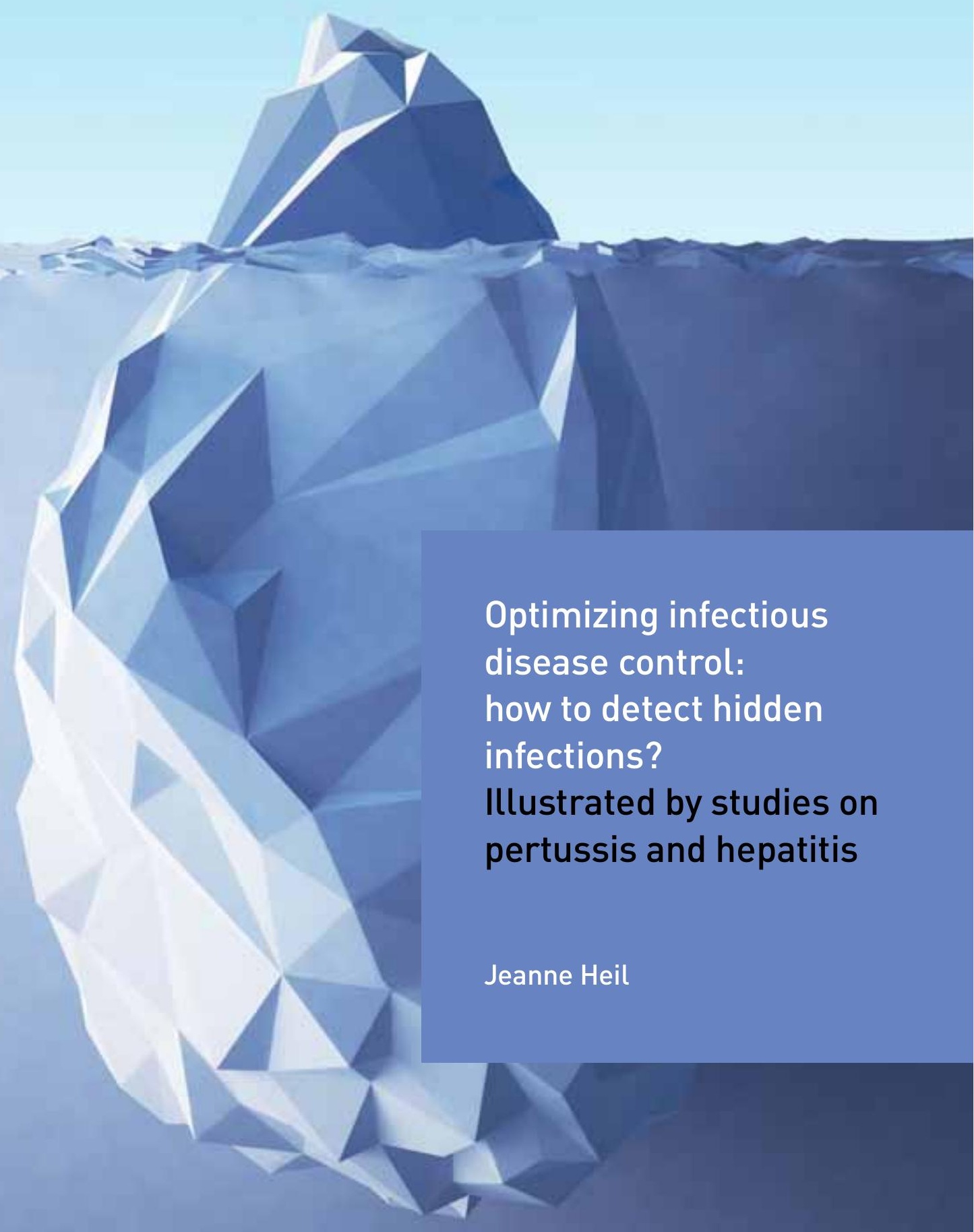





\section{OPTIMIZING INFECTIOUS DISEASE CONTROL: HOW TO DETECT HIDDEN INFECTIONS?}

Illustrated by studies on pertussis and hepatitis

Jeanne Heil

Academische Werkplaats Publieke Gezondheid Limburg 
(c) Copyright: Jeanne Heil, Maastricht 2018

Cover Design: Margret Reijnders I Creatieve Communicatie

Lay-out: Boekenplan

Printed by: Boekenplan

ISBN: 978-90-8666-457-3

No part of this thesis may be reproduced, stored, or transmitted in any form or by any means, electronic or mechanical, including photocopy, recording or any information storage or retrieval system, without prior permission of the copyright owner.

This thesis was prepared at the Department of Sexual Health, Infectious Diseases and Environmental Health at the Public Health Service South Limburg (GGD Zuid Limburg), the Care and Public Health Research Institute (CAPHRI) and the Department of Medical Microbiology at the Maastricht University Medical Centre.

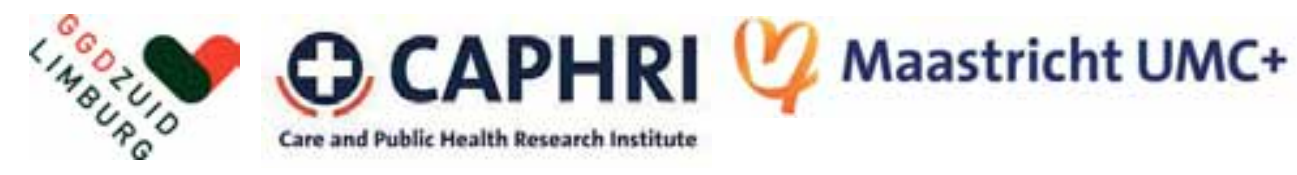




\section{OPTIMIZING INFECTIOUS DISEASE CONTROL: HOW TO DETECT HIDDEN INFECTIONS?}

Illustrated by studies on pertussis and hepatitis

\section{PROEFSCHRIFT}

ter verkrijging van de graad van doctor aan de Universiteit Maastricht,

op gezag van de Rector Magnificus, Prof. dr. Rianne M. Letschert

volgens het besluit van het College van Decanen,

in het openbaar te verdedigen

op donderdag 25 oktober 2018 om 12.00 uur

door

Jeanne Heil

Geboren op 27 november 1991 te Geleen. 


\section{Promotores}

Prof. dr. C.J.P.A. Hoebe

Prof. dr. J.W.L. Cals

\section{Copromotor}

Dr. N.H.T.M. Dukers-Muijrers

\section{Beoordelingscommissie}

Prof. dr. G.J. Dinant (voorzitter)

Prof. dr. M. Prins (GGD Amsterdam en AMC Amsterdam)

Prof. dr. J.H. Richardus (Erasmus MC Rotterdam)

Prof. dr. P. Savelkoul 
Dit proefschrift is tot stand gekomen vanuit de Academische Werkplaats Publieke Gezondheid Limburg, een samenwerkingsverband tussen de GGD Zuid Limburg, de faculteit Health, Medicine and Life Sciences van de Universiteit Maastricht en de 18 Zuid-Limburgse gemeenten. Het gepresenteerde onderzoek is uitgevoerd bij het Care and Public Health Research Institute: CAPHRI. CAPHRI participeert in de School of Primary Care Research (CaRe). 



\section{List of abbreviations}

$\begin{array}{ll}\text { ALAT } & \text { Alanine transferase } \\ \text { CDC } & \text { Centers for Disease Control and Prevention } \\ \text { CHC } & \text { Chronic hepatitis C } \\ \text { CI } & \text { Confidence interval } \\ \text { CT } & \text { Chlamydia Trachomatis } \\ \text { DAA } & \text { Direct-acting antiviral agents } \\ \text { DNA } & \text { Deoxyribonucleic acid } \\ \text { ECDC } & \text { European Centre for Disease Prevention and Control } \\ \text { ED } & \text { Emergency department } \\ \text { ELISA } & \text { Enzyme-linked immunosorbent assay } \\ \text { GIS } & \text { Geographic Information Systems } \\ \text { GP } & \text { General practitioner } \\ \text { GWPR } & \text { Geographically Weighted Poisson Regression } \\ \text { HAV } & \text { Hepatitis A virus } \\ \text { HBV } & \text { Hepatitis B virus } \\ \text { HCP } & \text { Health care provider } \\ \text { HCV } & \text { Hepatitis C virus } \\ \text { HEV } & \text { Hepatitis E virus } \\ \text { HIV } & \text { Human immunodeficiency virus } \\ \text { IDU } & \text { Injecting drug use } \\ \text { MSM } & \text { Men who have sex with men } \\ \text { NG } & \text { Neisseria Gonorrhoeae } \\ \text { NIP } & \text { National Immunisation Programme } \\ \text { OR } & \text { Odds ratio } \\ \text { PCR } & \text { Polymerase Chain Reaction } \\ \text { PHS } & \text { Public health service } \\ \text { PT } & \text { Pertussis toxin } \\ \text { PWID } & \text { People who inject drugs } \\ \text { RDS } & \text { Respondent Driven Sampling } \\ \text { RNA } & \text { Ribonucleic acid } \\ \text { RIVM } & \text { Rijks Instituut voor Volksgezondheid en Milieu } \\ \text { SD } & \text { Standard deviation } \\ \text { SES } & \text { Social economic status } \\ \text { STI } & \text { Sexually transmitted infection } \\ \text { WVR } & \text { Sustained virological response } \\ & \text { World Health Organization } \\ \text { WHO }\end{array}$





\section{Contents}

Chapter 1 General introduction

\section{Part 1 Pertussis}

Chapter 2 Pertussis surveillance and control: exploring variations and delays in testing, laboratory diagnostics and public health service notifications, the Netherlands, 2010 to 2013

J. Heil, H. ter Waarbeek, C. Hoebe, P. Jacobs, D. van Dam, T. Trienekens, J. Cals, I. van Loo, N. Dukers-Muijrers

Euro Surveill. 2017;22(28).

Chapter 3 Is the current pertussis incidence only the result of testing? A spatial and space-time analysis of pertussis surveillance data using cluster detection methods and geographically weighted regression modelling B. Kauhl, J. Heil, C. Hoebe, J. Schweikart, T. Krafft, N. Dukers-Muijrers PLoS One. 2017;12(3).

Chapter 4 Reasons for testing and non-testing for pertussis are not well known J. Heil, J. Cals, H. ter Waarbeek, C. Hoebe, N. Dukers-Muijrers Fam Pract 2018 (submitted)

\section{Part 2 Hepatitis}

Chapter 5 The Spatial Distribution of Hepatitis C Virus Infections and Associated Determinants-An Application of a Geographically Weighted Poisson Regression for Evidence-Based Screening Interventions in Hotspots B. Kauhl, J. Heil, C. Hoebe, J. Schweikart, T. Krafft, N. Dukers-Muijrers PLoS One. 2015;10(9).

Chapter 6 Detecting Hepatitis B and C by Combined Public Health and Primary Care Birth Cohort Testing

J. Heil, C. Hoebe, J. Cals, H. ter Waarbeek, I. van Loo, N. Dukers-Muijrers Ann Fam Med. 2018; 16(1).

Chapter 7 Hepatitis E prevalence in a sexual high-risk population compared to the general population

J. Heil, C. Hoebe, I. van Loo, J. Cals, G. van Liere, N. Dukers-Muijrers

PLoS One. 2018;13(1).

Chapter 8 General discussion

Chapter 9 Appendices

Summary

Samenvatting

Valorisation

Dankwoord

Portfolio

List of publications 

"Learn continually.

There's always 'one more thing' to learn."

Steve Jobs 



\section{Chapter 1}

General introduction 


\subsection{Infectious disease surveillance and control}

Infectious diseases are a public health problem worldwide and demand systematic preventive control measures. Infectious disease surveillance aims to monitor the impact of vaccination programmes, identify high-risk areas and detect outbreaks, monitor case management, take timely preventive measures and guide policy [1]. Infectious disease surveillance is the routine ongoing collection, analysis and dissemination of health data. Surveillance includes the monitoring of known infectious diseases and the detection of any emerging infectious diseases that may appear [2]. Efficient and reliable surveillance and notification systems are vital for monitoring public health trends and signalling disease outbreaks [3]. They form the backbone for evidence-based decision-making processes, as well as for infectious disease public health policies [3].

Some infectious diseases are vaccine-preventable. In the Netherlands, childhood vaccinations are covered by the National Immunisation Programme which includes vaccines for diphtheria, pertussis, tetanus, polio, haemophilus influenza type $b$, hepatitis $B$, pneumococcal, mumps, measles, rubella, meningococcal and human papillomavirus. Vaccination coverage is high, with 92 to $99 \%$, except for human papillomavirus vaccination where coverage is $58 \%$ [4]. Vaccinations for older people are routinely performed in general practice, while travellers may report to travel health clinics for vaccination. Apart from vaccination, certain public health interventions and preventive measures are key components of infectious disease control. Examples are the provision of safe blood and blood products for transfusion, infection prevention in hospitals and the management of needle stick injuries. Health education on hygiene and safe sex can limit the possible transmission of infectious diseases.

Prompt notifications of infectious diseases is important for public health services (PHS) in order to take appropriate and timely control measures and prevent further transmission of the infection. Source and contact tracing are at the centre of these interventions. The PHS identifies the original source of the infection and prevents possible transmission of the infection by tracing contacts of the patient. This may include vaccination or prophylactic use of antibiotics, advice to health care workers and other parties at risk, partner notification, hygiene measures, exclusion from work/school/day-care, monitoring exposed contacts, or in more severe cases isolation of contagious patients and quarantine for contacts.

Outbreak management is required in the case of a (re-)emerging infectious disease (threat) in the population. Surveillance followed by verification, case definition and active case-finding are the fundamentals of outbreak management. An outbreak management team is formed to coordinate control measures. Risk communication of the PHS to the general population, authorities and professionals can play an important role in reducing anxiety among the community and in giving advice on what people should do. Epidemic models and epidemiological investigation, like a case-control, cohort or cross-sectional research, might be necessary to determine the source of infection and transmission route. The choice of adequate public health response measures may depend on the outcome of such investigations. 
All notifiable diseases are reported anonymously by PHS to the national Centre of Infectious Disease Control (part of the Dutch National Institute for Public Health and the Environment; RIVM) in accordance with the Dutch Public Health Act. Notification of infectious diseases to regulating authorities is the basis of regional and national infectious disease surveillance, informing guidelines and policy in public health.

\subsection{Surveillance pyramid}

However, the number of notified infections are likely to represent just the tip of the surveillance pyramid. The total amount of infections in the community is under-estimated at several levels, see Figure 1.

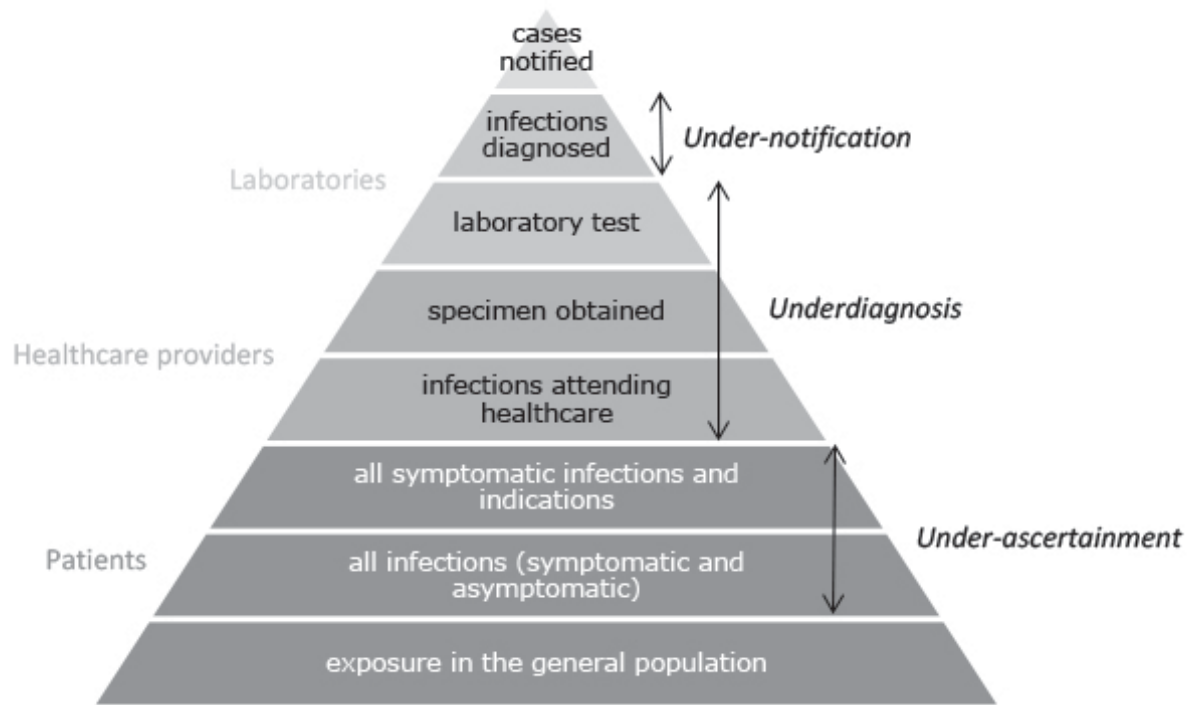

Figure 1. Overall surveillance data pyramid including three types of under-estimation of the total amount of infections in the general population.

Adapted from Gibbons et al. BMC Public Health 2014, 14:147 and the Centres of Disease Control and Prevention. FoodNet. Available at: http://www.cdc.gov/foodnet/surveillance.html [3, 5].

Starting from the bottom of the surveillance pyramid, some people in the general population are exposed to an infectious agent and some of those exposed become infected. Surveillance data are hampered by under-ascertainment as patients may not present themselves to healthcare for diagnosis, due to common mild and asymptomatic infections, low risk perception or because of care avoidance. Under-ascertainment can be estimated as the number of infections occurring in individuals not attending healthcare services for every case that attends [3]. The fact that many infections are asymp- 
tomatic in their early stage and thus go unnoticed, hampers the care seeking behaviour of patients and makes it difficult to assess and identify the total pool of infected individuals. For example, persons may be chronically infected with HBV or HCV infections for 20-30 years before they develop any clinical symptoms. Unless persons are tested and diagnosed, they are not aware of their disease and hidden inflammation progresses in the liver [6]. Health care avoidance is associated with serious psychological distress [7], undocumented migrants [8], uninsured homeless persons [9], preference for self-care or alternative care, dislike or distrust of doctors, fear or dislike of medical treatments, and a lack of time or money $[10,11]$.

General practitioners and physicians working in healthcare institutions and hospitals are the first to see, diagnose and treat a patient and play an important role as the eyes and ears of infectious disease control. In case of pertussis, infections may resemble other respiratory diseases, in particular in the early catarrhal phase when the patient is already highly contagious [12]. In adolescents and adults, the classical pertussis symptoms are often absent and therefore the case is not recognised by the healthcare provider [12-14].

In the case of a suspected infection, the healthcare provider can collect body fluids like blood, stool or saliva from the patient for a diagnostic procedure in a medical microbiological laboratory. If the laboratory confirms an infection and the disease is notifiable, the doctor or medical microbiologist reports the infection to the department of infectious disease control of the regional PHS. Primary schools and healthcare facilities, such as nursing homes, are liable to report cluster of certain syndromes, even in the absence of laboratory confirmation. Notifiable diseases are ranked within four categories ( $A, B 1, B 2$ and $C$ ) according to the severity of the infection and the corresponding preventive measures. Accurate diagnosis of infectious diseases depends on both the awareness and knowledge of physicians, and the sensitivity and specificity of laboratory tests. As the diagnostic process can be quite challenging, not all patients with an infection attending healthcare will be diagnosed correctly (underdiagnosis) or notified (under-notification). Underdiagnosis refers to those cases who attend healthcare but whose infection is not diagnosed or misdiagnosed [3]. Under-notification accounts for the failure to report all positive diagnoses through the notification system [3].

\subsection{Hidden infections}

Estimates suggest that $40-60 \%$ of major infections are currently hidden to care as they are undiagnosed and untreated [15-17]. In this doctoral thesis, as well as in infectious disease control in general, we distinguish the following definitions in the context of hidden infections: hard-to-reach populations, risk groups, hidden key populations, vulnerable and susceptible groups at risk.

Hard-to-reach populations is a term used to describe those sub-groups of the population who are difficult to involve in research or public health programmes due to their physical and geographical lo- 
cation or their social and economic situation [18]. Hidden infections might be more prevalent in hardto-reach populations such as individuals with low socio-economic status (SES) and low health literacy. In the Netherlands, for people with low levels of education life expectancy is six years shorter on average than for people with high levels [19]. In terms of life expectancy in good self-perceived health, the difference is 19 years [19]. Differences in health status also exist between ethnic Dutch versus ethnic minority populations and are strongly associated with work and income [19]. Health literacy is a wider concept than literacy, it is the combination of cognitive and social skills which determine the motivation and ability of individuals to gain access to, understand and use information in ways which promote and maintain good health [20]. Individuals with low health literacy often experience difficulties in understanding the information provided by health care providers and finding their way in the health care system, with consequent increased morbidity and mortality [21]. Low health literacy is associated with low patient activation, low knowledge of the disease and inadequate self-management [22]. Furthermore, individuals with low health literacy consult a general practitioner or medical specialist more frequently while they are less likely to participate in preventive programs [22].

Risk groups include individuals at higher risk of getting (or being) infected. Based on epidemiological research for each infectious disease several specific risk groups are identified based on characteristics such as age, gender and risk behaviour. For example, middle-aged men and injective drug users are risk groups for hepatitis $C[23,24]$.

In the context of balancing benefits and costs, those individuals at risk of getting infected who do not make use of needed medical care are considered as most important to identify. These hard-toreach risk groups are defined as hidden key population. For STI control, male sex workers form a hidden key population since they are at a very high risk of contracting STIs and HIV, hard to reach and largely invisible to regular care [25]. Identifying hidden key populations remains a challenge for improving infectious disease surveillance and control.

Overall, infectious diseases can be more severe in certain vulnerable and susceptible groups at risk, e.g. pertussis for unvaccinated young infants [26-29] and HEV for immunocompromised individuals [30-33].

Complications of infectious diseases are potentially severe. Hepatitis $\mathrm{C}$ virus for example can develop into progressive scarring of the liver (cirrhosis) and liver cancer (hepatocellular carcinoma). Moreover, the economic (costs) and public health (disease burden) impact of hidden infections is huge. Therefore, identifying and addressing these hidden infections could optimize the current infectious disease prevention, surveillance and control. Better insight into hidden infections allows for example more targeted and effective testing in order to eventually protect the most vulnerable and susceptible groups at risk. 


\subsection{Methods for identifying hidden infections}

Based upon knowledge of characteristics of hard-to-reach populations and specific risk groups, several methods can be used to identify hidden key populations in public health [18]. These methods assess the total number of underestimated (hidden) infections, including under-ascertainment, underdiagnosis and under-notification. Here, we describe the following methods aimed at identifying hidden infections: seroprevalence studies, surveillance studies, network based methods, the Workbook method, capture-recapture approach and the application of geographical analyses.

\section{Seroprevalence studies}

Seroprevalence studies estimate the prevalence of antibodies against an infectious disease in a defined population and period of time. The prevalence of notified cases may differ from the sampled seroprevalence. The difference may serve as an indicator of the prevalence of hidden infections. In pertussis, for example, the estimated seroprevalence according to national sero-surveys is 100 -fold higher than the prevalence of notified cases [34]. For Q-fever in particular, a study among blood donors concluded that the number of infected persons seems to be 10 -fold higher than the number of notified cases in the area most affected by Q-fever in 2009 [35].

\section{Surveillance studies}

During infectious disease surveillance, data is routinely collected by health care providers, laboratories, regional and national public health services. Identifying differences between surveillance systems can reveal under-notification [36]. The surveillance pyramid, as depicted in Figure 1, unravels the underestimation of the true total amount of infections in the general population and studying this pyramid can provide insight into the number of hidden infections.

\section{Network based methods}

Many infectious diseases spread largely between socially connected individuals, such as household members and schoolchildren, and they often occur in clusters [37,38]. There is growing evidence on the high potential of network based interventions. By using chain-referral methods such as Respondent Driven Sampling (RDS) and by partner notifications it is possible to reach hidden social and/or sexual networks. The basic idea behind RDS is that individuals with an infection (the indexes/seeds) function as an ambassador, they recruit and motivate others in their own network to get tested (first wave), and so on [39]. The RDS methodology has been applied to several risk groups such as injecting drug users, HIV patients and Chlamydia patients [40-43] and on syndromic surveillance [44]. RDS and partner notifications are feasible, promising and highly valuable tools. These network based methods reach hidden key populations, who are currently not in care. On the other hand, stigmatization, confidentiality and privacy issues can be important barriers to successful implementations of these methods $[40,45$, 46]. Additionally, the non-random recruitment of participants could bias the estimates of the hidden 
population in unknown ways [39]. Despite possible selection bias, chain-referral methods holds great promise for studying hidden populations.

\section{Workbook method}

The workbook method has been developed by the 'Joint United Nations program on HIV/AIDS' (UNAIDS) and the WHO, in collaboration with the UNAIDS Reference Group on Estimates, Modelling and Projections [47]. This method was developed for estimating the total HIV/AIDS prevalence in low endemic countries with concentrated epidemics [47], including both diagnosed and undiagnosed infections hidden to care. The workbook method identifies groups at high risk of becoming infected, estimating the size and the prevalence of those risk groups, and combining the groups to obtain a national estimate. In the Netherlands, the Workbook approach has been applied to $\operatorname{HCV}[15,48]$. This method is easy to use and standardises the approach to measuring surveillance in many countries which allows for estimation of global disease burden. This informs organisations in determining priorities, intervention strategies and treatment delivery. However, a lack of reliable data is one of the main obstacles for the Workbook method [47].

\section{Capture-recapture method}

The capture-recapture method originally comes from ecological studies estimating an animal population's size. This method is also suitable to estimate population size, coverage or sample success rate in epidemiological studies [18], e.g. for identifying hidden hepatitis C populations [24]. The method is based on at least two observations or sources of this population. The following variables have to be known in order to estimate the size of the total population: the number of individuals in the population observed in the first capture (or in the first source), the number observed in the second capture (or in the second source) and the number of individuals captured twice (observed in both sources) [49]. The primary assumption is that the population is homogeneous without any subgroups meaning each case in the population has the same catchability or probability of ascertainment. Second, for two sources at least, ascertainment of any case by the sources is independent. Third, the population should be closed/ stable over the study period. Furthermore, to minimize misclassification, each case should be diagnosed accurately [50]. Considering that all assumptions must be met for the model to be valid, estimates derived from this method may not be very precise. Nonetheless, in the case of populations not well known, even a rather imprecise estimate may yield valuable information [49].

\section{Geographic Information Systems}

Public health interventions targeted on behavioural risk groups can be effective in identifying and addressing hidden infections. However, the use of Geographic Information Systems (GIS) and spatial epidemiological methods may provide a more feasible basis for interventions through the identification of spatial clusters of infection, so-called hotspots, as well as demographic and socio-economic determinants [51-56]. Overall, by using GIS we can identify who is at risk, and where those at risk are located. 
Using GIS in real-time syndromic surveillance may be a valuable tool to minimise underdiagnosis, as has been shown to be the case retrospectively for the detection of hidden Q-fever outbreaks [57]. The increasing availability of a wide range of population-based variables allows a detailed analysis of demographic and socio-economic determinants of disease risk using spatial regression models at the ecological level. This information is important to facilitate cost-effective and targeted public health interventions. Such interventions are necessary to study to what extent the clusters and the demographic and socio-economic determinants really reflect the hidden population.

\subsection{Aim and outline of this thesis}

This thesis includes studies on how to detect hidden infections by using GIS (Chapter 3 and 5), a surveillance study (Chapter 2) and a seroprevalence study (Chapter 7). More in-depth studies relate to the underlying factors of hidden infections (Chapter 2 and 4) and on methods to reach (Chapter 6) hidden key populations. The thesis focuses on the evaluation of the current infectious disease surveillance and control in the Netherlands and will provide recommendations for future policy and research.

The first part of this thesis addresses pertussis surveillance and control. Chapter 2 evaluates the accuracy of the Dutch pertussis surveillance and control in the areas of medical care and public healthcare. Chapter 3 assesses whether current pertussis incidence is only the result of testing. The decision making of general practitioners in pertussis diagnostics is studied in Chapter 4.

The second part of the thesis focuses on the detection of hidden hepatitis infections. Spatial distribution of hepatitis $C$ infections is the subject of Chapter 5 . Chapter 6 includes a study on the diagnostic yield of a combined public health and primary care birth cohort testing strategy to detect hidden hepatitis $B$ and $C$ cases. The possible sexual transmission route of hepatitis $E$ is studied in Chapter 7 .

The overall aim of this thesis is to answer the research question "How to detect hidden infections and optimize infectious disease control?". 


\section{References}

1. WHO, WHO-recommended surveillance standards for surveillance of selected vaccine preventable diseases. 2003, WHO: Geneva, Switzerland.

2. Webber, R., Communicable disease epidemiology and control: a global perspective. 2nd edition ed. 2005.

3. Gibbons, C.L., et al., Measuring underreporting and under-ascertainment in infectious disease datasets: a comparison of methods. BMC Public Health, 2014. 14: p. 147.

4. van Lier, E.A., et al., Vaccinatiegraad Rijksvaccinatieprogramma Nederland. 2013, Rijksinstituut voor Volksgezondheid en Milieu (RIVM).

5. CDC. FoodNet Surveillance. Available from: http://www.cdc.gov/foodnet/surveillance. $\mathrm{html}$.

6. Global Hepatitis Report 2017. 2017, World Health Organization: Geneva.

7. Ye, J., R. Shim, and G. Rust, Health care avoidance among people with serious psychological distress: analyses of 2007 Health Information National Trends Survey. J Health Care Poor Underserved, 2012. 23(4): p. 1620-9.

8. Dorn, T., et al., Health care seeking among detained undocumented migrants: a cross-sectional study. BMC Public Health, 2011. 11: p. 190.

9. Slockers, M.T., I.R. van Laere, and R.B. Smit, [Street doctors warn of epidemic of uninsured homeless persons in the Netherlands]. Ned Tijdschr Geneeskd, 2015. 160: p. D214.

10. Kannan, V.D. and P.J. Veazie, Predictors of avoiding medical care and reasons for avoidance behavior. Med Care, 2014. 52(4): p. 336-45.

11. van Esch, T.E.M., et al., Rapportage inzicht in zorgmijden. 2015, NIVEL: Utrecht.

12. Wood, N. and P. Mclntyre, Pertussis: review of epidemiology, diagnosis, management and prevention. Paediatr Respir Rev, 2008. 9.

13. Winter, K., et al., California Pertussis Epidemic, 2010. J Pediatr, 2012. 161(6).

14. Barret, A.S., et al., Pertussis outbreak in northwest Ireland, January - June 2010. Euro Surveill, 2010. 15(35).
15. Vriend, H.J., et al., Hepatitis $\mathrm{C}$ virus prevalence in The Netherlands: migrants account for most infections. Epidemiol Infect, 2013. 141(6): p. 13107.

16. van Veen, M.G., et al., National estimate of HIV prevalence in the Netherlands: comparison and applicability of different estimation tools. AIDS, 2011. 25(2): p. 229-37.

17. Senior, K., Chlamydia: a much underestimated STI. Lancet Infect Dis, 2012. 12(7): p. 517-8.

18. Shaghaghi, A., R.S. Bhopal, and A. Sheikh, Approaches to Recruiting 'Hard-To-Reach' Populations into Re-search: A Review of the Literature. Health Promot Perspect, 2011. 1(2): $\mathrm{p}$. 86-94.

19. Hoeymans, N., et al., A healthier Netherlands: key findings from the Dutch 2014 Public Health Status and Foresight Report. 2014, National Institute for Public Health and the Environment (RIVM): Bilthoven, the Netherlands.

20. Nutbeam, D., Evaluating Health PromotionProgress, Problems and solutions. Health Promotion International, 1998. 13(1): p. 27-44.

21. Twickler, T.B., et al., [Low literacy and limited health literacy require health care measures]. Ned Tijdschr Geneeskd, 2009. 153: p. A250.

22. Fransen, M.P., K. Stronks, and M.L. Essink-Bot, Gezondheidsvaardigheden: Stand van zaken. 2011, Gezondheidsraad.

23. Nelson, P.K., et al., Global epidemiology of hepatitis $B$ and hepatitis $C$ in people who inject drugs: results of systematic reviews. Lancet, 2011. 378(9791): p. 571-83.

24. Vermeiren, A.P., et al., Identification of hidden key hepatitis $C$ populations: an evaluation of screening practices using mixed epidemiological methods. PLoS One, 2012. 7(12): p. e51194.

25. Verhaegh-Haasnoot, A., N.H. Dukers-Muijrers, and C.J. Hoebe, High burden of STI and HIV in male sex workers working as internet escorts for men in an observational study: a hidden key population compared with female sex workers and other men who have sex with men. BMC Infect Dis, 2015. 15: p. 291. 
26. WHO, Pertussis vaccines: WHO position paper, August 2015-Recommendations. Wkly Epidemiol Rec, 2015. 90(35): p. 433-58.

27. Pluta, R.M., C. Lynm, and R.M. Glass, Pertussis. J Amer Med Ass, 2010. 304(8).

28. Locht, C. and N. Mielcarek, New pertussis vaccination approaches: en route to protect newborns? FEMS Immunology and Medical Microbiology, 2012. 66.

29. Van der Maas, N.A.T., et al., Kinkhoest terug van weggeweest. Infectieziekten Bulletin, 2012.

30. Kamar, N., et al., Hepatitis E virus and chronic hepatitis in organ-transplant recipients. N Engl J Med, 2008. 358(8): p. 811-7.

31. Dalton, H.R., et al., Persistent carriage of hepatitis $E$ virus in patients with HIV infection. N Engl J Med, 2009. 361(10): p. 1025-7.

32. Kamar, N., et al., Factors associated with chronic hepatitis in patients with hepatitis E virus infection who have received solid organ transplants. Gastroenterology, 2011. 140(5): p. 1481-9.

33. Pas, S.D., et al., Hepatitis $E$ virus infection among solid organ transplant recipients, the Netherlands. Emerg Infect Dis, 2012. 18(5): p. 869-72.

34. de Greeff, S.C., et al., Seroprevalence of pertussis in The Netherlands: evidence for increased circulation of Bordetella pertussis. PLoS One, 2010. 5(12): p. e14183.

35. Hogema, B.M., et al., Coxiella burnetii infection among blood donors during the 2009 Q-fever outbreak in The Netherlands. Transfusion, 2012. 52(1): p. 144-50.

36. Gonfiantini, M.V., et al., Epidemiology of pertussis in Italy: disease trends over the last century. Euro Surveill, 2014. 19(40): p. 20921.

37. Mossong, J., et al., Social contacts and mixing patterns relevant to the spread of infectious diseases. PLoS Med, 2008. 5(3): p. e74.

38. Christakis, N.A. and J.H. Fowler, Social network sensors for early detection of contagious outbreaks. PLoS One, 2010. 5(9): p. e12948.

39. Salganik, M. and D. Heckathorn, Sampling and Estimation in Hidden Populations Using Re-
spondent-Driven Sampling. Sociological Methodology, 2004. 34: p. 193-239.

40. Theunissen, K.A., et al., Using intervention mapping for the development of a targeted secure web-based outreach strategy named SafeFriend, for Chlamydia trachomatis testing in young people at risk. BMC Public Health, 2013. 13: p. 996.

41. Malekinejad, M., et al., Using respondent-driven sampling methodology for HIV biological and behavioral surveillance in international settings: a systematic review. AIDS Behav, 2008. 12(4 Suppl): p. S105-30.

42. Theunissen, K., et al., A Web-Based Respondent Driven Sampling Pilot Targeting Young People at Risk for Chlamydia Trachomatis in Social and Sexual Networks with Testing: A Use Evaluation. Int J Environ Res Public Health, 2015. 12(8): p. 9889-906.

43. Johnston, L., et al., High HIV and hepatitis C prevalence amongst injecting drug users in Mauritius: findings from a population size estimation and respondent driven sampling survey. Int J Drug Policy, 2011. 22(4): p. 252-8.

44. Stein, M.L., et al., Enhancing Syndromic Surveillance With Online Respondent-Driven Detection. Am J Public Health, 2015. 105(8): p. e90-7.

45. Stein, M.L., et al., Comparison of contact patterns relevant for transmission of respiratory pathogens in Thailand and The Netherlands using respondent-driven sampling. PLoS One, 2014. 9(11): p. e113711.

46. Bauermeister, J.A., et al., Innovative recruitment using online networks: lessons learned from an online study of alcohol and other drug use utilizing a web-based, respondent-driven sampling (webRDS) strategy. I Stud Alcohol Drugs, 2012. 73(5): p. 834-8.

47. Lyerla, R., et al., The 2005 Workbook: an improved tool for estimating HIV prevalence in countries with low level and concentrated epidemics. Sex Transm Infect, 2006. 82 Suppl 3: p. iiii41-44.

48. Koopsen, J., et al., Chronic hepatitis B and C infections in the Netherlands: estimated prev- 
alence in high-risk groups and the general population. Submitted, 2018.

49. Marpsat, M. and N. Razafindratsima, Survey methods for hard-to-reach populations: introduction to the special issue. Methodological Innovations Online, 2010. 5(2): p. 3-16.

50. Hook, E.B. and R.R. Regal, Capture-recapture methods in epidemiology: methods and limitations. Epidemiol Rev, 1995. 17(2): p. 243-64.

51. Wang, L., et al., Spatial analysis on hepatitis $C$ virus infection in mainland China: from 2005 to 2011. PLoS One, 2014. 9(10): p. e110861.

52. Tanser, F., et al., Localized spatial clustering of HIV infections in a widely disseminated rural South African epidemic. Int J Epidemiol, 2009. 38(4): p. 1008-16.

53. Bush, K.R., et al., Mapping the core: chlamydia and gonorrhea infections in Calgary, Alberta. Sex Transm Dis, 2008. 35(3): p. 291-7.

54. Hu, M., et al., Determinants of the incidence of hand, foot and mouth disease in China using geographically weighted regression models. PLoS One, 2012. 7(6): p. e38978.

55. Haque, U., et al., Modelling malaria treatment practices in Bangladesh using spatial statistics. Malar J, 2012. 11: p. 63.

56. Lin, C.H. and T.H. Wen, Using geographically weighted regression (GWR) to explore spatial varying relationships of immature mosquitoes and human densities with the incidence of dengue. Int J Environ Res Public Health, 2011. 8(7): p. 2798-815.

57. van den Wijngaard, C.C., et al., In search of hidden Q-fever outbreaks: linking syndromic hospital clusters to infected goat farms. Epidemiol Infect, 2011. 139(1): p. 19-26. 



\section{Part 1}

\section{Pertussis}





\section{Chapter 2}

\section{Pertussis surveillance and control: exploring variations and delays in testing, laboratory diagnostics and public health service notifications, the Netherlands, 2010 to 2013}

Jeanne Heil, Henriëtte L.G. ter Waarbeek, Christian J.P.A. Hoebe, Peter H.A. Jacobs, Dirk W. van Dam, Thera A.M. Trienekens, Jochen W.L. Cals, Inge H.M. van Loo, Nicole H.T.M. Dukers-Muijrers 


\section{Abstract}

Pertussis is most severe among unvaccinated infants ( $<1$ year of age), and still leads to several reported deaths in the Netherlands every year. In order to avoid pertussis-related infant morbidity and mortality, pertussis surveillance data are used to guide pertussis control measures. However, more insight into the accuracy of pertussis surveillance and control, and into the range of healthcare and public health-related factors that impede this are needed. We analysed a unique combination of data sources from one Dutch region of 1.1 million residents, including data from laboratory databases and local public health notifications between 2010 and 2013. This large study ( $n=12,090$ pertussis tests) reveals possible misdiagnoses, substantial under-notification (18\%, 412/2,301 laboratory positive episodes) and a delay between patient symptoms and notification to the local public health services (median 34 days, interquartile range (IQR): 27-54). It is likely that the misdiagnoses, under-notification and overall delay in surveillance data are not unique to this area of the Netherlands, and are generalisable to other countries in Europe. In addition to preventive measures such as maternal immunisation, based on current findings, we further recommend greater adherence to testing guidelines, standardisation of test interpretation guidelines, use of automatic notification systems and earlier preventive measures. 


\section{Introduction}

Bordetella pertussis and Bordetella parapertussis infections are most severe among unvaccinated infants [1-4]. Complications of the resulting disease, pertussis, include pneumonia, failure to thrive from post-tussive vomiting, seizures, secondary bacterial infection and pulmonary hypertension $[2,5]$. The full implementation of general pertussis 7vaccination in the 1950s greatly reduced its incidence in the Netherlands [6] and led to a shift from cases in children to adults [5,7-9]. Even though worldwide vaccination coverage of $86 \%$ has been achieved [10], there were around 63,000 pertussislinked deaths in children under 5 years of age in 2012 [11]. In Europe, the highest number of cases were notified by the Netherlands in 2012 ( $n=12,868$ ), accounting for $30 \%$ of all notifications in Europe [12]. The Dutch incidence rate of symptomatic pertussis infections in 2011 was estimated to be 107 per 10,000 population [13].

The Netherlands has an extensive free of charge National Immunisation Programme (NIP) to protect all children against 12 infectious diseases, including pertussis [14]. The efficacy of pertussis vaccines has been debated because of waning immunity, incomplete protection of infants younger than 5 months of age, genetic changes in $\mathrm{B}$. pertussis and limited duration of protection $[3,15,16]$. Maternal immunisation is recommended by the WHO, ECDC and by the Health Council of the Netherlands $[12,17,18]$. In England, maternal immunisation was found to have a vaccine-effectiveness of $91 \%$ in infants $<2-3$ months of age with no side effects $[19,20]$. Despite a pertussis vaccination coverage in the Netherlands of $96 \%$, increasing numbers of pertussis notifications have been observed since 1996 [15,21,22], with epidemic peaks every 2-3 years [15] and 1 to 3 pertussis-related deaths per year [14].

Pertussis is a notifiable disease in the Netherlands according to Wet Publieke Gezondheid, the law that requires notification of NIP-targeted diseases [23]. Local public health services (PHS) must be notified when: (i) patients have typical symptom(s) or (ii) patients have at least 14 days of coughing, combined with either a positive laboratory test or recent contact with a confirmed pertussis case [24]. Legally, both healthcare providers (HCPs) and laboratories are responsible for notification, but in practice, most notifications originate from the laboratories. Local PHS collect and verify all notifications, advise patients' HCPs on vaccination and/or medical treatment of contacts, and report cases to the National Institute for Public Health and the Environment (RIVM). An overview of the guidelines and criteria for pertussis testing, diagnostics and notifications in the Netherlands is provided in Table 1. 
Table 1. Pertussis testing, diagnostics and notification guidelines and criteria, the Netherlands, 2010-2013

\begin{tabular}{|c|c|c|}
\hline Actor & Responsibility & Guidelines/criteria \\
\hline \multirow[t]{5}{*}{$\begin{array}{l}\text { Healthcare } \\
\text { provider }\end{array}$} & Clinical diagnostic & $\begin{array}{l}\text { Patients with typical symptoms }{ }^{\mathrm{a}} \text { or, during epidemics, patients with severe } \\
\text { coughing who have had contact with a proven pertussis case [45]. }\end{array}$ \\
\hline & $\begin{array}{l}\text { Requests for } \\
\text { laboratory testing }\end{array}$ & $\begin{array}{l}\text { When pertussis is suspected in a patient whose family includes unvaccinated } \\
\text { or incompletely vaccinated infants }<1 \text { year of age or a woman }>34 \text { weeks } \\
\text { pregnant [45]. } \\
\text { Test method for: } \\
\text { - Infants }<1 \text { year of age, PCR or culture } \\
\text { - Individuals }>1 \text { year of age and with }>3 \text { weeks of coughing, serology } \\
\text { - Individuals }>1 \text { year of age and with }<3 \text { weeks of coughing, PCR }[24,40,45] \text {. }\end{array}$ \\
\hline & $\begin{array}{l}\text { Medical treatment of } \\
\text { index case and/or } \\
\text { at-risk contacts }\end{array}$ & $\begin{array}{l}\text { First confirm the clinical diagnoses of the index case by laboratory test. In a } \\
\text { possible index case whose family includes unvaccinated or incompletely } \\
\text { vaccinated infants }<1 \text { year of age, a woman }>34 \text { weeks pregnant or a child } \\
\text { with severe heart or lung failure, treatment is indicated for all family members } \\
\text { and can start before laboratory confirmation of the index case. Medical } \\
\text { treatment outside the family only occurs after PHS advice and laboratory } \\
\text { confirmation of the index case }[24,45] \text {. } \\
\text { Preferably, start treatment of the index case within } 3 \text { weeks of illness onset } \\
{[24,45] \text {. }}\end{array}$ \\
\hline & $\begin{array}{l}\text { Vaccination of at-risk } \\
\text { contacts }\end{array}$ & $\begin{array}{l}\text { Administer first vaccination prior to vaccination of NIP or administer } \\
\text { vaccination to unvaccinated or incompletely vaccinated children }<5 \text { years old } \\
\text { in the family }[24,45] \text {. }\end{array}$ \\
\hline & $\begin{array}{l}\text { Notification of local } \\
\text { PHS [23] }\end{array}$ & $\begin{array}{l}\text { Patients with typical symptom(s) or with at least } 14 \text { days of coughing } \\
\text { combined with either a positive laboratory test or contact within past three } \\
\text { weeks with a confirmed pertussis case [24]. } \\
\text { Notify within one workday [44]. }\end{array}$ \\
\hline \multirow[t]{2}{*}{ Laboratory } & $\begin{array}{l}\text { Laboratory } \\
\text { diagnostics }\end{array}$ & $\begin{array}{l}\text { Interpret as positive for pertussis when detection of } B \text {. pertussis or } B \text {. } \\
\text { parapertussis or high antibody titre in single serology }{ }^{\mathrm{b}} \text { or significant increase } \\
\text { of titre in multiple serology. }\end{array}$ \\
\hline & $\begin{array}{l}\text { Notification of local } \\
\text { PHS [23] }\end{array}$ & $\begin{array}{l}\text { Patients with typical symptom(s) or with at least } 14 \text { days of coughing } \\
\text { combined with either a positive laboratory test or contact within past three } \\
\text { weeks with a confirmed pertussis case [24]. } \\
\text { Notify within one workday [44]. }\end{array}$ \\
\hline \multirow[t]{2}{*}{$\begin{array}{l}\text { Local public } \\
\text { health } \\
\text { services }\end{array}$} & Surveillance & $\begin{array}{l}\text { Collect notifications and clinical data from HCPs and laboratories and report it } \\
\text { to RIVM [23]. } \\
\text { Notify within one week [44]. }\end{array}$ \\
\hline & $\begin{array}{l}\text { Medical treatment } \\
\text { and/or vaccination } \\
\text { advice to the } \\
\text { patient's HCP }\end{array}$ & $\begin{array}{l}\text { Provide advice on medical treatment and vaccination according to national } \\
\text { guidelines. }\end{array}$ \\
\hline
\end{tabular}

HCP: healthcare provider; NIP: National Immunisation Programme; PHS: public health services; RIVM: National Institute for Public Health and the Environment.

a Typical symptoms include paroxysmal coughing, a whooping sound after coughing or vomiting after coughing [24].

${ }^{b}$ Single serological testing is not suitable to detect recent infection in individuals vaccinated with an acellular pertussis vaccine within the past year. Multiple serology is also recommended when the first titre is below the cutoff value specific for a pertussis infection [24]. 
Pertussis surveillance aims to monitor the impact of the vaccination programme, identify high-risk areas and detect outbreaks, monitor case management and take timely preventive measures [25]. However, pertussis surveillance and control are greatly hampered by, for example, under-ascertainment as individuals with mild symptoms or who are asymptomatic may not present to healthcare for diagnosis $[26,27]$. Clinically, the disease resembles other respiratory diseases, particularly in the early catarrhal phase when an individual is already highly contagious [26]. Also, the classical pertussis symptoms are often absent in adolescents and adults such that these cases may not be recognised by HCPs $[26,28,29]$. In 2006-2007, the estimated seroprevalence of pertussis infections was 100-fold higher than the reported notifications at that time [15]. Laboratory diagnostic procedures, especially interpretation of serology, are complicated because of changing cut-off value recommendations, in cases of recent immunisation and the limitations of available diagnostic tests $[5,27,30]$. As the pertussis diagnostic process is quite challenging, not all cases presenting to healthcare are diagnosed (underdiagnosis) or notified (undernotification) [31]. Moreover, there is debate about how to reduce the overall delay until notification to improve pertussis control [32,33].

A quantification of healthcare and public health factors that may compromise the accuracy of pertussis surveillance and quality of pertussis control in infants $<1$ year of age in day-to-day practice is missing. This study aims to assess possible pertussis misdiagnosis, under-notification and delay in laboratory testing and delay in notifications to PHS.

\section{Methods}

We evaluated the possible pertussis misdiagnosis, under-notification and delay using laboratory testing data and notification data from local PHS.

\section{Study location}

This study was conducted in Limburg, the southernmost province of the Netherlands. There are 1.1 million inhabitants and this population is comparable to the rest of the Netherlands in terms of sex composition and urbanisation, although it is slightly older [34]. All six medical microbiology laboratories in this province provided test data for this study. Notification data were retrieved from the two local PHS.

\section{Laboratory records and standardisation of results}

Laboratory data from pertussis testing requested by HCPs (general practitioners (GPs) and hospital specialists) and conducted by all laboratories in the study area between 2010 and 2013 were retrieved. The data included patient data on age, type of test performed (serology IgA/lgG, PCR and culture), type of HCP (GP or specialist), date of test request, date of test result, test result and interpretation of test result. No data on sex was reported. Based on regional GP testing-behaviour questionnaires, we estimated that the laboratory data covered at least $90 \%$ of all pertussis tests in our region. A total of 12,090 tests on 10,131 individuals were performed. 


\section{Laboratory tests}

The laboratories used different test assays, cut-off values and algorithms for interpreting test results, including interpretation of disease duration and patient age as the sensitivity of the diagnostic tests for pertussis depends on the age of the patient and the duration of illness [35]. Whether laboratories received clinical data to include into their algorithms depends on the HCP who requested the test. $\mathrm{B}$. pertussis IgA and/or pertussis toxin IgG ELISA from Virion/Serion (Würzburg, Germany) or Virotech (Rüsselsheim, Germany) was used for serology. The sensitivity and specificity of these serological test kits varied between $68 \%$ and $89 \%$ and between $67 \%$ and $87 \%$, respectively [36]. At one laboratory, the serological cut-off values changed on 1 September 2011. Two laboratories switched from Virotech Units (VU) to International Units (IU), one on 1 May 2011 and the other on 16 January 2012. Charcoal blood agar (Oxoid) with and without cephalexin were used for culture. Four of the laboratories used an inhouse multiplex PCR test with target gene IS481 (B. pertussis) and target gene IS1001 (B. parapertussis). The other two laboratories were unable to distinguish between B. pertussis and B. parapertussis because target gene IS1002 or target gene IS481 were used.

\section{Serology interpretation}

There are a lack of uniform laboratory guidelines on serology interpretation so different cut-off values are used by laboratories across Europe [27,37]. To correct for the different cut-off values used in our study area and to detect other inter-laboratory differences, we compared laboratory test interpretation to standardised serological test results. The conversion from $\mathrm{VU} / \mathrm{ml}$ to $\mathrm{IU} / \mathrm{ml}$ was calculated with the following formula:

\section{$\left((\text { number of } V U / m l /(33.3-\text { number of } V U / m l))^{1.15}\right) \times 112=I U / m l$.}

A single high titre of $\operatorname{lgG} \geq 62.5 \mathrm{IU} / \mathrm{ml}$ or $\mathrm{IgG} \geq 13 \mathrm{VU} / \mathrm{ml}$ was defined as positive as these cut-off values have been shown to be sensitive and specific indicators of infection in the past year [15,38,39]. International guidelines recommend measuring IgA antibodies with intermediate IgG levels or when no second sample can be obtained [40,41]. IgA antibodies were not taken into account in our standardisation as most laboratories did not use IgA antibody results in their serology interpretation. Furthermore, measuring IgA antibodies has been proven to be less specific and sensitive $[5,36]$. The standardised test result was considered positive when multiple serology was applied and all serology tests were positive, and it was considered negative when all serology tests applied were negative. When multiple serology test results were inconsistent, the standardised test result was considered positive when seroconversion occurred from a negative test to a positive test result.

\section{Notification data}

Notification data were collected from the two local PHS that serve the study area. These data included date of first day of illness, notifier (laboratory/GP/hospital), date of notification to PHS, date of notifica- 
tion to national notification system of RIVM and information on preventive measures taken by the PHS, including giving advice and providing vaccination or prophylaxes to at-risk contacts.

\section{Statistical analyses}

The laboratory data were analysed at the test-level and at the episode-level. Notably, a possible episode of pertussis disease was considered unique if the same individual was tested once or more within an 8-week interval. However, if an individual was tested twice within an interval longer than 8-weeks it was considered two possible pertussis episodes. Descriptive statistics and chi-squared tests were used to compare categorical variables such as type of HCP, laboratory, type of test and year of test.

Independent sample t-tests were performed to study differences in delay. For analyses of the notification data, we used descriptive statistics. Analyses were performed using the SPSS package version 21.0 (IBM Inc., Somers, New York, United States).

\section{Results}

\section{Possible misdiagnosis (underdiagnosis and overdiagnosis) of pertussis}

Of all HCP-requested pertussis tests done in the study region in 2010-2013 ( $n=12,090$ ), the majority $(81 \%, n=9,818)$ were requested by GPs, varying from $72 \%$ to $88 \%$ per laboratory $(p<0.001)$. The remaining pertussis tests were requested by hospital specialists $(19 \%, n=2,272)$. Most tests $(93 \%, n=11,190)$ were serological tests, $6 \%(n=729)$ were PCR tests and culture was performed in $1 \%(n=171)$. This distribution of test type differed between laboratories, ranging from, for example, $77 \%$ to $99 \%$ for serological tests $(p<0.001)$. Serological tests were more likely to be requested by GPs $(95 \%, n=9,275)$ compared with hospital specialists $(84 \%, n=1,915), p<0.001$.

In 44\% (134/303) of tested infants $<1$ year of age, serology was performed instead of the recommended PCR or culture (Table 2). This proportion differed by laboratory, varying from $24 \%$ to $70 \%$ ( $p<$ $0.001)$ and decreased over time, from $64 \%$ in 2010 to $33 \%$ in $2013(p<0.01)$. In these infants, GPs requested serology more often $(65 \%, 52 / 80)$ than hospital specialists $(37 \%, 82 / 223), p<0.001$. 
Table 2. Recommended tests and performed serology pertussis testing stratified into age groups, the Netherlands, 2010-2013

\begin{tabular}{lllll} 
Age group & $\begin{array}{l}\text { Recommended } \\
\text { test } \\
{[24,40,45]}\end{array}$ & $\begin{array}{l}\text { Total number of } \\
\text { performed } \\
\text { tests } \\
(\mathrm{n}=12,090)\end{array}$ & $\begin{array}{l}\text { Number of } \\
\text { performed } \\
\text { serology tests } \\
(\mathrm{n}=11,190)\end{array}$ & $\begin{array}{l}\text { Percent of } \\
\text { performed } \\
\text { serology tests (\%) }\end{array}$ \\
$\begin{array}{l}<1 \text { year } \\
>\text { 1 year with }>3\end{array}$ & PCR or culture & 303 & 134 & 44 \\
$\begin{array}{l}\text { weeks of } \\
\text { coughing } \\
>\text { 1 year with }<3\end{array}$ & Serology & & & 94 \\
$\begin{array}{l}\text { weeks of } \\
\text { coughing }\end{array}$ & PCR & 11,787 & 11,056 & \\
\hline
\end{tabular}

In total, 10,590 possible pertussis episodes were identified between 2010 and 2013 (Figure 1). Overall, $22 \%(n=2,370)$ of these possible episodes were interpreted by the laboratory as positive, with this varying between laboratories (15\% to $28 \%$ ) and over time (from $11 \%$ in 2010 to $27 \%$ in 2012 ) without a clear trend, $\mathrm{p}<0.001$. Serological tests had higher positivity rates $(23 \%, 2,276 / 9,736)$ compared to $\mathrm{PCR}$ tests and culture with positivity rates of $12 \%(83 / 715)$ and $8 \%(11 / 139)$ respectively, $p<0.001$.

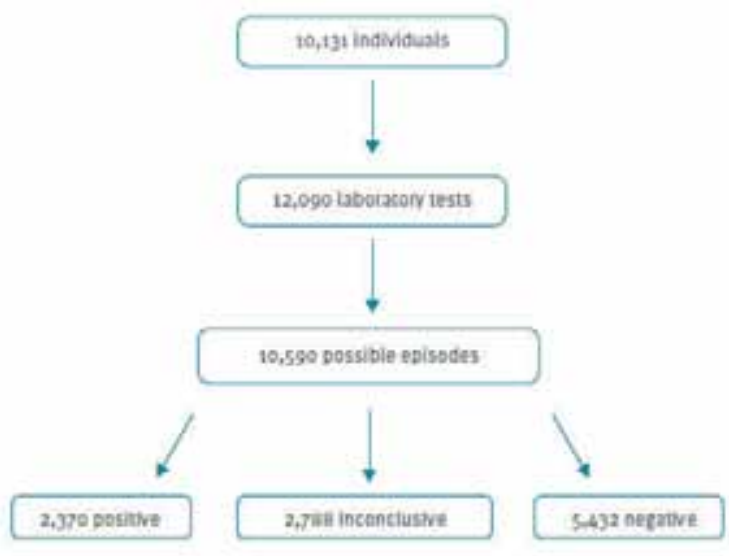

Figure 1. Possible pertussis episodes ${ }^{a}$ considered positive, inconclusive and negative by laboratories ${ }^{b}$, the Netherlands, 2010-2013 ( $\left.n=12,090\right)$

a A possible episode of pertussis disease was considered unique if the same person was tested once or more within an 8-week interval. If an individual was tested twice within an interval longer than 8-weeks, it was considered two possible pertussis episodes.

${ }^{\mathrm{b}}$ The laboratories used different test assays, cut-off values and algorithms for interpreting serology, PCR and culture test results as positive, inconclusive or negative. 
Furthermore, in $26 \%$ ( $n=2,788$ ) of the possible episodes, no conclusive laboratory test interpretation was available. These tests were inconclusive due to missing additional serological testing $(n=1,520)$, missing clinical data such as the first day of illness $(n=321)$, the possibility of past infections or antibodies after vaccination $(n=214)$ and no/dubious result available $(n=733)$. The proportion of possible episodes with an inconclusive laboratory result varied between laboratories ( $0 \%$ to $60 \%$ ) and increased over time (from $18 \%$ in 2010 to $35 \%$ in 2013), $p<0.001$.

Of all possible pertussis episodes with an available IgG-titre $(n=8,929), 22 \%(n=1,998)$ were positive according to the laboratory and $19 \%(n=1,700)$ appeared positive after standardisation. This standardised positivity rate varied between laboratories (15\% to $23 \%$ ) and over time ( $9 \%$ in 2013 to $24 \%$ in 2012), $p<0.001$. Of all episodes considered positive by the laboratory, $32 \%(n=644)$ were negative after standardisation. This was due to high IgA-titres in combination with IgG-titres below $62.5 \mathrm{IU} / \mathrm{ml}$. Of all inconclusive episodes, $9 \%(n=248)$ were positive after standardisation. This was due to the use of a grey area in both the interpretation of $\lg A$ - and $\lg G$-titres of some laboratories in combination with IgG-titres higher or equal to $62.5 \mathrm{IU} / \mathrm{ml}$. Of all negative episodes, $2 \%(n=98)$ were positive after standardisation (Table 3).

Table 3. Standardised test results for possible pertussis episodes using serology with available IgG-titres, Limburg province, the Netherlands, 2010-2013

\begin{tabular}{|c|c|c|c|c|c|c|}
\hline & \multicolumn{3}{|c|}{$\begin{array}{l}\text { Standardised }{ }^{\mathrm{a}} \text { result negative } \\
(\mathrm{n}=7,229)\end{array}$} & \multicolumn{3}{|c|}{$\begin{array}{l}\text { Standardised }{ }^{\mathrm{a}} \text { result positive } \\
(\mathrm{n}=1,700)\end{array}$} \\
\hline & Number (n) & $\begin{array}{l}\text { Percent } \\
(\%)\end{array}$ & $\begin{array}{l}\text { Variation } \\
\text { between } \\
\text { laboratories } \\
\text { (range of \%) }\end{array}$ & Number (n) & $\begin{array}{l}\text { Percent } \\
(\%)\end{array}$ & $\begin{array}{l}\text { Variation } \\
\text { between } \\
\text { laboratories } \\
\text { (range of \%) }\end{array}$ \\
\hline \multicolumn{7}{|c|}{$\begin{array}{l}\text { Laboratory interpretation of possible episodes with IgG titres } \\
(n=8,929)\end{array}$} \\
\hline $\begin{array}{l}\text { Positive } \\
(n=1,998)\end{array}$ & 644 & 32 & $0-57^{b}$ & 1,354 & 68 & $43-100^{b}$ \\
\hline $\begin{array}{l}\text { Inconclusive } \\
(\mathrm{n}=2,672)\end{array}$ & 2,424 & 91 & $45-95^{c}$ & 248 & 9 & $5-55^{c}$ \\
\hline $\begin{array}{l}\text { Negative } \\
(\mathrm{n}=4,259)\end{array}$ & 4,161 & 98 & $90-100$ & 98 & 2 & $0-10$ \\
\hline
\end{tabular}

a Cut-off values of $\mathrm{IgG} \geq 62.5 \mathrm{IU} / \mathrm{ml}$ and $\mathrm{IgG} \geq 13 \mathrm{VU} / \mathrm{ml}$ were used for standardisation. A single high titre at/above these values was defined as positive. The standardised test result was considered positive when multiple serology was applied and all serology tests were positive, and it was considered negative when all serology tests applied were negative. When multiple serology test results were inconsistent, the standardised test result was considered positive when seroconversion occurred from a negative test to a positive test result.

${ }^{\mathrm{b}} \mathrm{p}<0.01$.

${ }^{c} p<0.001$. 


\section{Under-notification of pertussis}

Of all notifications to local PHS between 2010 and $2013(n=2,241), 93 \%(n=2,090)$ were notified by a laboratory. The remaining notifications were by a GP $(3 \%)$, a hospital $(2 \%)$ or others $(2 \%)$. Of the total number of laboratory-positive episodes of persons living in the study region ( $n=2,301), 412(18 \%)$ were not notified to the PHS. This under-notification varied between laboratories from $10 \%$ to $39 \%$, and varied from 13\% in 2011 to $59 \%$ in 2010 with no trend, $\mathrm{p}<0.001$. All notifications were evaluated and verified by the local PHS, which were only able to take timely preventive measures, such as giving advice or providing vaccination or prophylaxes to at-risk contacts, in $1 \%(n=26)$ of all notifications.

\section{Delay in pertussis control cascade}

The median time between patients' first day of illness and HCP request for a laboratory test, patient and HCP delay, was 28 days (interquartile range (IQR): 21-47) (Figure 2). It was longer for serological test requests (median $=29$ days, IQR: 21-49) compared with PCR or cultures (median = 18 days, IQR: 13-24), $\mathrm{p}<0.001$. For infants, this delay was shorter (median $=12$ days, IQR: 6-19) compared with all other ages (median $=28$ days, IQR: 21-48), $\mathrm{p}<0.05$. Of all laboratory notifications, $28 \%(\mathrm{n}=571)$ were tested within 3 weeks. Median time from a requested laboratory test to a test result, median test delay, was 4 days (IQR: 3-7). The median test delay was longest for culture (7 days) and shortest for PCR and serology (4 days), $p<0.001$. In terms of notification delay, the median time between patients' first day of illness to local PHS notification was 34 days (IQR: 27-54). Of all laboratory notifications, $12 \%(n=245)$ were notified to the local PHS within 3 weeks. It then took local PHS a median of 2 days (IQR: $0-5$ ) to collect all patient and patient contacts information for a proper risk assessment and to notify RIVM. This is usually done by contacting HCPs for further essential risk information in order to decide on any necessary preventive measures. In $96 \%(1,538 / 1,601)$ of the notifications, it took less than 7 days for the local PHS report to the national system of RIVM.

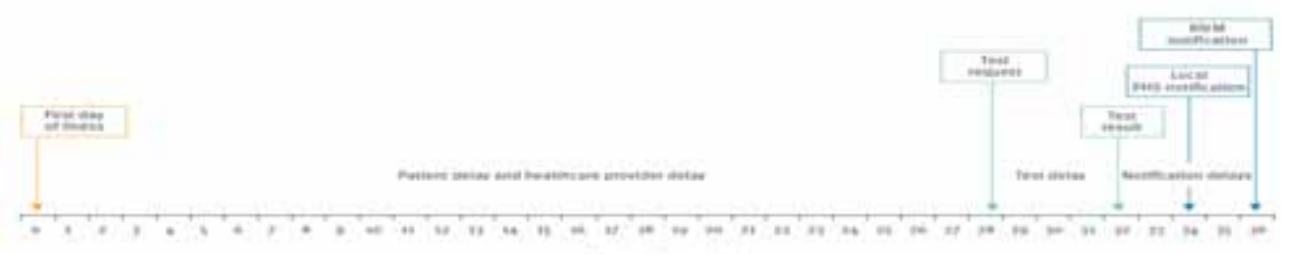

Meation nume uaver

Figure 2. Median time of Bordetella pertussis and Bordetella parapertussis infection from first day of illness to notification of the RIVM, Limburg province, the Netherlands, 2010-2013

PHS: public health services; RIVM: National Institute for Public Health and the Environment. 


\section{Discussion}

This study reveals possible pertussis misdiagnosis by both HCPs and laboratories, substantial undernotification of positive pertussis episodes by laboratories, and a large delay in the pertussis control cascade. All these factors negatively impact control strategies and jeopardise the effectiveness of the national pertussis surveillance system. The accuracy of pertussis surveillance is of urgent interest to all countries using notification data to guide pertussis surveillance and control. In our study, large variations in test behaviour, laboratory assays used, test interpretation and notification behaviour were observed between HCPs and between laboratories in the pertussis diagnostic process. This variation is likely to cause the accuracy of surveillance data to be different at the local level, yet which areas are more accurate than other areas is unknown. These results are also likely applicable to the other countries in Europe with similar surveillance systems considering the generalisability of misdiagnosis, under-notification and overall delay in surveillance data.

Just slightly over half of the infants were tested for pertussis using the recommended PCR or culture. Furthermore, a quarter of possible episodes in all ages lacked a conclusive laboratory test result. These results show the possibility of misdiagnosis and the complexity of the pertussis diagnostic process both for HCPs and for the laboratories. It is unknown whether the possible misdiagnoses caused underdiagnosis or overdiagnosis. The standardisation of test results using IgG-titres revealed that positivity rate differences between laboratories remained after correcting for the different cut-off values used. Laboratory differences in test interpretation, the variation in tests used and positivity rates have also been found in prior studies $[5,27,30]$.

Our study shows that almost one fifth of all laboratory pertussis diagnoses were not notified to the local PHS. A comparable under-notification rate has been reported in Italy [42]. Administrative and logistical problems are possible contributors to this under-notification. In the laboratory that used an automatic digital notification system, there was less under-notification $(10 \%)$ compared to the other laboratories, $p<0.001$.

There was a considerable delay in the national surveillance data. Overall, it took a median of 34 days from first day of illness before the local PHS was notified, and only $12 \%$ of all laboratory notifications were reported within three weeks, which is comparable to other Dutch findings [32,43]. Time from the laboratory test result to local PHS notification and from local PHS to RIVM was in accordance with the guidelines [44]. However, time from the first day of illness to a laboratory test request was 28 days, while pertussis remains contagious up to 3-4 weeks after the first symptoms [5]. Clinical diagnosis and diagnosis after laboratory testing is therefore made too late to start treatment or take any necessary preventive measures. Adequate and early diagnosis followed by antibiotic treatment is particularly important as it can prevent further transmission to infants, HCPs and pregnant women [21]. For optimal effectiveness, treatment has to be started early after onset of illness as pertussis is no longer present in respiratory secretions after about 3 weeks [45]. The long patient and/or HCP delay seen in this study therefore limits early treatment and optimal pertussis control. 
This study benefited from a large sample size and having complete regional data via a large database that included around $90 \%$ of laboratory tests for pertussis in one geographical area. Another strength was the availability of information on advice given or preventive measures taken by the local PHS for all notifications. Moreover, we studied data from across the pertussis control chain for both healthcare as well as public health. However, data on patient symptoms, disease awareness or healthcare-seeking behaviour were lacking. We were therefore unable to assess these patient-related factors as an explanation for patient delay. More information on the HCP's reasons to test for pertussis would have been desirable. It would be of interest to know whether they initiated any preventive measures for close contacts since notification often comes too late for local PHS to take action. Given that date of consultation was not known, we were unable to identify how much delay was attributable to patient and HCP delay, respectively. We were also unable to estimate under-notifications specifically for notifications by GPs or hospital specialists since we have no data on the number of clinical diagnoses. At last, the standardisation of laboratory results was only based on IgG antibodies and did not take any clinical data like vaccination status, duration of coughing or age into account. This meant that we were not able to estimate possible false positives or false negatives, but this limited standardisation does illustrate differences between laboratories that could lead to local differences in diagnosis or misdiagnosis.

\section{Conclusion and recommendations}

In conclusion, this study revealed several factors that prevent good pertussis control by PHS by contributing to misdiagnosis, under-notification and delay in notifications. These factors include suboptimal testing behaviour, laboratory diagnostic procedures, and notification behaviour. While the number of notifications are the current basis for pertussis surveillance, the accuracy of this indicator for disease occurrence and as a management tool is likely poor.

The accuracy of surveillance would be improved by focusing on the factors identified here. First, to reduce misdiagnosis and the variation in pertussis diagnostics, we recommend that laboratories and HCPs improve their adherence to national guidelines about when to perform which type of test and on whom. A national uniform guideline on serology cut-off values and the use of IgA and/or IgG is desirable. Testing all patients presenting with cough is not feasible as previous research has shown that only $3 \%$ of adult patients in 12 European countries presenting with acute cough in primary care had evidence of an acute pertussis infection [46]. In the Netherlands, the current pertussis incidence is largely the result of testing and more testing would not necessarily improve pertussis control [47]. Therefore, HCPs should focus more on diagnosing patients with pertussis-like symptoms who have pregnant women or infants in their proximity. Second, to reduce under-notification, laboratories and HCPs could benefit from using an automated notification system. Third, as public health is almost always too late to intervene, preventive measures should be carried out earlier in the pertussis control 
chain of actions. GPs, midwives and child care workers could play a major role here. Creating awareness among these professionals and patients about taking timely preventive measures could lead to lower individual disease burden and increased pertussis care cost-effectiveness. Additional preventive measures such as the recommended maternal vaccination [18] and shortening the chain of actions would contribute to improving the surveillance system and more importantly, preventing pertussis infection, morbidity and mortality prevention in infants.

\section{Acknowledgements}

We wish to thank Jos Bus (Zuyderland Medical Centre, Heerlen), Trix van Dijke (Laurentius Hospital, Roermond and St. Jans Gasthuis, Weert) for involvement in data collection. This work was supported by the National Institute for Public Health and the Environment - Centre for Infectious Disease Control (RIVM-Clb), the Netherlands (Grant number: 3910007379 ). 


\section{References}

1. WHO. Pertussis vaccines: WHO position paper - September 2015.Wkly Epidemiol Rec. 2015;90(35):433-58.PMID: 26320265

2. Pluta RM, Lynm C, Glass RM. Pertussis.JAMA. 2010;304(8):922. DOI: 10.1001/jama.304.8.922 PMID: 20736479

3. Locht C, Mielcarek N. New pertussis vaccination approaches: en route to protect newborns?FEMS Immunol Med Microbiol. 2012;66(2):121-33. DOI: 10.1111/j.1574695X.2012.00988.x PMID: 22574832

4. van der Maas NAT, Mooi FR, Berbers GAM, Swaan C, de Greeff S, de Melker HE. Kinkhoest, terug van weggeweest. [Recurrence of pertussis]. Infectieziekten Bulletin. 2012;23(8):229-34. Dutch. Available from: http://www.rivm.nl/dsresource?objectid=a57c96e4-a421-4e81-a292 -92aeebb5092c\&type=org\&disposition=inline

5. Crowcroft NS, Pebody RG. Recent developments in pertussis. Lancet. 2006;367(9526):192636. DOI: 10.1016/S0140-6736(06)68848-X PMID: 16765762

6. van Wijhe M, McDonald SA, de Melker HE, Postma MJ, Wallinga J. Effect of vaccination programmes on mortality burden among children and young adults in the Netherlands during the $20^{\text {th }}$ century: a historical analysis.Lancet Infect Dis. 2016;16(5):592-8. DOI: 10.1016/S14733099(16)00027-X PMID: 26873665

7. Pebody RG, Gay NJ, Giammanco A, Baron S, Schellekens J, Tischer A, et al. The seroepidemiology of Bordetella pertussis infection in Western Europe. Epidemiol Infect. 2005;133(1):15971. DOI: $10.1017 / S 0950268804003012$ PMID: 15724723

8. Zepp F, Heininger U, Mertsola J, Bernatowska $E_{1}$ Guiso N, Roord J, et al. Rationale for pertussis booster vaccination throughout life in Europe. Lancet Infect Dis. 2011;11(7):557-70. DOI: 10.1016/ S1473-3099(11)70007-X PMID: 21600850

9. von König $\mathrm{CH}$, Halperin $\mathrm{S}$, Riffelmann $\mathrm{M}$, Guiso $\mathrm{N}$. Pertussis of adults and infants.Lancet Infect Dis. 2002;2(12):744-50. DOI: 10.1016/S14733099(02)00452-8 PMID: 12467690
10. World Health Organization (WHO). Global and regional immunization profile. Geneva: WHO; 2017. Available from: http://www.who.int/immunization/monitoring_surveillance/data/ gs_gloprofile.pdf?ua=1

11. World Health Organization (WHO). Global Health Observatory Data Respository. By category $>$ Mortality and global health estimates $>$ Child mortality $>$ Causes of child death $>$ Number of deaths by cause $>$ By region $>$ World. Geneva: WHO. [Accessed 26 Sep 2016]. Available from: http://apps.who.int/gho/data/node. main.ChildMortREG100?lang=en.

12. European Centre for Disease Prevention and Control (ECDC). Annual epidemiological report 2014 - Vaccine-preventable diseases. Stockholm: ECDC; 2014.Available from: https://ecdc. europa.eu/sites/portal/files/media/en/publications/Publications/AER-2014-VPD-FINAL. pdf

13. McDonald $S A$, Teunis $P$, van $\operatorname{der}$ Maas $N$, de Greeff S, de Melker H, Kretzschmar ME. An evidence synthesis approach to estimating the incidence of symptomatic pertussis infection in the Netherlands, 2005-2011.BMC Infect Dis. 2015;15(1):588. DOI: 10.1186/s12879-015-1324-y PMID: 26715486

14. Schurink-van 't Klooster TM, de Melker HE. The National Immunisation Programme in the Netherlands: Developments in 2013. Bilthoven: National Institute for Public Health and the Environment (RIVM); 2013. Available from: http://www.rivm.nl/bibliotheek/rapporten/150202002.pdf

15. de Greeff SC, de Melker HE, van Gageldonk PGM, Schellekens JFP, van der Klis FRM, Mollema $L$, et al. Seroprevalence of pertussis in The Netherlands: evidence for increased circulation of Bordetella pertussis. PLoS One. 2010;5(12):e14183. DOI: 10.1371/journal. pone.0014183 PMID: 21152071

16. Cherry JD. Why do pertussis vaccines fail?Pediatrics. 2012;129(5):968-70. DOI: 10.1542/ peds.2011-2594 PMID: 22529282 
17. WHO. Pertussis vaccines: WHO position paper, August 2015--Recommendations.Vaccine. 2016;34(12):1423-5. DOI: 10.1016/j.vaccine.2015.10.136 PMID: 26562318

18. Gezondheidsraad. Vaccinatie tegen kinkhoest: doel en strategie. [Vaccination against pertussis: aims and strategy]. The Hague: Gezondheidsraad; 2015. Dutch. Available from: https:// www.gezondheidsraad.nl/sites/default/ files/201529_vaccinatie_tegen_kinkhoestdoel_ en_strategie.pdf

19. Amirthalingam $G$, Andrews $N$, Campbell $H$, Ribeiro $S$, Kara $E$, Donegan $K$, et al. Effectiveness of maternal pertussis vaccination in England: an observational study. Lancet. 2014;384(9953):1521-8. DOI: 10.1016/S01406736(14)60686-3 PMID: 25037990

20. Dabrera G, Amirthalingam $G$, Andrews $N$, Campbell H, Ribeiro S, Kara E, et al. A case-control study to estimate the effectiveness of maternal pertussis vaccination in protecting newborn infants in England and Wales, 2012-2013. Clin Infect Dis. 2015;60(3):333-7. DOI: 10.1093/ cid/ciu821 PMID: 25332078

21. de Greeff $S$, de Melker HE, Mooi FR. Kinkhoest in Nederland. [Pertussis in the Netherlands]. Ned Tijdschr Geneeskd. 2010;154: A1383. Dutch. Available from: https://www.ntvg.nl/ artikelen/kinkhoest-nederland/artikelinfo PMID:20170575

22. de Greeff SC, Mooi FR, Schellekens JFP, de Melker HE. Impact of acellular pertussis preschool booster vaccination on disease burden of pertussis in The Netherlands.Pediatr Infect Dis J. 2008;27(3):218-23. DOI: 10.1097/INF.0b013e318161a2b9 PMID: 18277916

23. Wet Publieke Gezondheid. [Public Health Act]. Pub. L. No. BWBR0024705. (9 Oct 2008). Dutch. Available from: http://wetten.overheid.nl/ BWBR0024705/2016-08-01

24. National Institute for Public Health and the Environment (RIVM). LCl - richtlijn kinkhoest. [ $\mathrm{LCl}$ guideline on pertussis]. Bilthoven: RIVM; 2012. Dutch. Available from: http:// www.rivm.nl/dsresource? objectid $=$ c $81 \mathrm{bb}$ f6c-1047-476b-bfbd-057f7ade3614\&type =pd- f\&disposition=inline

25. World Health Organization (WHO). WHO-recommended standards for surveillance of selected vaccine-preventable diseases. Geneva: WHO; 2003. Available from: http:// apps. who.int/iris/bitstream/10665/68334/1/ WHO_V-B_03.01_eng.pdf

26. Wood N, Mclntyre P. Pertussis: review of epidemiology, diagnosis, management and prevention.Paediatr Respir Rev. 2008;9(3):201-11, quiz 211-2. DOI: 10.1016/j.prrv.2008.05.010 PMID: 18694712

27. He Q, Barkoff AM, Mertsola J, Glismann S, Bacci S. High heterogeneity in methods used for the laboratory confirmation of pertussis diagnosis among European countries, 2010: integration of epidemiological and laboratory surveillance must include standardisation of methodologies and quality assurance.Euro Surveill. 2012;17(32):20239.PMID: 22913939

28. Winter $\mathrm{K}$, Harriman $\mathrm{K}$, Zipprich J, Schechter R, Talarico J, Watt J, et al. California pertussis epidemic, 2010. J Pediatr. 2012;161(6):1091-6. DOI: 10.1016/j.jpeds.2012.05.041 PMID: 22819634

29. Barret AS, Ryan A, Breslin A, Cullen L, Murray $A$, Grogan J, et al. Pertussis outbreak in northwest Ireland, January - June 2010. Euro Surveill. 2010;15(35):19654.PMID: 20822735

30. Dempsey AF, Cowan AE, Broder KR, Kretsinger K, Stokley S, Clark SJ. Diagnosis and testing practices for adolescent pertussis among a national sample of primary care physicians. Prev Med. 2009;48(5):500-4. DOI: 10.1016/j. ypmed.2009.02.020 PMID: 19264095

31. Solano $R$, Crespo I, Fernández MI, Valero C, Álvarez $\mathrm{Ml}$, Godoy $\mathrm{P}$, et al. Underdetection and underreporting of pertussis in children attended in primary health care centers: Do surveillance systems require improvement? Am J Infect Control. 2016;44(11):e251-6. DOI: 10.1016/j. ajic.2016.03.033 PMID: 27184210

32. Bonačić Marinović $A$, Swaan $C$, van Steenbergen J, Kretzschmar M. Quantifying reporting timeliness to improve outbreak control.Emerg Infect Dis. 2015;21(2):209-16. DOI: 10.3201/ eid2102.130504 PMID: 25625374 
33. Kraaij - Dirkzwager M. Ottovay $\mathrm{K}$, Kardamanidis $\mathrm{K}$, Swaan C. Melding op tijd of te laat? Terugkoppelingsrapportages aan GGD hebben meerwaarde. [Notification in time or too late? Feedback reports to PHS have added value]. Infectieziekten Bulletin. 2015;26(8):1759. Dutch. Available from: http://www.rivm.nl/ dsresource? objectid $=78965 \mathrm{~b} 5 \mathrm{f}-854 \mathrm{~b}-4 \mathrm{cb} 4-\mathrm{bd}$ $9 f-f c 02 f f 4 c 4 c 5 a \&$ type $=$ org\&disposition=inline

34. Centraal Bureau voor de Statistiek (CBS) Regionale kerncijfers Nederland. [Regional key figures the Netherlands]. The Hague: CBS. [Accessed 26 Sep 2016]. Dutch. Available from: http://statline.cbs.nl/Statweb/publication/?DM=SLNL\&PA $=70072$ NED\&D1 $=1-2,12$ $-23,42-45,51-56 \& D 2=0,16 \& D 3=18 \& H D R=T \& S T-$ $B=G 1, G 2 \& V W=T$

35. van der Zee A, Schellekens JF, Mooi FR. Laboratory Diagnosis of Pertussis.Clin Microbiol Rev. 2015;28(4):1005-26. DOI: 10.1128/CMR.00031-15 PMID: 26354823

36. Riffelmann $M$, Thiel $K$, Schmetz J, Wirsing von Koenig $\mathrm{CH}$. Performance of commercial enzyme-linked immunosorbent assays for detection of antibodies to Bordetella pertussis.J Clin Microbiol. 2010;48(12):4459-63. DOI: 10.1128/ JCM.01371-10 PMID: 20943873

37. Xing $D$, Markey $K$, Newland $P$, Rigsby $P$, Hockley J, He Q. EUVAC. NET collaborative study: evaluation and standardisation of serology for diagnosis of pertussis.J Immunol Methods. 2011;372(1-2):137-45. DOI: 10.1016/j.jim.2011.07.005 PMID: 21782823

38. Giammanco A, Chiarini A, Maple PA, Andrews N, Pebody R, Gay N, et al. European Sero-Epidemiology Network: standardisation of the assay results for pertussis. Vaccine. 2003;22(1):11220. DOI: $10.1016 / S 0264-410 X(03) 00514-0$ PMID: 14604578

39. de Melker HE, Versteegh FG, Conyn-van Spaendonck MA, Elvers LH, Berbers GA, van der Zee $A$, et al. Specificity and sensitivity of high levels of immunoglobulin $G$ antibodies against pertussis toxin in a single serum sample for diagnosis of infection with Bordetella pertussis. J Clin Microbiol. 2000;38(2):800-6.PMID: 10655388
40. Guiso N, Berbers G, Fry NK, He Q, Riffelmann M, Wirsing von König $\mathrm{CH}$. What to do and what not to do in serological diagnosis of pertussis: recommendations from EU reference laboratories. Eur J Clin Microbiol Infect Dis. 2011;30(3):307-12 DOI: 10.1007/s10096-010-1104-y PMID: 21069406

41. Centre for Disease Prevention and Control (ECDC). Guidance and protocol for the serological diagnosis of human infection with Bordetella pertussis. Stockholm: ECDC; 2012 Available from: https://ecdc.europa.eu/sites/ portal/files/media/en/publications/Publications/bordetella-pertussisguidance-protocol-serological-diagnosis.pdf

42. Gonfiantini MV, Carloni E, Gesualdo F, Pandolfi $E$, Agricola $E$, Rizzuto $E$, et al. Epidemiology of pertussis in Italy: disease trends over the last century. Euro Surveill. 2014;19(40):20921. DOI: 10.2807/1560-7917.ES2014.19.40.20921 PMID: 25323077

43. Niessen WJ, Broer J, Schellekens JF. Meldingsplicht voor kinkhoest niet effectief om ongevaccineerde kinderen te beschermen. [The obligatory notification of pertussis is not effective for the protection of unvaccinated children].Ned Tijdschr Geneeskd. 2008;152(2):8690. Dutch.PMID: 18265798

44. Meldingsnorm voor meldingsplichtige ziekten. [Notification norm for notifiable diseases] (2017). Dutch. Available from: http://www.rivm nl/Documenten_en_publicaties/Algemeen_ Actueel/Uitgaven/Infectieziekten/Meldingsnorm_voor_meldingsplichtige_ziekten

45. Verheij TJM, Hopstaken RM, Prins JM, Salomé $\mathrm{PL}$, Bindels PJ, Ponsioen BP, et al. NHG-Standaard Acuut hoesten (eerste herziening). [NHG guideline on acute coughing]. Huisarts Wet.2011;54(2):68-92. Dutch. Available from: https://www.nhg.org/standaarden/volledig/ nhg-standaard-acuut-hoesten

46. Teepe J, Broekhuizen BD, leven $M_{1}$, Loens $K_{1}$ Huygen $K$, Kretzschmar $M$, et al. Prevalence, diagnosis, and disease course of pertussis in adults with acute cough: a prospective, observational study in primary care. $\mathrm{Br} \mathrm{J}$ Gen Pract. 2015;65(639):e662-7. DOI: 10.3399/bjgp15X686917 PMID: 26412843 
47. Kauhl B, Heil J, Hoebe CJPA, Schweikart J, Krafft T, Dukers-Muijrers NHTM. Is the current pertussis incidence only the results of testing? A spatial and space-time analysis of pertussis surveillance data using cluster detection methods and geographically weighted regression modelling.PLoS One. 2017;12(3):e0172383. DOI: 10.1371/journal.pone.0172383 PMID: 28278180 



\section{Chapter 3}

Is the current pertussis incidence only the result of testing? A spatial and space-time analysis of pertussis surveillance data using cluster detection methods and geographically weighted regression modelling

Boris Kauhl, Jeanne Heil, Christian J.P.A. Hoebe, Jürgen Schweikart, Thomas Krafft, Nicole H.T.M. Dukers-Muijrers 


\section{Abstract}

\section{Background}

Despite high vaccination coverage, pertussis incidence in the Netherlands is amongst the highest in Europe with a shifting tendency towards adults and elderly. Early detection of outbreaks and preventive actions are necessary to prevent severe complications in infants. Efficient pertussis control requires additional background knowledge about the determinants of testing and possible determinants of the current pertussis incidence. Therefore, the aim of our study is to examine the possibility of locating possible pertussis outbreaks using space time cluster detection and to examine the determinants of pertussis testing and incidence using geographically weighted regression models.

\section{Methods}

We analysed laboratory registry data including all geocoded pertussis tests in the southern area of the Netherlands between 2007 and 2013. Socio-demographic and infrastructure related population data were matched to the geo-coded laboratory data. The spatial scan statistic was applied to detect spatial and space-time clusters of testing, incidence and test positivity. Geographically weighted Poisson regression (GWPR) models were then constructed to model the associations between the age-specific rates of testing and incidence and possible population-based determinants.

\section{Results}

Space-time clusters for pertussis incidence overlapped with space-time clusters for testing, reflecting a strong relationship between testing and incidence, irrespective of the examined age group. Testing for pertussis itself was overall associated with lower socio-economic status, multi-person-households, proximity to primary school and availability of healthcare. The current incidence in contradiction is mainly determined by testing and is not associated with a lower socioeconomic status.

\section{Discussion}

Testing for pertussis follows to an extent the general healthcare seeking behaviour for common respiratory infections, whereas the current pertussis incidence is largely the result of testing. More testing would thus not necessarily improve pertussis control. Detecting outbreaks using space-time cluster detection is feasible but needs to adjust for the strong impact of testing on the detection of pertussis cases. 


\section{Introduction}

Pertussis is a highly infectious respiratory disease caused by Bordetella Pertussis and is especially severe in unvaccinated and incomplete vaccinated children [1]. Despite the implementation of extensive vaccination schemes, the incidence of pertussis is increasing in many countries with a shifting tendency towards adults and elderly [2-7]. In fully vaccinated children and adults with waning immunity, the symptoms are often mild and indistinguishable from other respiratory diseases [5]. The clinical diagnosis of pertussis is challenging, not only because symptoms are often unspecific, but also because co-infection with respiratory diseases complicates diagnosis $[5,8,9]$. Additionally, sensitivity and specificity of the applied laboratory tests are influenced by vaccination coverage, frequency of mild cases within the population, exposure to pertussis and age of the patient so that no single laboratory test can be considered as "gold standard" for confirming pertussis cases [10]. The lack of universal standards to confirm pertussis infections thus further facilitates the spread of undiagnosed infections.

This is problematic, as transmission through infected, but undiagnosed members of the same household are held responsible for most transmissions to not or incomplete vaccinated infants [11]. To further reduce transmission, several countries such as France, USA and Australia have incorporated adult booster doses in their respective vaccination schemes [12-15] and the Dutch health council recently recommended the introduction of maternal vaccination to the national vaccination program [16].

In the Netherlands, the pertussis incidence is amongst the highest in Europe and rates have increased since 1996 [17]. The underlying reasons of this increase are not fully conclusive. Several studies attribute the increase of pertussis to a waning immunity in adults $[2,17]$ and new emerging strains of Bordetella Pertussis $[18,19]$. Other studies suggest that an increase of detected pertussis infections occurs mainly because of an increased awareness of the population and general practitioners (GPs) [20-22] and enhanced notification systems [21-23].

According to current general practitioner guidelines in the Netherlands, a clinical pertussis diagnosis is considered in patients having typical symptoms such as severe coughing who had contact with a proven pertussis case. Additional testing for pertussis is only recommended for patients in a household with an unvaccinated or incomplete vaccinated child younger than one year old and in households with a woman, which is more than 34 weeks pregnant [24]. For all other groups, testing is rather induced by the patient than the GP [25].

As pertussis is a notifiable disease in the Netherlands [26] and many other countries, the resulting surveillance data on testing and infections is used to monitor changes over space and time [27-29]. Despite previous findings that pertussis is highly heterogeneously distributed in space as well as in space-time [30,31], a substantial amount of current surveillance activities on pertussis is still restricted to a temporal analysis only $[7,28,29,32]$, masking important regional variations and thus complicating an effective public health response.

Geographic Information Systems (GIS) and cluster detection methods-both, purely spatial as 
well as in time and space have proven useful to locate possible outbreaks of infectious diseases [33-35], including pertussis [30], resulting in a timely and effective response in affected areas. Such an approach might ultimately help to minimize the spread of pertussis at an early stage when the risk of transmission is highest [36].

Efficient pertussis control however, requires additional background knowledge about the determinants of pertussis testing and the determinants of the current pertussis incidence. However, personal patient information such as occurrence of infections within the same household, household composition, vaccination status and socio-demographic characteristics are mostly unavailable on an individual level due to privacy restrictions of surveillance data [37]. Detailed population information on household composition, socio-economic variables and information on available healthcare and infrastructure is in the Netherlands only available on an aggregated level such as neighbourhoods or municipalities [38,39].

In this context, spatial regression models at the ecological level have been increasingly applied in epidemiological studies of infectious diseases in recent years as regression modelling based on aggregated population data allows an analysis of possible risk factors that are unavailable on an individual level [39-41].

Geographically weighted regression modelling (GWR) is an extension of traditional global spatial regression models and measures how the association between disease risk and sociodemographic population characteristics varies over space. This approach often led to the conclusion that the key populations for certain diseases depend largely on the place of residence, resulting in more cost-effective, targeted public health interventions aimed those groups who are most at risk in specific locations $[39,42,43]$.

This approach has shown to be effective in revealing associated determinants of several infectious diseases such as Hepatitis C [39], HIV [44] and Japanese encephalitis [42] but has also been useful to examine determinants of treatment seeking behaviour i.e. for Malaria [45] and could thus provide a feasible basis to examine the determinants of pertussis testing and the associated determinants of the current pertussis incidence.

The aim of our article is therefore (i) to examine spatial and space-time clustering of pertussis testing, incidence and test-positivity and (ii) to model the associations between sociodemographic, healthcare and infrastructure related determinants and pertussis testing and incidence using geographically weighted regression models.

\section{Data and methods}

\section{Ethics statement}

The medical ethics committee of the Maastricht University Medical Centre (Maastricht, the Netherlands) approved the study (11-4-136) and waived the need for consent to be collected from participants. 
Since retrospective data originated from standard care (in which one can opt-out for the use of their data for scientific research) and were analysed anonymously, no further informed consent for data analysis was obtained.

\section{Laboratory data}

Pertussis laboratory data were collected between Jan. 1st 2007 and Dec. 31st 2013 in the province Limburg, the Netherlands, comprising a population of 1,121,820 inhabitants [46]. Testing for pertussis was performed by GPs and hospitals in the area and the test-samples were then sent to the six laboratories in the region, which are capable of analysing the collected samples. The data for this study were therefore retrieved from the registries of these six laboratories in the province and included all pertussis tests requested by health care providers. In total, the data consisted of 15,429 tested persons of which $3,312(21.5 \%)$ persons were tested positive. Positivity was either based on the test result of the PCR ( $5.5 \%$ of tests), culture ( $2.4 \%$ of tests) or serology (IgG, $92.2 \%$ of tests); for the latter the international standard cut-off value of $\lg \mathrm{G} \geq 62.5 \mathrm{IU} / \mathrm{ml}$ or $\mathrm{lgG} \geq 13 \mathrm{VU} / \mathrm{ml}$ was used to be a sensitive and specific indicator of a pertussis infection in the past year $[47,48]$. This standardisation was made, instead of using the laboratory interpretation, because laboratories used test cut-offs that differed between the laboratories and over time. When multiple serology was applied to test a person and test results were inconsistent, the standardised test result was positive when seroconversion occurred from a negative test to a positive test result. In $8.8 \%(1,361)$ of the tested persons, standardization was not possible because IgG-titres were unavailable for the serological test. We were able to filter the laboratory result for most of these tests, but for a total of $1.0 \%$ (151) the test result remained missing.

Besides the results of the laboratory diagnosis, the available information included the four-digits postal code, sex, age and date of testing. In total 14,810 tested persons (96.0\%) and 3,150 positive persons $(95.1 \%)$ had valid postal codes assigned and were therefore included in our analyses.

\section{Outcomes}

As outcomes, we examined three different rates: (i) the proportion of tested persons per inhabitants (testing); (ii) the incidence of pertussis expressed as proportion of positive tested persons per inhabitants (incidence) and (iii) the proportion of positive to tested persons (test-positivity). Due to the different vulnerability between age groups [7], four demographic strata were used to calculate the rates outlined above: (i) children aged 0-14, (ii) adults between 15-64, (iii) persons aged 65 and older and (iv), total population. Although infants display the highest vulnerability to pertussis [1], an analysis of pertussis testing and incidence among 0-5 year olds was not advisable due to the low number of tests and infections in this age group.

\section{Explanatory variables}

We assessed several socio-demographic, infrastructure and healthcare-related variables for their association with the proportion of tested persons and pertussis incidence among the different age strata. 
The data and map sources were available from Statistics Netherlands [49]. The data were available per neighbourhood and had to be aggregated to the four-digits postal codes to match the pertussis laboratory data. In the Netherlands, a neighbourhood is an administrative area within a municipality with a homogenous socio-economic structure $[38,39,49]$. Due to privacy restrictions of statistics Netherlands, data for each variable is only reported for a minimum of inhabitants or households. For example, the number of persons in a specific age group is only reported for neighbourhoods with more than 50 persons, while average income is only reported for neighbourhoods with more than 100 persons $[38,39,49]$. The population-weighted aggregation was therefore only based on the neighbourhoods, for which data were made available. The age stratified population data, which were used for the calculation of the proportion of tested persons and the Pertussis incidence, was only available for 2013 from the Central Bureau for statistics Netherlands. As transmission occurs mainly between members of the same households [11], testing between different demographic strata is expected to follow a comparable pattern. We therefore included testing among the other age groups as independent variables in a regression analysis for testing in a specific age group. To analyse the determinants of the incidence, we included the rate of tested persons within the same age group and the rates of infected persons in the other age groups as independent variables. This should in a later stage confirm through GWR in which areas the effect of testing and potential intra-household transmission is stronger than in other areas.

\section{Exploratory disease mapping}

As our study aimed to highlight geographic heterogeneity among different demographic strata and different epidemiological outcomes on a small spatial scale, the numbers in the numerator for each examined demographic strata and epidemiological outcome can be considered as fairly low. This leads to a large variance of the respective rate simply due to varying population densities of relatively arbitrary administrative boundaries. As pertussis testing and infections are highly depending on local characteristics, neighbouring areas can therefore be expected to display similar rates and abrupt changes are more likely to occur due to the effect of relatively arbitrary administrative boundaries - also referred to as the modifiable area unit Problem (MAUP) [50]. We therefore applied a local empirical Bayesian smoothing approach where the respective rates are smoothed towards a local mean. The neighbours were defined as an area sharing a common edge or boundary [51]. The analysis was carried out in GeoDa 1.2.0 [52]. The resulting rates were then imported in ESRI ArcGIS 10.2.

\section{Local cluster detection}

Purely spatial cluster detection. The spatial scan statistic is a local cluster test, which identifies the geographic location and statistical significance of local clusters $[39,53,54]$. The rationale behind a cluster analysis in our study was to detect significant local clusters of high rates within one demographic stratum and compare the location of clusters within the other demographic strata. In this study, we used two different models in SaTScan: For the proportion of tested persons and the incidence of pertussis, we used a purely spatial Poisson model $[39,55]$. The input data for this model consisted of 
the number of tested persons / positive tested persons and the population per demographic stratum as well as the centroid coordinates of each postal code [56]. For the proportion of positive tested persons, we used a purely spatial Bernoulli model $[54,57]$. For this model, the input data consisted of the number of positive tested persons, the number of negative tested persons per demographic stratum and the centroid coordinates for each postal code [56]. The spatial scan statistic then uses a circular scanning window, which is flexible in size up to a user-specified maximum or the standard setting of including up to $50 \%$ of the population inside a cluster. The scanning window gradually moves over the coordinates over the study area, evaluating all possible cluster locations and sizes. The statistical significance is evaluated by computing 999 Monte-Carlo replications [58]. In our study, we set the maximum population at risk to be included in a possible cluster not to exceed $5 \%$. This was done since the default settings in SaTScan are more likely to produce very large clusters and therefore contain locations of low relative risk simply because of the circular scanning window [59]. The value of $5 \%$ of the maximum population at risk was based on the experience of a previous study in the area, which met our criterion of including only locations of elevated risk in a cluster [39].

Space-time cluster detection. A space-time cluster analysis was employed in this study to evaluate whether testing, incidence and test-positivity occur at the same geographical locations and in the same time periods, providing background information whether space-time clusters of pertussis incidence are correlated in space-time with testing.

The space-time cluster analysis in SaTScan is comparable to a purely spatial model, except that the scanning window may be represented as a cylinder, where the base of the cylinder represents the geographic location and the height of the cylinder represents the time component of the scanning window. The scanning window then moves over all centroid coordinates across the study area and evaluates all possible space-time clusters within the study area and study period [60]. Similar to the purely spatial cluster analysis, we used for both, proportion of tested persons and incidence a spacetime Poisson model and for the proportion of positive to tested persons, a space-time Bernoulli model [61]. In this study, we used a scanning window that may contain up to $10 \%$ of the background population and up to 12 months of the study period. The calculation of purely spatial and space-time clusters was carried out using SaTScan v9.4.1.

Selection of explanatory variables. To select a meaningful set of explanatory variables for the regression analysis, we used a data-mining tool called "exploratory regression" in ESRI ArcGIS 10.2. This tool is comparable to a forward step-wise regression. In each step, one additional variable is added to the regression equation and evaluated based on following criteria in our analysis: (i) The regression coefficients are statistically significant $(p<0,05)$ and (ii) do not display multicollinearity (Variance Inflation Factor < 7.5) [62]. We then chose a set of statistically significant explanatory variables as suggested by the exploratory regression that delivered a plausible explanation of the respective outcome (the proportion of tested persons or the pertussis incidence in the respective age group).

Geographically weighted poisson regression. We constructed spatial regression models based on the variables suggested by the exploratory regression, which delivered a plausible explanation of the 
respective outcome. Global spatial regression models are often applied to determine the strength of the association between the dependent variable and a set of explanatory variables, but the obtained coefficients are averaged over the whole study area [51,63]. Our study area however, consisted of 258 postal codes and the socio-demographic composition and available infrastructure varies at local level. It is therefore unlikely that one single coefficient per explanatory variable would be a good estimator of the strength of the association for the whole study area. We therefore favoured a geographically weighted regression (GWR) approach over a global approach. Geographically weighted regression modelling measures how the relationship between a set of explanatory variables and an epidemiological outcome varies over space, resulting in more detailed understanding of the spatially varying key populations and local characteristics of the study area for different epidemiological outcomes [39,41,43,45,64].

The Poisson distribution among the available GWR models is most suitable for diseases, especially if observed counts of cases are low in certain areas [39,65-67]. The dependent variable was in the analysis for testing specified as the number of tests and in the analysis for incidence as positive cases per postal code. The offset variable was specified as the number of inhabitants per postal code. The centroids of each postal code area were used as input coordinates. The geographically weighted Poisson regression (GWPR) calculates an additional global Poisson model to allow a comparison between a global and a local approach. The GWPR uses a kernel function to fit a regression equation for each postal code area, where the centre of the kernel is the regression point. The kernel function assigns decreasing weights to the observations, depending on the distance (bandwidth) of the respective observation to the centre. The bandwidth of the kernel in GWPR can be either fixed or adaptive and the shape of the kernel can follow a Gaussian or a bi-square distribution. The optimization of the bandwidth in a GWPR model can be based on one of the three available criteria: (i) Akaikes Information Criterion (AIC); (ii) Akaikes corrected Information Criterion (AICc) and (iii) Bayesian Information Criterion (BIC) $[63,68]$. We thus evaluated all 12 possible combinations of kernel shape, bandwidth type and bandwidth optimization method for the eight different dependent variables. The models without clustered residuals were further considered and out of those, the models with the lowest AICc value and highest adjusted $\mathrm{R}^{2}$ were then chosen as the final models. The statistical significance of each coefficient per postal code was calculated using pseudo t-values [63]. The statistic behind GWPR is described in detail elsewhere [63].

We assessed clustering of the residuals of the GWPR using the global Moran `s I test in ESRI ArcGIS 10.2. The computation of GWPR was carried out in the GWR4 software [68]. The coefficients were standardized to allow a direct comparison of the strength of association among the examined explanatory variables. To enhance visualization of the spatially varying coefficients, we used the software `s "prediction at non-sample points" function and calculated the predicted values for a grid of Limburg based on a cell size of $100 \mathrm{~m} \times 100 \mathrm{~m}$. The obtained values were then interpolated using ordinary kriging in ESRI ArcGIS 10.2 . 


\section{Results}

\section{Purely spatial analysis}

Testing. The spatial distribution of the proportion of tested persons among the different demographic strata displayed strong local variations and local clustering (Fig 1). The proportion of tested persons differed widely between the examined age groups and is highest in children (Table 1).

All demographic groups displayed strong local clustering. Despite the differences in the proportion of tested persons, local clustering displayed similar patterns among the different demographic strata. Local clusters were observed especially in the central and northern parts of the study area. In the southern part in contradiction, no clusters could be observed.

Table 1. Rates of testing, test positivity and population incidence

\begin{tabular}{lllllll} 
& Tested (\%) & \multicolumn{2}{c}{ Positive tested (\%) } & \multicolumn{2}{c}{ Incidence (\%) } \\
& Mean & SD & Mean & SD & Mean & SD \\
Age & & & & & & \\
$0-14$ & 2.39 & 1.52 & 29.77 & 22.83 & 0.72 & 0.70 \\
$15-64$ & 1.27 & 0.75 & 18.45 & 13.20 & 0.23 & 0.16 \\
$>65$ & 0.92 & 0.93 & 18.22 & 17.49 & 0.16 & 0.24 \\
All ages & 1.36 & 0.72 & 21.27 & 14.09 & 0.29 & 0.22 \\
\hline
\end{tabular}

$\mathrm{SD}=$ standard deviation.

Incidence. The incidence of pertussis varied between the different demographic groups and was also highest in children (Table 1). Overall, the clusters of the pertussis incidence followed closely the locations of the observed clusters for testing (Fig 1), reflecting a strong spatial correlation to the patterns of testing. The clusters of pertussis incidence among children partially overlapped with clusters among adults and the clusters among adults overlapped in certain areas with those for seniors.

Test-positivity. Test-positivity was again highest in children, but the positivity rate did not differ much between adults and seniors (Table 1). Test-positivity in children was the only rate that did not display any local clusters (Fig 1). Among adults, seniors and the total tested persons, only a small number of clusters were observed. Except for one cluster in the southwestern part of the study area for the total tested persons, the clusters observed for test-positivity overlapped with the clusters for testing and incidence.

\section{Space-time analysis}

Testing. In all demographic groups, space-time clustering started generally in the beginning of 2012 and lasted partially until the beginning of 2013 (Fig 2). Only in children, one cluster in 2007 and one cluster starting in 2011 could be observed. Space-time clustering for testing thus started relatively uniform across the study area in the beginning of 2012. 
a) Pertussis tests per inhabitants stratified by age, $2007-2013(\%)$
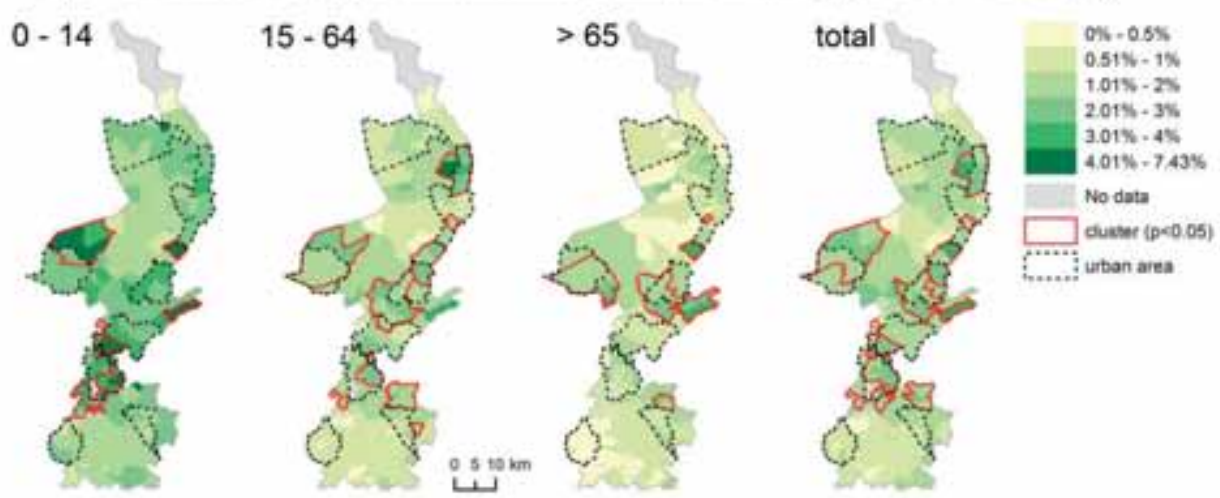

b) Pertussis incidence stratified by age, $2007-2013(\%)$

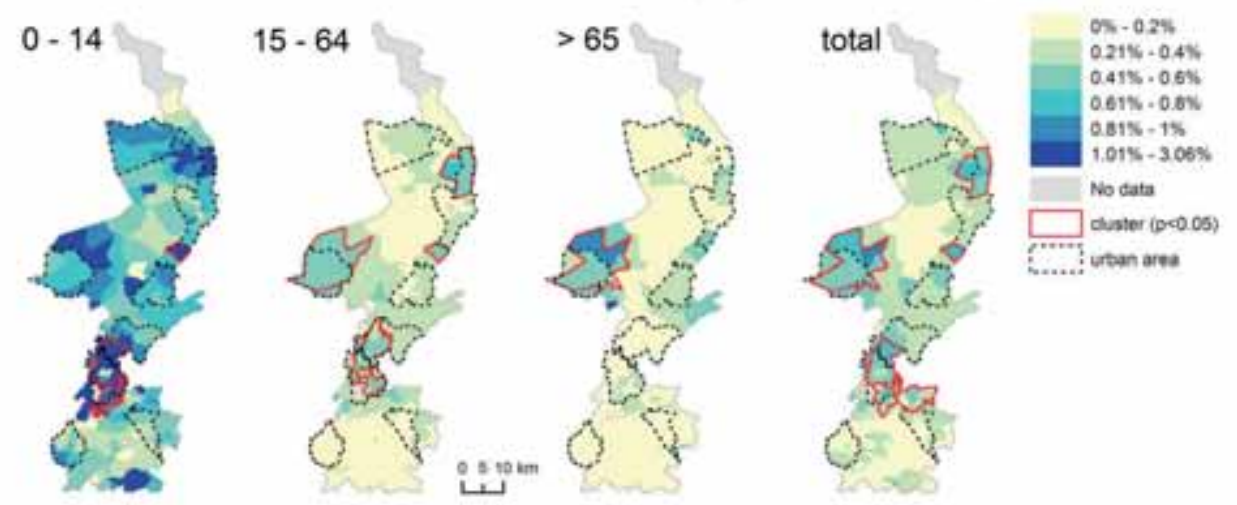

c) Proportion of positive Pertussis tests stratified by age, $2007-2013$ (\%)

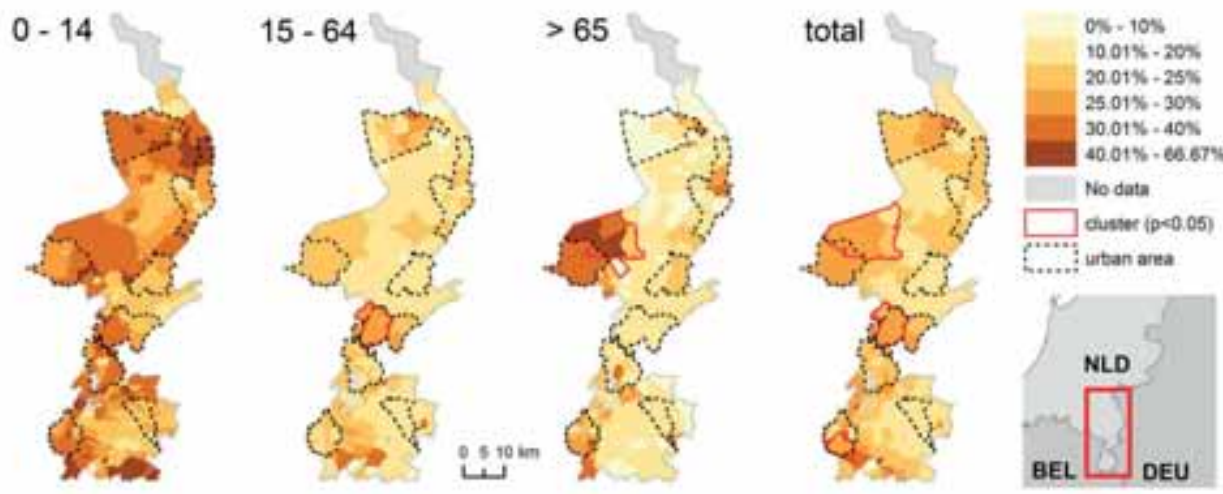

Figure 1. Spatial distribution of a) pertussis testing, b) incidence and c) test-positivity, 2007-2013 
Incidence. In adults, seniors and among the total population, the space-time distribution of clusters for the pertussis incidence followed closely the space-time distribution of clusters for testing (Fig 2). The majority of clusters were observed in the beginning of 2012 , lasting partially until the beginning of 2013 and were located in the same locations as space-time clusters for testing. In children however, space-time clusters were also observed in 2007 and 2009, for which no space-time clusters for testing were observed.

Test-positivity. The distribution of space-time clusters for positivity differed strongly from the observed clusters from testing and pertussis incidence (Fig 2). In children, a cluster observed in 2009 in the centre of the study area overlapped with a cluster for pertussis incidence. In seniors, a cluster observed in 2012 in the northwestern part overlapped with the clusters for testing and pertussis incidence. The other clusters were scattered over the entire study area and study period.

\section{Geographically weighted poisson regression}

Determinants of testing. For pertussis testing, the Gaussian kernel type using a fixed, AlCc optimized bandwidth fulfilled the requirements of the residuals not displaying spatial autocorrelation among all evaluated demographic groups (Table 2). The local models generally outperformed the global models, reflecting important local differences in the associations between testing and the examined explanatory variables.

Testing in children: For testing in children, testing in adults was the strongest predictor, followed by a moderate association to testing in seniors. The negative association to unmarried persons reflects that parents, which have ever been married, are a determinant for testing in children. The negative association to mean property value indicates that children in deprived neighbourhoods are more likely to get tested for pertussis.

Testing in adults: Testing in children and seniors had the strongest impact on testing in adults. The positive association to household size indicates that adults in multi-person households are more likely to get tested. Similar to testing in children, mean property value was negatively associated. Additionally, testing in adults was associated with proximity to primary schools and GPs, but was also associated with increasing distance to pharmacies.

Testing in seniors: Testing in adults had the strongest impact on testing in seniors. The strength of the association to testing in children was relatively weak. Additionally, testing in seniors was negatively associated with proportion of households with high income.

Testing in the total population: The strongest predictor for testing among the total population was the positive association to household size, followed by the negative associations to mean property value, proximity to GPs and primary schools. The proportion of children and distance to pharmacies were overall positively associated. However, none of the predictors was significant in the entire study area. The results of the GWPR model additionally point out important local variations of the association between testing among the total population and the examined explanatory variables (Fig 3). 
a) Space-time clusters of Pertussis testing stratified by age, 2007 - 2013

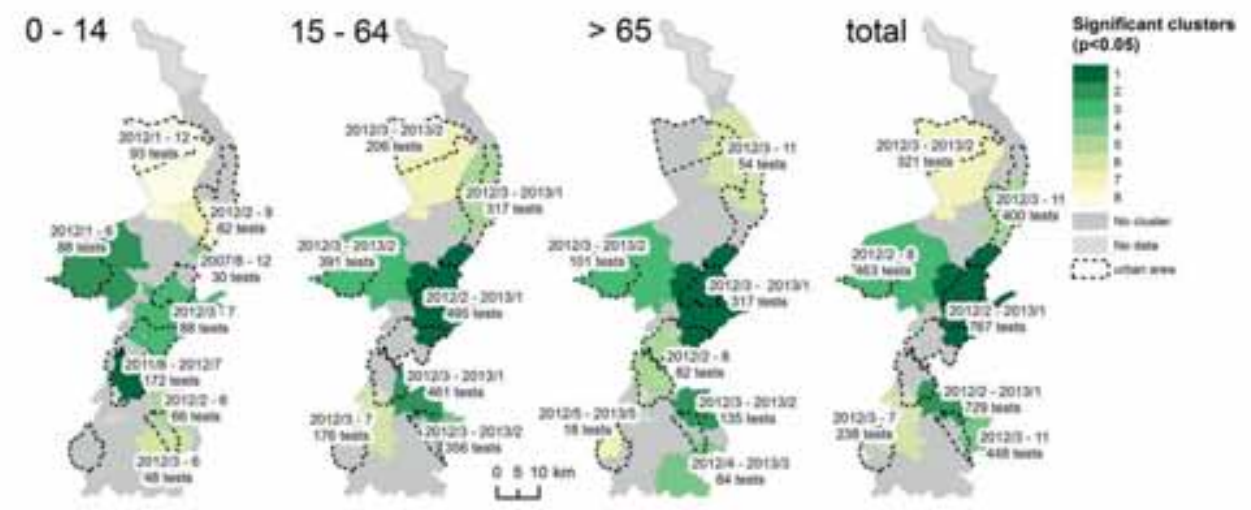

b) Space-time clusters of Pertussis incidence stratified by age, $2007-2013$

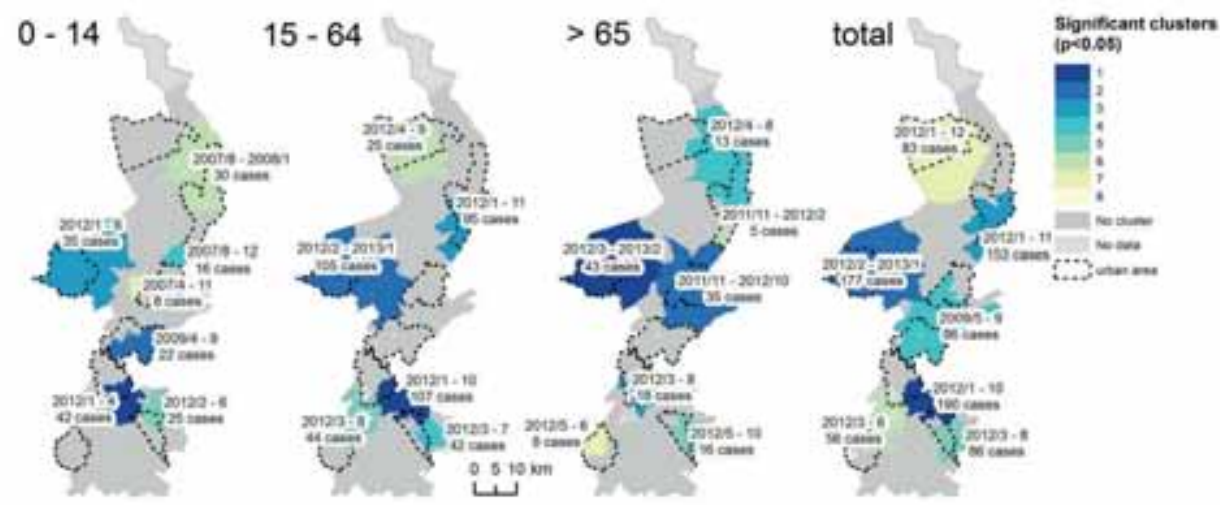

c) Space-time clusters of Pertussis positivity stratified by age, 2007 - 2013

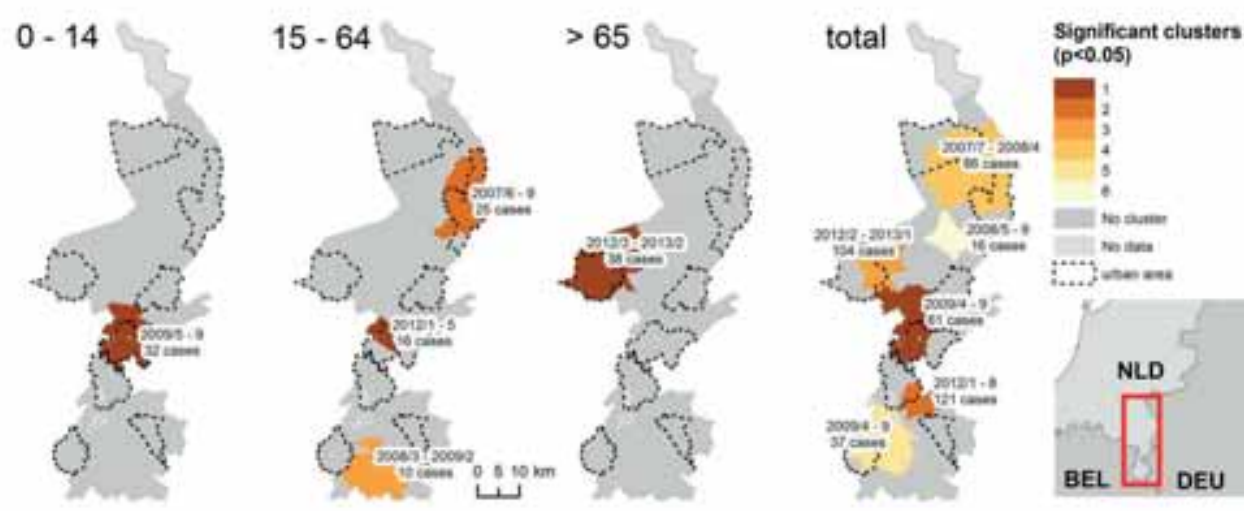

Figure 2. Space-time clusters of a) testing, b) incidence and c) test-positivity, 2007-2013 
Table 2. Poisson regression models for pertussis testing, stratified by age

\begin{tabular}{lllll} 
& \multicolumn{2}{l}{ Standardized coefficients of pertussis testing } & \\
& $0-14$ & $15-64$ & $>65$ & Total \\
Tested 0-14 (\%) & & $0.2033^{* * *}$ & $0.0818^{* *}$ & \\
Tested 15-64 (\%) & $0.2655^{* * *}$ & & $0.3874^{* * *}$ & \\
Tested seniors (\%) & $0.0659^{* *}$ & $0.2360^{* * *}$ & & \\
Children (\%) & & $0.0610^{* * *}$ & & $0.0525^{* * *}$ \\
Unmarried (\%) & $-0.0418^{*}$ & & & \\
One person households (\%) & & $-0.0769^{* * *}$ & & $-0.1567^{* * *}$ \\
Property value (Euro) & $-0.0576^{* * *}$ & $-0.0419^{* * *}$ & & $-0.1380^{* * *}$ \\
HH with high income & & & $-0.0750^{* *}$ & \\
Dist. Prim. school (km) & & $-0.0354^{*}$ & & $-0.0973^{* * *}$ \\
Dist. GP (km) & & $-0.1930^{* * *}$ & & $-0.1367^{* * *}$ \\
Dist. Pharmacy (km) & & $0.0700^{* * *}$ & & $0.0441^{* *}$ \\
AlCc global & 608 & 1151 & 523 & 2722 \\
Deviance expl. global & 0.35 & 0.51 & 0.40 & 0.17 \\
AlCc local & 543 & 697 & 469 & 925 \\
Deviance expl. local & 0.44 & 0.83 & 0.49 & 0.81 \\
Moran `s I of residuals & $\mathrm{I}=0.06 ; \mathrm{p}>0.05$ & $\mathrm{I}=-0,00 ; \mathrm{p}>0,05$ & $\mathrm{I}=0.03 ; \mathrm{p}>0.05$ & $\mathrm{I}=-0.01 ; \mathrm{p}>0.05$ \\
\hline
\end{tabular}

Significance levels: ${ }^{*}=0.05 ;{ }^{* *}=0.01{ }^{* * *}=0.001$. Only significant predictors are reported.

Determinants of pertussis incidence. For modelling the pertussis incidence, the Gaussian kernel type using a fixed, AIC optimized bandwidth fulfilled the requirements of the residuals not displaying spatial autocorrelation among all evaluated demographic groups (Table 3). The local models outperformed the global models, although the difference was not as pronounced as the difference between global and local models in testing. 
Table 3. Poisson regression models of pertussis incidence stratified by age

\begin{tabular}{|c|c|c|c|c|}
\hline & \multicolumn{4}{|c|}{ Standardized coefficients of pertussis incidence } \\
\hline & $0-14$ & $15-64$ & $>65$ & Total \\
\hline Tested 0-14 (\%) & $0.5191^{* * *}$ & & & \\
\hline Tested 15-64 (\%) & & $0.4425^{* * *}$ & & \\
\hline Tested seniors (\%) & & & $0.5591^{* * *}$ & \\
\hline Tested total (\%) & & & & $0.4692^{* * *}$ \\
\hline Incidence 0-14 (\%) & & $0.0819^{* *}$ & & \\
\hline Incidence 15-64 (\%) & & & $0.3093^{* * *}$ & \\
\hline Incidence senior (\%) & & $0.0654^{* *}$ & & \\
\hline Children (\%) & & & & \\
\hline One pers. households (\%) & & $-0.0975^{* * *}$ & & \\
\hline Immigrants (\%) & & & & \\
\hline Property value (Euro) & & & & \\
\hline HH with low income (\%) & & & & $-0.0546^{* *}$ \\
\hline Dist. Kinder garden (km) & & & & \\
\hline Dist. Pharmacy (km) & & & & \\
\hline Dist. Hospital (\%) & & $-0.1481^{* * *}$ & & $-0.0676^{*}$ \\
\hline AIC global & 273 & 285 & 275 & 375 \\
\hline Deviance expl. global & 0.53 & 0.60 & 0.36 & 0.65 \\
\hline AIC local & 268 & 280 & 249 & 309 \\
\hline Deviance expl. local & 0.55 & 0.65 & 0.47 & 0.78 \\
\hline Moran `s I of residuals & $I=0.02 ; p>0.05$ & $I=-0.00 ; p>0.05$ & $I=-0.04 ; p>0.05$ & $I=-0.01 ; p>0.05$ \\
\hline
\end{tabular}

Incidence in children: In children, testing was the only significant predictor for the pertussis incidence.

Incidence in adults: In adults, testing was by far the strongest predictor. The strength of the association to the incidence in children and seniors was comparably small. One-person households were-similar to testing in adults-negatively associated. A significant association to proximity to hospitals could also be observed.

Incidence in seniors: Testing was also the strongest predictor in seniors, followed by the incidence in adults.

Incidence in the total population: Among the incidence for the total population, testing had again the strongest impact on the pertussis incidence. The strength of the negative association to households with low income and proximity to hospitals was comparatively weak. The visualized results of the GWPR model point out that testing was significant in the total study area, despite strong local differences in the strength of this association. The negative association to households with low income and proximity to hospitals was only significant in specific areas (Fig 4). 

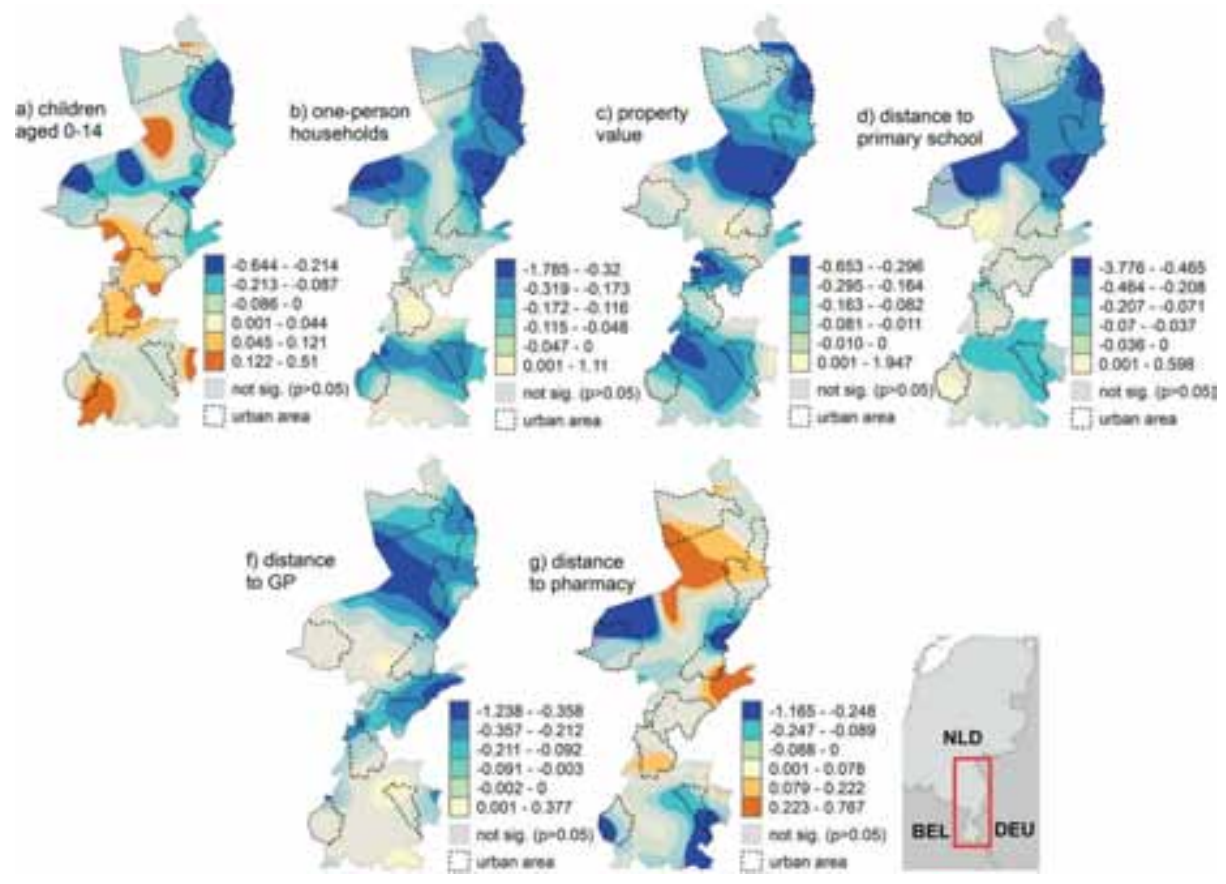

Figure 3. Results of the geographically weighted Poisson regression of pertussis testing among the total population

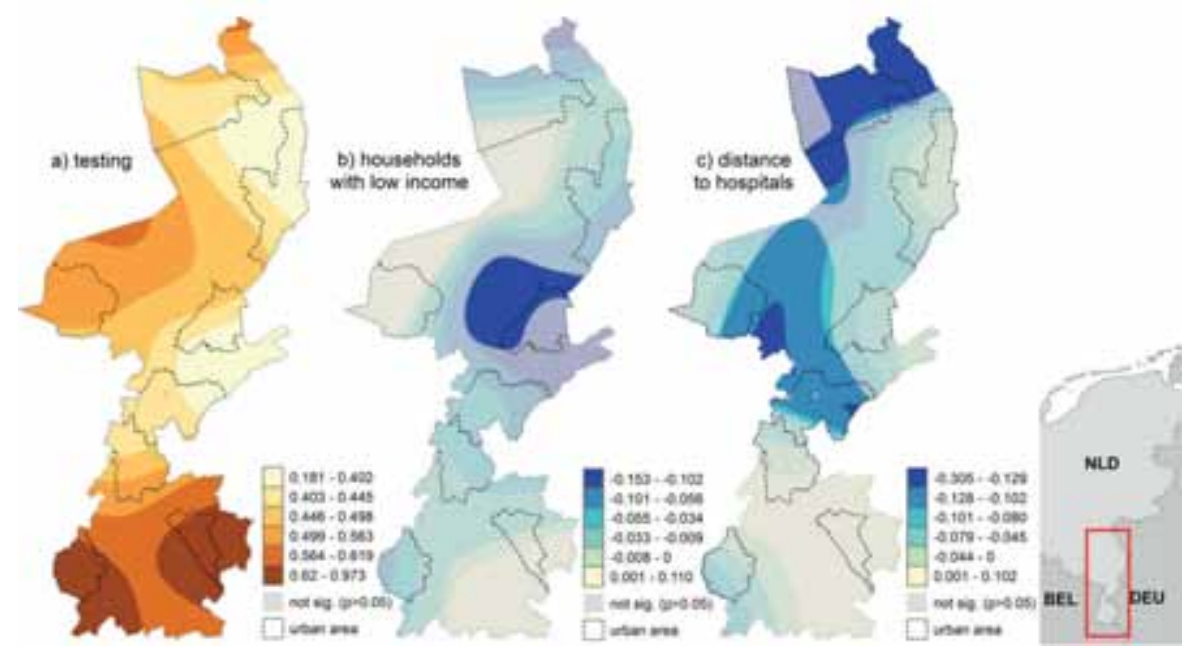

Figure 4. Results of the geographically weighted Poisson regression of pertussis incidence among the total population 


\section{Discussion}

The main findings of this study are: (i) The determinants of pertussis testing reflect to a certain extent the healthcare seeking behaviour of the general population for common respiratory infections; (ii) the current pertussis incidence is mainly determined by testing and (iii) outbreak detection for pertussis is feasible using surveillance data but needs to adjust for the strong impact of testing.

\section{Determinants of pertussis testing}

Pertussis testing follows to an extent the healthcare seeking behaviour of the general population for common respiratory infections. This can be seen by the associations of proximity to GPs and distance to pharmacies as both compliment each other. Especially in areas where distance to GPs was negatively associated, distance to pharmacies was positively associated. Self-medication for common respiratory infections resulting in coughing is typical in countries where over the counter medication is available [69]. Our results thus could indicate that in areas, where a pharmacy is easily accessible, self-medication for coughing is the first option to choose, whereas in areas where a physician is close, patients with symptoms related to coughing are more likely to consult a GP [70]. As a result, testing for pertussis is to an extent related to treatment-seeking behaviour for common respiratory infections. The association to proximity to primary schools in certain areas indicates potentially an increased awareness of pertussis vulnerability among parents and GPs for children enrolled in primary schools [71]. An overall positive association of pertussis testing among the general population to the proportion of children within the study area was expected as the incidence of pertussis in children is generally higher than in other age groups [72]. The negative association to unmarried persons and mean property value both display a comparable spatial pattern. This could indicate that in families, where the parents have ever been married and are located in a more deprived area are tested more frequently for pertussis, at least in the areas where both associations were significant. Previous studies noted a lower participation rate in childhood immunization schemes among persons with a lower socio-economic status [73]. These associations could therefore be seen as an indicator for an increased awareness of a higher vulnerability to pertussis among this population group, although it has to be noted that the vaccination coverage in the Netherlands is generally very high with approximately $95 \%$ [74]. Additionally, higher healthcare use is typical for persons living in deprived areas [75].

When analysing the determinants of pertussis testing in specific age groups, we found that testing in the adjacent age group had the strongest impact on testing in the examined age group. This strong association between the examined age groups corresponds well to previous studies suggesting that intra-household transmission is the most likely route of infection $[11,76]$ and thus logically leads to testing among the same households. 


\section{Determinants of pertussis incidence}

The spatial and space-time distribution of clusters for pertussis incidence followed closely the spatial and space-time distribution of pertussis testing, reflecting a strong spatial and space time correlation between testing and incidence.

We found evidence that space-time clustering of testing for pertussis and the pertussis incidence itself increased across the total study area in the first quarter of 2012, irrespective of the examined demographic group. An increase of diagnosed pertussis cases between 2011 and 2012 has also been noted by the US [77], Great Britain [78] and Spain [79]. When we searched for newspaper articles related to pertussis in the Netherlands within the NexisLexis database (www.nexislexis.com), we found that the number of newspaper articles related to pertussis increased sharply in 2012 as compared to the previous years.

Other studies also suggest a "positive feedback loop" where an increase of diagnosed pertussis cases subsequently causes an increase in testing, which in turn results in an increase of diagnosed pertussis cases again $[80,81]$. In our study area, the strong increase of testing and pertussis incidence in 2012 could be the result of a combination of several factors; an increased awareness of GPs due to the noted increase in other countries [77-79], stronger media attention and the noted positive feedback loop $[80,81]$. The effect of the positive feedback loop is indicated by the fact that space-time clusters for testing and incidence occurred mostly in the same areas and time periods across all evaluated age groups. These findings highlight the importance of monitoring changes in pertussis testing in addition to monitoring the pertussis incidence.

The GWPR analyses confirmed what became already apparent during the spatial and space-time analyses. Regardless of age group, testing was the most important predictor of the pertussis incidence. The second most important predictor for the pertussis incidence in a specific age group was the incidence of pertussis in the adjacent age groups. As our analysis is based on aggregated data, we see these associations as an indicator for intra-household transmission [11,76].

In children, testing was the only predictor for pertussis. No other variables were found to be significant in a regression analysis. Thus, the current incidence among the most vulnerable group does not exhibit any socio-economic associations and can be explained by testing only. In adults, we found an additional association to proximity to hospitals. Increased exposure to pertussis and outbreaks among persons employed in hospitals has been previously noted in several countries such as the US [82] and France [83]. The results of our analysis for adults thus indicate a possible exposure to pertussis in our study area. The positive association to household-size indicates, that for adults living in multi-person households, intra-household transmission might be an important risk factor as well, despite the findings of previous studies that intra-household transmission occurs mainly from parents to children $[11,76]$.

The results of the GWPR model for the pertussis incidence among the total population confirm that testing is the most important predictor for pertussis, despite local differences in the strength of this association. The negative association to households with low income in a small part of the study area 
was the only significant variable related to socio-economic status. An overall assumption that pertussis is related to specific socio-economic characteristics is therefore not possible. Similar to adults, an association to proximity to hospitals was observed in a small part of the study area. However, further research on an individual level would be necessary to confirm whether an increased pertussis exposure in hospitals exists in this area.

\section{Outbreak detection using space-time cluster detection}

Our results clearly demonstrate that space-time cluster detection is feasible using surveillance data and the methods described in this study. However, in light of the similar increase in testing and incidence in 2012 and its potential association to an increased awareness of the population and GPs, it is necessary to adjust for the impact of testing. This is reflected by the fact that we mostly detected space-time clusters for pertussis incidence in 2012, where the majority of clusters overlap with those for testing. We found only in children clusters in earlier years in 2007-2009, which did not overlap with clusters for testing. It is clear that the incidence of pertussis has to be strongly correlated to testing, no matter which algorithm is used. Logically, pertussis incidence is not suitable in our study area to detect outbreaks. By using test-positivity as indicator however, we could locate space-time clusters within the whole study area and study period, which were not the results of testing only. Test-positivity as indicator is to a certain extent adjusted for testing in a space-time analysis as a similar increase in positive cases and tested persons would not increase the ratio of positive cases to tested persons in the three dimensional cylindrical scanning window used by the spatial scan statistic. Our results clearly demonstrate that test-positivity could be a better indicator for locating outbreaks, which are not the results of testing only. This conclusion is supported by previous studies, which evaluated the temporal correlation of pertussis incidence to testing behaviour over time $[80,81]$.

When surveillance data-as in our study are used to locate outbreaks, a prospective space time cluster analysis using daily updated surveillance data would allow a detection of recent outbreaks in an automated surveillance system as early as possible. Prospective space-time cluster detection has been widely applied in syndromic surveillance $[84,85]$ and an automated, space-time analysis could be implemented for pertussis as well [86].

\section{Implications for pertussis surveillance}

The surveillance data for pertussis in our study were collected by the respective local laboratories and had to merged manually for our study area to allow a retrospective analysis for a whole province. Surveillance of pertussis would thus greatly benefit from an automated near real-time data transfer of each respective laboratory to a centralized institution to allow a detailed, prospective analysis of possible disease outbreaks as early as possible. However, such an approach should focus on a day-wise analysis rather than a month-wise analysis as employed in this study to capture possible outbreaks as precisely as possible [35]. 


\section{Strengths and limitations of this study}

Strengths. First, a major strength of this study is that the design of this study can be repeated for the whole country to confirm whether testing is also in the whole of the Netherlands the most important predictor of pertussis.

Second, the majority of studies on pertussis focus on a purely temporal analysis $[7,28,29,32]$. Our approach of analysing the spatial and space-time distribution of pertussis therefore provides a novel level of detail as our approach of detecting clusters in space as well as in space-time could allow a more focused detection of outbreaks, resulting in a more timely and cost-effective response.

Third, we analysed the spatial distribution of pertussis testing and incidence at the smallest possible spatial scale, for which surveillance data and population data can be combined without violating privacy restrictions of surveillance data. The four-digit postal code areas are very suitable for smallscale spatial-epidemiological analyses in the Netherlands [38] and thus allow a very detailed analysis of the determinants of pertussis testing and incidence.

Fourth, the use of GWPR allowed us to examine the spatially varying associations between the evaluated outcomes (testing and incidence) and the examined predictor variables. We could therefore clearly see in which areas several predictors such as distance to GPs, pharmacies and hospitals were significant. Our results can therefore be used to allow more targeted investigations for example if working in hospitals in the areas outlined in our study comprises an exposure factor on an individual level as well.

Fifth, our study highlighted that the detection of outbreaks using space-time cluster detection is feasible, when using test-positivity as indicator.

Limitations. First, we used the international standard IgG cut-off value of 62.5 to consider a diagnosed pertussis infection. As a consequence, the incidence in our study does not necessarily reflect the notification data, which is based on laboratory interpretation.

Second, our analysis was based on aggregated data. The associations detected in our study may not necessarily reflect determinants of pertussis testing and incidence on an individual level. Given the current privacy protection of surveillance data [37], the ecological analysis employed here allowed us to analyse potential determinants that are unavailable on an individual level. Therefore, further research is necessary to confirm whether the associations captured in the ecological analysis really reflect associations on an individual level as well.

Third, we may have missed associations simply because several variables were not available within the data of Statistics Netherlands such as educational level. Lower educational level has been shown to be an important risk factor for poorer health outcomes [87] and could thus also be a possible risk factor for pertussis as well.

Fourth, the GWR4 software currently allows only a purely spatial geographically weighted regression but does not account for space-time differences [63]. Given the strong temporal component of Pertussis testing and infections, a geographically weighted temporal regression might yield more de- 
tailed results. However, given the mathematical complexity of such a model [88], this approach could not be implemented in this study.

Fifth, we could not account for the role of vaccinations in our study, as this information is not available in the examined surveillance data. Potentially, data on vaccination among children and booster doses among adults could have a strong impact on the serological test results presented here and could be of additional value for future analyses.

Sixth, we could not verify whether the space-time clusters detected for pertussis incidence or test-positivity capture true outbreaks. However, we think it is reasonable to assume that space-time clusters for the pertussis incidence, which are the results of testing only, are not of interest for the detection of outbreaks. Ultimately, verifying the detected space-time clusters with known outbreaks should be discussed with public health officials residing in the area.

Seventh, we performed a month-wise space-time cluster analysis because a day-wise analysis did consume considerable computation time [35]. Our results are therefore not as temporally precise as it would be technically possible with the surveillance data of our study.

Eight, it would be useful to compare both approaches to detect outbreaks-purely temporal algorithms with the results of the space-time cluster analysis to evaluate (i) which method allows a more focused outbreak detection and (ii), to evaluate whether the purely temporal algorithms or the spacetime cluster detection delivers fewer false alarms. However, such a comparison was beyond the scope of this paper.

\section{Conclusion}

We found empirical evidence that testing for pertussis and the current pertussis incidence in our study area increased similar to other countries in 2012. Testing was higher in deprived areas and was also associated with proximity to primary schools and availability of healthcare. Testing for pertussis thus reflects to an extent the overall healthcare seeking behaviour for common respiratory infections. The pertussis incidence in our study area is largely the result of testing and does not display a specific socio-economic association. The main population at risk for pertussis remains therefore still unknown. Given the strong association of detected pertussis cases to testing, it is questionable whether more testing would enhance pertussis control.

The detection of outbreaks using space-time cluster detection is feasible and could help to facilitate an early and appropriate public health response. However, this approach has to be adjusted for the strong dependency to testing and is probably most efficient when using test positivity as indicator. 


\section{Acknowledgments}

We wish to thank Peter Jacobs (North Limburg Public Health Service, Venlo), Inge van Loo (Maastricht University Medical Centre, Maastricht), Jos Bus (Zuyderland Medical Centre, Heerlen), Dick van Dam (Zuyderland Medical Centre, Sittard-Geleen), Thera Trienekens (VieCuri Medical Centre, Venlo) and Trix van Dijke (Laurentius Hospital, Roermond and St. Jans Gasthuis, Weert) for involvement in data collection. We would like to thank Inge van Loo (Maastricht University Medical Centre, Maastricht), Alexandra Ziemann (Maastricht University), Jochen Cals (Maastricht University) and Henriëtte ter Waarbeek (South Limburg Public Health Service, Geleen) for their contribution to the study proposal. This work was supported by the National Institute for Public Health and the Environment - Centre for Infectious Disease Control (RIVM-Clb), the Netherlands (Grant number: 3910007379). 


\section{References}

1. Parkhill J, Sebaihia M, Preston A, Murphy LD, Thomson N, et al. (2003) Comparative analysis of the genome sequences of Bordetella pertussis, Bordetella parapertussis and Bordetella bronchiseptica. Nature genetics 35: 32-40. doi: 10.1038/ng1227 PMID: 12910271

2. Sizaire V, Garrido-Estepa M, Masa-Calles J, Martinez de Aragon MV (2014) Increase of pertussis incidence in 2010 to 2012 after 12 years of low circulation in Spain. Euro Surveill 19.

3. Jenkinson D (2012) Increase in pertussis may be due to increased recognition and diagnosis. BMJ 345: e5463. doi: 10.1136/bmj.e5463 PMID: 22915721

4. Vitek CR, Pascual FB, Baughman AL, Murphy TV (2003) Increase in deaths from pertussis among young infants in the United States in the 1990s. Pediatr Infect Dis J 22: 628-634. doi: 10.1097/01. inf. 0000073266.30728.0e PMID: 12867839

5. Barlow RS, Reynolds LE, Cieslak PR, Sullivan AD (2014) Vaccinated children and adolescents with pertussis infections experience reduced illness severity and duration, Oregon, 20102012. Clinical Infectious Diseases 58: 1523-1529. doi: 10.1093/cid/ciu156 PMID: 24633685

6. Rozenbaum MH, De Cao E, Postma MJ (2012) Cost-effectiveness of pertussis booster vaccination in the Netherlands. Vaccine 30: 73277331. doi: 10.1016/j.vaccine.2012.06.026 PMID: 22749838

7. van der Maas NA, Mooi FR, de Greeff SC, Berbers GA, Spaendonck MA, et al. (2013) Pertussis in the Netherlands, is the current vaccination strategy sufficient to reduce disease burden in young infants? Vaccine 31: 4541-4547. doi: 10.1016/j.vaccine.2013.07.060 PMID: 23933365

8. Zouari A, Smaoui H, Kechrid A (2012) The diagnosis of pertussis: which method to choose? Critical reviews in microbiology 38: 111-121. doi: 10.3109/1040841X.2011.622715 PMID: 22103249

9. Nuolivirta $K$, Koponen $P, H e$, Halkosalo $A$,

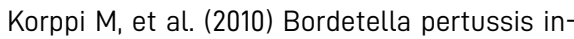
fection is common in nonvaccinated infants admitted for bronchiolitis. The Pediatric infectious disease journal 29: 1013-1015. PMID: 21046700

10. Tozzi AE, Celentano LP, degli Atti MLC, Salmaso $S$ (2005) Diagnosis and management of pertussis. Canadian Medical Association Journal 172: 509-515. doi: 10.1503/cmaj.1040766 PMID: 15710944

11. Te Beest $D E$, Henderson D, van der Maas NA, de Greeff SC, Wallinga J, et al. (2014) Estimation of the serial interval of pertussis in Dutch households. Epidemics 7: 1-6. doi: 10.1016/j.epidem.2014.02.001 PMID: 24928663

12. Rozenbaum $M H$, De Vries $R$, Le HH, Postma MJ (2012) Modelling the impact of extended vaccination strategies on the epidemiology of pertussis. Epidemiol Infect 140: 1503-1514. doi: 10.1017/ S0950268811002354 PMID: 22115361

13. Wendelboe AM, Njamkepo E, Bourillon A, Floret DD, Gaudelus J, et al. (2007) Transmission of Bordetella pertussis to young infants. The Pediatric infectious disease journal 26: 293-299. doi: 10.1097/01. inf.0000258699.64164.6d PMID: 17414390

14. de Greeff SC, Mooi FR, Westerhof A, Verbakel J, Peeters MF, et al. (2010) Pertussis disease burden in the household: how to protect young infants. Clinical Infectious Diseases 50: 13391345. doi: 10.1086/ 652281 PMID: 20370464

15. Coudeville L, Van Rie A, Andre P (2008) Adult pertussis vaccination strategies and their impact on pertussis in the United States: evaluation of routine and targeted (cocoon) strategies. Epidemiology and infection 136: 604-620. doi: 10.1017/S0950268807009041 PMID: 17612417

16. Gezondheidsraad (2015) Vaccinatie tegen kinkhoest: doel en strategie. The Hague.

17. de Greeff SC, de Melker HE, van Gageldonk PG, Schellekens JF, van der Klis FR, et al. (2010) Seroprevalence of pertussis in The Netherlands: evidence for increased circulation of Bordetella pertussis. PLoS One 5: e14183. doi: 10.1371/ journal.pone.0014183 PMID: 21152071 
18. He Q, Mertsola J (2008) Factors contributing to pertussis resurgence.

19. Mooi FR (2010) Bordetella pertussis and vaccination: the persistence of a genetically monomorphic pathogen. Infection, Genetics and Evolution 10: 36-49. doi: 10.1016/j.meegid.2009.10.007 PMID: 19879977

20. Cherry JD (2003) The science and fiction of the "resurgence" of pertussis. Pediatrics 112: 405406. PMID: 12897292

21. Greenberg DP (2005) Pertussis in adolescents: increasing incidence brings attention to the need for booster immunization of adolescents. The Pediatric infectious disease journal 24: 721728. PMID: 16094229

22. Cherry JD (2012) Epidemic pertussis in 2012 - the resurgence of a vaccine-preventable disease. New England Journal of Medicine 367: 785-787. doi: 10.1056/NEJMp1209051 PMID: 22894554

23. Galanis $E$, King AS, Varughese $P$, Halperin $S A$ (2006) Changing epidemiology and emerging risk groups for pertussis. Canadian Medical Association Journal 174: 451-452. doi: 10.1503/ cmaj.050379 PMID: 16477052

24. Verheij TJM, Hopstaken RM, Prins JM, Salomé $\mathrm{PL}$, Bindels PJ, et al. (2011) Acuut hoesten Samenvattingskaart M78. Huisarts Wet 2011: 2.

25. Heil J, ter Waarbeek HLG, Hoebe CJPA, Jacobs PHA, van Dam DW, Trienekens TAM, Cals JWL, van Loo IHM, Dukers-Muijrers NHTM. Pertussis surveillance and control in the Netherlands, 2010-2013: exploring variations and delays in healthcare provider testing, laboratory diagnostics and public health service notifications. Eurosurveillance. In press (2017)

26. de Melker HE, Schellekens J, Neppelenbroek S,

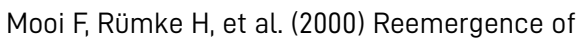
pertussis in the highly vaccinated population of the Netherlands: observations on surveillance data. Emerging infectious diseases 6: 348. doi: 10.3201/eid0604.000404 PMID: 10905967

27. Guimaraes LM, Carneiro EL, Carvalho-Costa FA (2015) Increasing incidence of pertussis in Brazil: a retrospective study using surveillance data. BMC Infect Dis 15: 442. doi: 10.1186/s12879015-1222-3 PMID: 26498058
28. Choe YJ, Park YJ, Jung C, Bae GR, Lee DH (2012) National pertussis surveillance in South Korea 1955-2011: epidemiological and clinical trends. Int J Infect Dis 16: e850-854. doi: 10.1016/j. ijid.2012. 07.012 PMID: 22921258

29. Wymann MN, Richard JL, Vidondo B, Heininger $U$ (2011) Prospective pertussis surveillance in Switzerland, 1991-2006. Vaccine 29: 2058-2065. doi: 10.1016/j.vaccine.2011.01.017 PMID: 21251904

30. Omer SB, Enger KS, Moulton LH, Halsey NA, Stokley S, et al. (2008) Geographic clustering of nonmedical exemptions to school immunization requirements and associations with geographic clustering of pertussis. Am J Epidemiol 168: 1389-1396. doi: 10.1093/aje/kwn263 PMID: 18922998

31. Choisy M, Rohani P (2012) Changing spatial epidemiology of pertussis in continental USA. Proc Biol Sci 279: 4574-4581. doi: 10.1098/ rspb.2012.1761 PMID: 23015623

32. Fathima $S$, Ferrato $C$, Lee $B E$, Simmonds $K$, Yan $L$, et al. (2014) Bordetella pertussis in sporadic and outbreak settings in Alberta, Canada, July 2004-December 2012. BMC Infect Dis 14: 48. doi: 10.1186/ 1471-2334-14-48 PMID: 24476570

33. Dhewantara PW, Ruliansyah A, Fuadiyah ME, Astuti EP, WidawatiM (2015) Space-time scan statistics of 2007-2013 dengue incidence in Cimahi city, Indonesia. Geospat Health 10: 373. doi: 10.4081/gh. 2015.373 PMID: 26618319

34. Ndiath M, Faye B, Cisse B, Ndiaye JL, Gomis JF, et al. (2014) Identifying malaria hotspots in Keur Soce health and demographic surveillance site in context of low transmission. Malar J 13: 453. doi: 10.1186/ 1475-2875-13-453 PMID: 25418476

35. Van Den Wijngaard CC, Van Asten L, Van Pelt W, Doornbos G, Nagelkerke NJ, et al. (2010) Syndromic surveillance for local outbreaks of lower-respiratory infections: would it work? PLoS One 5: e10406. doi: 10.1371/journal.pone.0010406 PMID: 20454449

36. Centre for Disease Control and Prevention (2007) Outbreaks of respiratory illness mistakenly attributed to pertussis $Đ$ New Hampshire, Massachusetts, and Tennessee, 2004-2006. MMWRMorbidity and mortality weekly report 


\section{6: 837. PMID: 17717512}

37. Regidor $E$ (2004) The use of personal data from medical records and biological materials: ethical perspectives and the basis for legal restrictions in health research. Social science \& medicine 59: 1975- 1984.

38. Dijkstra A, Janssen F, De Bakker M, Bos J, Lub $\mathrm{R}$, et al. (2013) Using spatial analysis to predict health care use at the local level: a case study of type 2 diabetes medication use and its association with demographic change and socioeconomic status. PLoS One 8: e72730. doi: 10.1371/journal.pone.0072730 PMID: 24023636

39. Kauhl B, Heil J, Hoebe CJ, Schweikart J, Krafft T, et al. (2015) The Spatial Distribution of Hepatitis C Virus Infections and Associated Determinants-An Application of a Geographically Weighted Poisson Regression for Evidence-Based Screening Interventions in Hotspots. PLoS One 10: e0135656. doi: 10.1371/ journal.pone.0135656 PMID: 26352611

40. Kauhl B, Pilot E, Rao R, Gruebner O, Schweikart $J$, et al. (2015) Estimating the spatial distribution of acute undifferentiated fever (AUF) and associated risk factors using emergency call data in India. A symptom-based approach for public health surveillance. Health Place 31: 111119. doi: 10.1016/j. healthplace.2014.11.002 PMID: 25463924

41. Shoff C, Yang TC (2012) Spatially varying predictors of teenage birth rates among counties in the United States. Demogr Res 27: 377-418. doi: 10.4054/DemRes.2012.27.14 PMID: 23144587

42. Robertson $C$, Pant DK, Joshi DD, Sharma $M_{1}$ Dahal $M$, et al. (2013) Comparative spatial dynamics of Japanese encephalitis and acute encephalitis syndrome in Nepal. PLoS One 8: e66168. doi: 10.1371/ journal.pone.0066168 PMID: 23894277

43. Weisent J, Rohrbach B, Dunn JR, Odoi A (2012) Socioeconomic determinants of geographic disparities in campylobacteriosis risk: a comparison of global and local modeling approaches. Int J Health Geogr 11: 45. doi: 10.1186/1476072X-11-45 PMID: 23061540

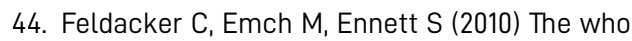

and where of HIV in rural Malawi: Exploring the effects of person and place on individual HIV status. Health Place 16: 996-1006. doi: 10.1016/j. healthplace. 2010.06.004 PMID: 20598623

45. Haque $U$, Scott LM, Hashizume $M$, Fisher $E$, Haque $R_{1}$ et al. (2012) Modelling malaria treatment practices in Bangladesh using spatial statistics. Malar J 11: 63. doi: 10.1186/1475-287511-63 PMID: 22390636

46. Centraal Bureau voor de Statistiek (CBS) (2015) http://www.cbs.nl/nl-NL/menu/themas/ dossiers/nederland-regionaal/publicaties/ geografische-data/archief/2014/2013-wijk-enbuurtkaart-art.htm.

47. Giammanco A, Chiarini A, Maple P, Andrews N, Pebody R, et al. (2003) European Sero-Epidemiology Network: standardisation of the assay results for pertussis. Vaccine 22: 112-120. PMID: 14604578

48. De Melker $H$, Versteegh F, Conyn-van Spaendonck M, Elvers L, Berbers G, et al. (2000) Specificity and sensitivity of high levels of immunoglobulin $G$ antibodies against pertussis toxin in a single serum sample for diagnosis of infection with Bordetella pertussis. Journal of clinical microbiology 38: 800-806. PMID: 10655388

49. Centraal Bureau voor de Statistiek (CBS) (2010) Toelichting Wijk- en Buurtkaart 2010. Update 2. Den Haag/Heerlen,: Centraal Bureau voor de Statistiek.

50. Lawson $A B$, Biggeri $A B$, Boehning $D$, Lesaffre $E$, Viel JF, et al. (2000) Disease mapping models: an empirical evaluation. Disease Mapping Collaborative Group. Stat Med 19: 2217-2241. PMID: 10960849

51. Waller LA, Gotway CA (2004) Applied spatial statistics for public health data: John Wiley \& Sons.

52. Anselin L (2005) Exploring Spatial Data with GeoDaTM: A Workbook. Urbana, Illinois, USA: Spatial Analysis Laboratory, Department of Geography, University of Illinois at Urbana-Champaign.

53. Kulldorff M, Feuer EJ, Miller BA, Freedman LS (1997) Breast cancer clusters in the northeast United States: a geographic analysis. Am J Epi- 
demiol 146: 161-170. PMID: 9230778

54. Tanser F, Barnighausen T, Cooke GS, Newell ML (2009) Localized spatial clustering of HIV infections in a widely disseminated rural South African epidemic. Int J Epidemiol 38: 1008-1016. doi: 10.1093/ije/dyp148 PMID: 19261659

55. Wang $T, X u e F$, Chen Y, Ma Y, Liu Y (2012) The spatial epidemiology of tuberculosis in Linyi City, China, 2005-2010. BMC Public Health 12: 885. doi: 10.1186/1471-2458-12-885 PMID: 23083352

56. KulldorffM (2011) SaTScan user guide for version 9.0.

57. Coleman M, Coleman M, Mabuza AM, Kok G, Coetzee $M$, et al. (2009) Using the SaTScan method to detect local malaria clusters for guiding malaria control programmes. Malar J 8: 10.1186 .

58. KulldorffM (2013) SaTScanTM User Guide for version 9.2.

59. Chen J, Roth RE, Naito AT, Lengerich EJ, Maceachren AM (2008) Geovisual analytics to enhance spatial scan statistic interpretation: an analysis of U.S. cervical cancer mortality. Int J Health Geogr 7: 57. doi: 10.1186/1476-072X-7-57 PMID: 18992163

60. Kulldorff M, Heffernan R, Hartman J, Assunçao R, Mostashari F (2005) A space-time permutation scan statistic for disease outbreak detection. PLoS medicine 2: 216.

61. KulldorffM (2010) SaTScan-Software for the spatial, temporal, and space-time scan statistics. Boston: Harvard Medical School and Harvard Pilgrim Health Care.

62. ESRI Interpreting Exploratory Regression results. ESRI.

63. Fotheringham AS, Brunsdon $C$, CharltonM (2003) Geographically weighted regression: the analysis of spatially varying relationships: John Wiley \& Sons.

64. Hu M, Li Z, Wang J, Jia L, Liao $Y$, et al. (2012) Determinants of the incidence of hand, foot and mouth disease in China using geographically weighted regression models. PLoS One 7: e38978. doi: 10. 1371/journal.pone.0038978 PMID: 22723913
65. Nakaya T, Fotheringham AS, Brunsdon C, Charlton M (2005) Geographically weighted Poisson regression for disease association mapping. Stat Med 24: 2695-2717. doi: 10.1002/sim.2129 PMID: 16118814

66. Lovett AA, Bentham C, Flowerdew R (1986) Analysing geographic variations in mortality using poisson regression: the example of ischaemic heart disease in England and Wales 1969-1973. Social Science \& Medicine 23: 935-943.

67. Lovett A, Flowerdew R (1989) Analysis of count data using poisson regression*. The Professional Geographer 41: 190-198.

68. Nakaya T (2012) GWR4 user manual.WWWdocument, http://www.st-andrews.ac.uk/geoinformatics/wp-content/uploads/GWR4manual_201311.pdf.

69. Smith SM, Schroeder K, Fahey T (2008) Overthe-counter (OTC) medications for acute cough in children and adults in ambulatory settings. Cochrane Database Syst Rev 1.

70. Campbell SM, Roland MO (1996) Why do people consult the doctor? Family practice 13: 75-83. PMID:8671107

71. Centre for Disease Control and Prevention (2004) School-associated pertussis outbreak Yavapai County, Arizona, September 2002-February 2003. MMWRMorb Mortal Wkly Rep 53: 216-219. PMID: 15029116

72. Chuk LM, Lambert SB, May ML, Beard FH, Sloots TP, et al. (2008) Pertussis in infants: how to protect the vulnerable? Commun Dis Intell Q Rep 32: 449-456. PMID: 19374274

73. van Lier A, van de Kassteele J, de Hoogh P, Drijfhout I, de Melker H (2013) Vaccine uptake determinants in The Netherlands. The European Journal of Public Health: ckt042.

74. Van Lier $\mathrm{E}$, Oomen $\mathrm{P}$, Oostenbrug $\mathrm{M}$, Zwakhals $\mathrm{S}$, Drijfhout I, et al. (2009) [High vaccination coverage of the National Immunization Programme in the Netherlands]. Nederlands tijdschrift voor geneeskunde 153: 950-957. PMID: 19490720

75. Barnett K, Mercer SW, Norbury M, Watt G, Wyke $S$, et al. (2012) Epidemiology of multimorbidity 
and implications for health care, research, and medical education: a cross-sectional study. The Lancet 380:37-43.

76. Terry JB, Flatley $C J$, van den Berg DJ, Morgan GG, Trent M, et al. (2015) A field study of household attack rates and the effectiveness of macrolide antibiotics in reducing household transmission of pertussis. Commun Dis Intell Q Rep 39: E27-33. PMID: 26063095

77. From C (2012) Pertussis epidemic - Washington, 2012. Morbidity and Mortality Weekly Report (MMWR) 61: 517-522.

78. Service NH (2012) Sharp rise in whooping cough cases. NHS.

79. Sizaire V, Garrido-Estepa M, Masa-Calles J, Martinez de Aragon M (2014) Increase of pertussis incidence in 2010 to 2012 after 12 years of low circulation in Spain. Euro Surveill 19.

80. Fisman DN, Tang $P$, Hauck $T$, Richardson $S$, Drews SJ, et al. (2011) Pertussis resurgence in Toronto, Canada: a population-based study including test-incidence feedback modeling. BMC public health 11:1.

81. Kaczmarek MC, Valenti L, Kelly HA, Ware RS, Britt HC, et al. (2013) Sevenfold rise in likelihood of pertussis test requests in a stable set of Australian general practice encounters, 20002011. Med J Aust 198: 624-628. PMID: 23919712

82. Calugar $A$, Ortega-Sánchez IR, Tiwari T, Oakes $L$, Jahre JA, et al. (2006) Nosocomial pertussis: costs of an outbreak and benefits of vaccinating health care workers. Clinical infectious diseases 42: 981-988. doi: 10.1086/500321 PMID: 16511764

83. Ward A, Caro J, Bassinet $L$, Housset $B$, O'Brien $J A$, et al. (2005) Health and economic consequences of an outbreak of pertussis among healthcare workers in a hospital in France. Infection Control 26: 288-292.

84. Heffernan R, Mostashari F, Das D, Karpati A, Kulldorff $M$, et al. (2004) Syndromic surveillance in public health practice, New York City. Emerg Infect Dis 10: 858-864. doi: 10.3201/ eid1005.030646 PMID:15200820

85. Ziemann A, Riesgo LG-C, Boris $K$, Schrell $S$, Rosenkötter $N$, et al. (2012) Added value of routine emergency medical data for detecting clusters of acute gastrointestinal illness in Europe. Resuscitation 83:e30.

86. Robertson C, Nelson TA (2010) Review of software for space-time disease surveillance. International Journal of Health Geographics 9: 1.

87. Cutler DM, Lleras-Muney A (2006) Education and health: evaluating theories and evidence. National Bureau of Economic Research.

88. Huang B, Wu B, Barry M (2010) Geographically and temporally weighted regression for modeling spatio-temporal variation in house prices. International Journal of Geographical Information Science 24:383-401. 




\section{Chapter 4}

\section{Reasons for testing and non-testing for pertussis are not well known}

Jeanne Heil, Jochen W.L. Cals, Henriëtte L.G. ter Waarbeek, Christian J.P.A. Hoebe, Nicole H.T.M. Dukers-Muijrers 


\section{Dear editor,}

Pertussis infections are underdiagnosed and underreported. In Europe, the highest number of cases were notified by the Netherlands in 2012 ( $n=12,868)$, representing $30 \%$ of all notifications in Europe [1] and $70 \%$ of all national notifications [2]. Pertussis infections can develop severely in unimmunised infants with the highest rates of complications and death [3]. These young infants can be protected by preventive measures in their close contacts. However, pertussis notifications are often reported too late for public health authorities to take any preventive measures $[4,5]$. We showed that the median time from the onset of symptoms to the notification of the public health authorities in the Netherlands was 34 days [4]. Of all healthcare providers, general practitioners (GPs) request the majority (81\%) of diagnostic test for pertussis [4]. It was shown that a substantial number of GPs do not utilise pertussis testing at all and may not be able to recognise the clinical symptoms in adolescents [6]. The clinical diagnosis of pertussis is difficult because of often unspecific symptoms as well as co-infection with respiratory diseases. Currently, it is largely unknown why GPs decide to test specifically for pertussis or refrain from doing so, and whether they base these decisions on clinical symptoms of patients or their proximity to vulnerable groups at risk. As many cases remain undetected at present, unvaccinated or incompletely vaccinated infants $<1$ year of age, women $>34$ weeks pregnant and children with severe heart or lung failure cannot be adequately protected. To improve pertussis surveillance and control, we evaluated GP-reported diagnostic practices as well as their reasons for (not) testing and intentions towards pertussis testing using an online standardised questionnaire. In contrast to national guidelines, our results suggest that GPs test mainly based on clinical symptoms rather than based on protecting vulnerable groups at risk.

\section{Study setting}

This pilot study was conducted in Limburg, the southernmost province of the Netherlands. Its population of 1.1 million is comparable to the rest of the Netherlands in terms of sex composition and urbanisation, although it is slightly older [7]. According to the national guidelines, pertussis testing is recommended when pertussis is suspected in patients living with infants aged under one year old who are not or not completely vaccinated, with women who are more than 34 weeks pregnant or with children who have severe heart or lung failure in the household [8]. The Netherlands provides an extensive National Immunisation Programme (NIP) free of charge to protect all children against 12 infectious diseases, including pertussis [3]. The introduction of general pertussis vaccination in the 1950s has tremendously reduced its incidence [9]. Currently, the efficacy of pertussis vaccines has been debated because of waning immunity, incomplete protection of infants younger than 5 months of age, genetic changes in Bordetella pertussis and the limited duration of protection [10-12]. Maternal immunisation is recommended by the WHO, the ECDC and the Health Council of the Netherlands $[1,13,14]$, and im- 
munisation will be offered to pregnant women from 2019 onwards in the Netherlands. As yet, maternal immunisation is not part of routine care or guidelines in the Netherlands.

\section{General practitioner questionnaire}

All GPs in the study area ( $n=594)$ were invited by email to complete an online standardised questionnaire, in which they were asked to reflect on their clinical diagnosis and diagnostic testing of pertussis patients in the year 2013. A reminder email was sent to non-responding GPs after three weeks. We asked the GPs about their demographics, number of clinical diagnoses (based on clinical history), number of laboratory diagnoses (based on medical microbiology laboratory testing), reports of additional laboratory diagnostic testing after a clinical diagnosis and total patients tested during one year. We also provided a list of reasons for (not) testing for pertussis. We measured the intention to test by presenting GPs with eight clinical vignettes on a five-point scale. These clinical pertussis vignettes were grouped into three different types on the basis of the national GP guideline [8]: one typical pertussis case vignette, four symptom-based vignettes and three vignettes of vulnerable groups at risk (see Table 1). Of the 594 invited GPs, 122 (21\%) completed the questionnaire. Respondents were on average 48 years old $(S D=9.4)$, of which most were male $(61 \%)$, worked at a practice with 3,336 patients on average (SD=1712.1), had on average 18 years of clinical experience $(S D=9.7)$ and $41 \%$ worked fulltime. In comparison, Dutch GPs are on average 49 years old, of which $55 \%$ are male and $40 \%$ work fulltime [15]. GPs sent their pertussis samples mainly to the six medical microbiology laboratories in the study region, while only a minority of $7 \%(9 / 122)$ sent their tests primarily to laboratories outside the region.

\section{GP reported pertussis diagnostic testing}

GPs annually diagnosed 6.1 ( $S D=7.0$, range $0-40)$ pertussis cases on average and $84 \%(n=103)$ of the GPs had at least one diagnosed case of pertussis in that year. In case of a clinical pertussis diagnosis $(n=93), 88 \%(n=82)$ of GPs indicated that they requested a confirmatory laboratory test. Of all GPS, $14 \%(n=17)$ did not perform any pertussis diagnostic testing during the study year, while $39 \%(n=47)$ of the GPs requested one to four tests and $48 \%(n=58)$ of the GPs requested five or more tests (mean $=5.9, \mathrm{SD}=6.5$, range $=0-30$ ). GP characteristics were similar for the groups of testing and nontesting general practitioners.

General practitioners' reported reasons for testing, reasons for not testing and intention to test for pertussis can be seen in Table 1. When asked about their considerations to perform diagnostic testing for pertussis, the most frequently mentioned reasons to test were to confirm the clinical pertussis diagnosis $(70 \%)$, on patients' request $(57 \%)$, to rule out pertussis $(51 \%)$, to give more information on the duration of symptoms such as coughing (50\%) or to start preventive measures $(43 \%)$. Only $7 \%$ of the 
GPs tested in order to enable treatment to start. The most important reported reason for not testing was that GPs considered the diagnostic test result not to influence the treatment (70\%; see Table 1).

The clinical vignette in which GPs were most likely to perform diagnostic testing for pertussis was the typical pertussis case vignette presented (a patient with two weeks of persistent coughing who had direct contact with a person diagnosed with pertussis; 64\%). GPs reported that they were more likely to perform laboratory testing for pertussis in the symptom-based vignettes than in the vignettes of vulnerable groups at risk. Frequent testers (GPs performing five or more laboratory pertussis tests annually) were more likely to test on the basis of vulnerable groups at risk (mean=0.1, SD=0.9) compared to non-frequent testers (mean $=-0.3, S D=0.8, p=0.006$ ).

\section{Limitations}

As no medical records were available for research purposes, we collected self-reported data for this pilot study. The use of these self-reported data may introduce recall bias, whereas the numbers depicted in this study are estimates rather than exact figures. In general, the use of vignettes can influence the construct-, internal and external validity of study results [16]. Whether the reported reasons and intention to test for pertussis accurately reflect GPs' actual clinical practice is not completely known from our study. However, studying this in a observational study or self-reported study without clinical vignettes will have ethical, practical and other scientific limitations [16]. Moreover, our study may be prone to selection bias due to the low response rate of $21 \%$. This could influence the generalizability of our results. Yet, the response rate was only slightly lower than other questionnaire studies in GPs $[17,18]$ and the characteristics of responding GPs were comparable to the demographic characteristics of Dutch GPs in general [15].

\section{Implications for practice}

Our findings suggest that GPs mostly decide whether or not to test for pertussis based on clinical symptoms rather than on vulnerable groups at risk, GPs reasons for (not) testing for pertussis confirm this symptom-based testing. In conclusion, we recommend to focus pertussis testing practices of GPs more on vulnerable groups at risk instead of symptom-based testing on patients' request, as advised in the Dutch national guidelines. GPs need to be aware that it is recommended to consider testing in families with incompletely vaccinated infants $<1$ year of age, women $>34$ weeks pregnant and children with severe comorbidities such as heart or lung failure. Therefore, they are advised to check whether patients with symptoms suggestive of pertussis have vulnerable groups at risk in their household. 
Table 1. General practitioners' reported reasons for testing, reasons for not testing and intention to test for pertussis, the Netherlands, $2013(\mathrm{~N}=122)$

\begin{tabular}{|c|c|c|}
\hline Reasons for testing & $\%(n)$ & \\
\hline To confirm the clinical pertussis diagnosis & $70(86)$ & \\
\hline On patients' request & $57(70)$ & \\
\hline To rule out pertussis & $51(62)$ & \\
\hline To give more information on the duration of symptoms & $50(61)$ & \\
\hline To start preventive measures & $43(53)$ & \\
\hline To start treatment & $7(8)$ & \\
\hline Reasons for not testing & $\%(n)$ & \\
\hline The diagnostic test result does not influence treatment & $70(86)$ & \\
\hline $\begin{array}{l}\text { No direct contact with risk groups (hence no need for } \\
\text { treatment) }\end{array}$ & $52(64)$ & \\
\hline $\begin{array}{l}\text { Clear diagnosis due to direct link to a confirmed } \\
\text { pertussis case }\end{array}$ & $41(50)$ & \\
\hline $\begin{array}{l}\text { Clinical assessment alone is sufficient to diagnose } \\
\text { pertussis }\end{array}$ & $33(40)$ & \\
\hline Costs for patients & $28(34)$ & \\
\hline Treatment is already started & $25(31)$ & \\
\hline Collecting blood samples in children is too stressful & $25(31)$ & \\
\hline Child is fully vaccinated & $17(21)$ & \\
\hline Time to receive test result & $16(20)$ & \\
\hline Referral to specialist & $16(19)$ & \\
\hline Intention to test ${ }^{a}$ & mean (SD) & $\begin{array}{l}\%(n) \text { likely or would } \\
\text { definitely test }\end{array}$ \\
\hline \multicolumn{3}{|l|}{ Typical pertussis case vignette: } \\
\hline $\begin{array}{l}\text { A patient with two weeks of persistent coughing who } \\
\text { had direct contact with a person diagnosed with } \\
\text { pertussis }\end{array}$ & $0.7(1.1)$ & $64(78)$ \\
\hline Symptom based vignettes & $0.5(0.8)$ & $57(70)$ \\
\hline Patient with a cough and a 'whooping' inhalation & $0.6(1.1)$ & $57(70)$ \\
\hline Patient with frequent expiratory coughing & $0.6(1.0)$ & $53(65)$ \\
\hline Patient who vomits after coughing & $0.5(1.1)$ & $49(60)$ \\
\hline $\begin{array}{l}\text { Patient with a persistent cough of more than six weeks } \\
\text { without other symptoms }\end{array}$ & $0.3(1.0)$ & $46(56)$ \\
\hline Vulnerable groups at risk vignettes & $-0.1(0.9)$ & $25(30)$ \\
\hline $\begin{array}{l}\text { Infants of } 3 \text { months to } 1 \text { year old with two weeks of } \\
\text { persistent coughing }\end{array}$ & $-0.1(1.0)$ & $30(37)$ \\
\hline $\begin{array}{l}\text { A pregnant woman (third trimester) with two weeks of } \\
\text { persistent coughing }\end{array}$ & $-0.1(1.0)$ & $29(35)$ \\
\hline $\begin{array}{l}\text { An adult with two weeks of persistent couching who has } \\
\text { a baby of two months old }\end{array}$ & $-0.2(1.1)$ & $26(32)$ \\
\hline
\end{tabular}

a Likelihood to test case ranging from -2=definitely not, -1=probably not, $0=$ possibly, $1=$ likely, 2 =definitely. 


\section{Acknowledgements}

We wish to thank Vivian Claessen for her input in the development of the questionnaire. This work was supported by the National Institute for Public Health and the Environment - Centre for Infectious Disease Control (RIVM-Clb), the Netherlands (Grant number: 3910007379). 


\section{References}

1. ECDC. Annual epidemiological report 2014 vaccine-preventable diseases. Stockholm: ECDC, 2014.

2. Aantal meldingen per infectieziekte per jaar [database on the Internet]. RIVM. [cited 7-72015]. Available from: http://www.rivm.nl/ Onderwerpen/M/Meldingsplicht_infectieziekten/Open_rapportages_meldingsplichtige_infectieziekten/Aantal_meldingen_per_infectieziekte_per_jaar.

3. Schurink-van 't Klooster TM, de Melker HE. The National Immunisation Programme in the Netherlands. Developments in 2013. Bilthoven: RIVM, 2013 Contract No.: 150202002.

4. Heil J, Ter Waarbeek HLG, Hoebe C, Jacobs PHA, van Dam DW, Trienekens TAM, et al. Pertussis surveillance and control: exploring variations and delays in testing, laboratory diagnostics and public health service notifications, the Netherlands, 2010 to 2013. Euro Surveill. 2017 Jul 13;22(28). PubMed PMID: 28749331. Pubmed Central PMCID: PMC5545763.

5. Crabbe H, Saavedra-Campos M, Verlander NQ, Leonard A, Morris J, Wright A, et al. Are pertussis cases reported too late for public health interventions? Retrospective analysis of cases in London and South East England, 2010 to 2015. Euro Surveill. 2017 Jul 20;22(29). PubMed PMID: 28749334. Pubmed Central PMCID: PMC5532964.

6. Dempsey $A F$, Cowan $A E$, Broder $K R$, Kretsinger K, Stokley S, Clark SJ. Diagnosis and testing pratices for adolescents pertussis among a national sample of primary care physicians. Prev Med. 2009;48.

7. Regionale kerncijfers Nederland [database on the Internet]. Centraal Bureau voor de Statistiek. [cited 26-9-2016]. Available from: http:// statline.cbs.nl/Statweb/publication/?DM=SLNL\&PA $=70072$ NED\&D1=1-2,12-23,42-45,51-56\&D $2=0,16 \& \mathrm{D} 3=18 \& \mathrm{HDR}=\mathrm{T} \& \mathrm{STB}=\mathrm{G} 1, \mathrm{G} 2 \& \mathrm{VW}=\mathrm{T}$.

8. Verheij TJM, Hopstaken RM, Prins JM, Salomé
PL, Bindels PJ, Ponsioen BP, et al. NHG-Standaard Acuut hoesten (eerste herziening). Huisarts Wet. 2011;54(2):68-92.

9. Brenzel L, Wolfson LJ, Fox-Rushby J, Miller M, Halsey NA. Vaccine-preventable Diseases. In: Jamison DT, Breman JG, Measham AR, Alleyne $G$, Claeson M, Evans DB, et al., editors. Disease Control Priorities in Developing Countries. 2nd ed. Washington (DC)2006.

10. Locht $C$, Mielcarek N. New pertussis vaccination approaches: en route to protect newborns? FEMS Immunology and Medical Microbiology. 2012;66.

11. de Greeff SC, de Melker HE, van Gageldonk PG, Schellekens JF, van der Klis FR, Mollema $L$, et al. Seroprevalence of pertussis in The Netherlands: evidence for increased circulation of Bordetella pertussis. PLoS One. 2010 Dec 1;5(12):e14183. PubMed PMID: 21152071. Pubmed Central PMCID: PMC2995730.

12. Cherry DJ. Why Do Pertussis Vaccines Fail? Pediatrics. 2012;129(968).

13. WHO. Pertussis vaccines: WHO position paper, August 2015-Recommendations. Wkly Epidemiol Rec. 2015 Aug 28:90(35):433-58. PubMed PMID: 26320265.

14. Gezondheidsraad. Vaccinatie tegen kinkhoest: doel en strategie. Den Haag: Gezondheidsraad; 2015.

15. van Hassel DTP, Kasteleijn A, Kenens RJ. Peiling 2014. Utrecht: NIVEL, 2015.

16. Evans SC, Roberts MC, Keeley JW, Blossom JB, Amaro CM, Garcia AM, et al. Vignette methodologies for studying clinicians' decision-making: Validity, utility, and application in ICD-11 field studies. International Journal of Clinical and Health Psychology. 2015;15(2):160-70.

17. Cals JW, Schols AM, van Weert HC, Stevens $F$, Zeijen CG, Holtman G, et al. [Point-of-care testing in family practices: present use and need for tests in the future]. Ned Tijdschr Geneeskd. 2014;158:A8210. PubMed PMID: 25515388. Snelt- 
esten in de huisartspraktijk: huidig gebruik en behoefte aan testen in de toekomst.

18. Schoots $M$, Honkoop $P$, Dunselman $H_{\text {, Joziasse }}$ I. Waar wil 'de nieuwe huisarts' zich vestigen? Huisarts en wetenschap. 2012 November 01;55(11):494-9. 




\section{Part 2}

Hepatitis

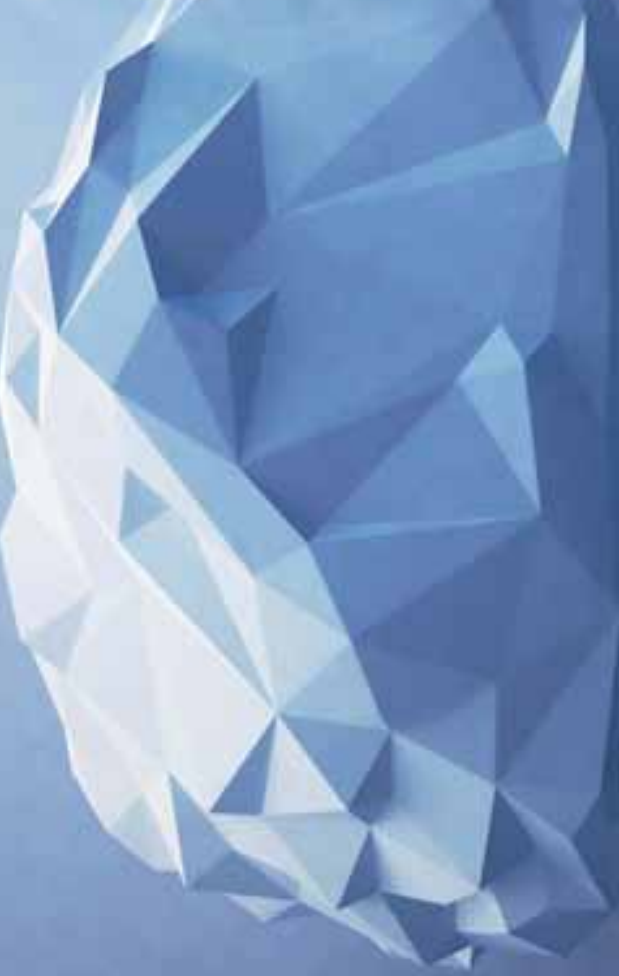





\section{Chapter 5}

\section{The Spatial Distribution of Hepatitis C Virus Infections and Associated Determinants-An Application of a Geographically Weighted Poisson Regression for Evidence-Based Screening Interventions in Hotspots}

Boris Kauhl, Jeanne Heil, Christian J.P.A.Hoebe, Jürgen Schweikart, Thomas Krafft, Nicole H.T.M. Dukers-Muijrers 


\section{Abstract}

\section{Background}

Hepatitis C Virus (HCV) infections are a major cause for liver diseases. A large proportion of these infections remain hidden to care due to its mostly asymptomatic nature. Population-based screening and screening targeted on behavioural risk groups had not proven to be effective in revealing these hidden infections. Therefore, more practically applicable approaches to target screenings are necessary. Geographic Information Systems (GIS) and spatial epidemiological methods may provide a more feasible basis for screening interventions through the identification of hotspots as well as demographic and socio-economic determinants.

\section{Methods}

Analysed data included all HCV tests $(n=23,800)$ performed in the southern area of the Netherlands between 2002-2008. HCV positivity was defined as a positive immunoblot or polymerase chain reaction test. Population data were matched to the geocoded HCV test data. The spatial scan statistic was applied to detect areas with elevated HCV risk. We applied global regression models to determine associations between population-based determinants and HCV risk. Geographically weighted Poisson regression models were then constructed to determine local differences of the association between $\mathrm{HCV}$ risk and population-based determinants.

\section{Results}

HCV prevalence varied geographically and clustered in urban areas. The main population at risk were middle-aged males, non-western immigrants and divorced persons. Socio-economic determinants consisted of one-person households, persons with low income and mean property value. However, the association between HCV risk and demographic as well as socio-economic determinants displayed strong regional and intra-urban differences.

\section{Discussion}

The detection of local hotspots in our study may serve as a basis for prioritization of areas for future targeted interventions. Demographic and socio-economic determinants associated with HCV risk show regional differences underlining that a one-size-fits-all approach even within small geographic areas may not be appropriate. Future screening interventions need to consider the spatially varying association between HCV risk and associated demographic and socio-economic determinants. 


\section{Introduction}

Hepatitis $\mathrm{C}$ virus (HCV) infections are a major cause of liver diseases and are the leading cause for liver cirrhosis worldwide [1]. The World Health Organization estimates that 123 million people globally are infected with HCV [2]. A major challenge for public health response to HCV is its mostly asymptomatic nature and therefore the limited number of HCV positive individuals aware of their HCV status. Infected, but undiagnosed persons are an important source for further transmission [3]. Several studies estimated the proportion of asymptomatic infections to account for $70 \%[4,5]$ to $90 \%$ [6] of acute infections, leading to only a small proportion of infected individuals seeking medical attention for symptoms related to $\mathrm{HCV}$ infection [7]. It is estimated that less than one-third of HCV infected individuals are aware of their HCV status [8-10]. Many infections are either undetected or are detected at a late stage. Highly effective therapeutic options for HCV are becoming available, [11,12] but logically only to persons, who's HCV infection is diagnosed.

To provide an opportunity for treatment of HCV positive persons, which are yet undiagnosed and therefore currently hidden to care, preventive screening is necessary.

The HCV prevalence and its associated risk factors varies considerable between countries $[13,14]$. Past interventions focused on the population in general were not very cost-effective, especially in countries where the overall HCV prevalence is low. In the Netherlands, the HCV prevalence in the Dutch adult population is estimated to be relatively low with $0.2 \%$, although estimates vary between 0.1 and $0.4 \%$, depending largely on the study design and population studied $[15,16]$. A meta analysis on the effectiveness of screening interventions suggests that for low HCV prevalence populations, pre-screening selection criteria should be used to increase efficiency [17]. The World Health Organisation (WHO) recommends in its new guidelines to offer HCV tests to people with high risk behaviour and to people from high risk populations [18]. These target populations include transmission risk groups such as injecting drug users (IDU) [5,10,11], blood transfusion recipients [3], surgery and dialysis patients [13], professionals in patient care [5], immigrants from endemic countries [13], persons with low socio-economic status [5] and HIV positive men who have sex with men (MSM) [3]. However, screening approaches to target these risk groups have not been shown to be effective in revealing the totality of hidden cases as the identification of people who belong to such risk groups in the first place appeared to be quite challenging. Furthermore, in the Netherlands it had been shown that a substantial part (25\%) of all HCV infections is not attributable to any of the aforementioned risk groups and is therefore not included in screening interventions targeted at risk groups [16]. Although the prevalence of HCV in the US is higher with an estimated 2\% [19], the Centre for Disease Control (CDC) similar to the WHO advises screening of persons in risk groups (IDU, blood transfusion or organ transplant recipients before July 1992, health care personnel with history of exposure and born to an HCV-positive mother) [20]. However, these criteria appeared also in the US difficult to include in practical screening interventions [10]. As a result, future screening interventions need to find characteristics of HCV that are more practically applicable than the risk groups and behavioural factors outlined above. 
Other relevant factors than behavioural and demographic risk factors associated with HCV are socio-economic characteristics. As for many infectious diseases, including HCV, lower socio-economic status tends to be associated with higher prevalence $[1,13,21,22]$. The identification of socio-economic determinants provides a more practically applicable basis for screening interventions [10], as population characteristics are typically available within population data [23]. The application of Geographic Information Systems (GIS) is essential to display the spatial heterogeneity of disease risk and to quantify the impact of socio-economic determinants on the incidence of infectious diseases [22,24].

Exploratory disease mapping and local cluster tests have shown to help identifying areas with statistically significant high risks (often referred to as hotspots or clusters) for prioritizing future interventions for Hepatitis $C$ in the mainland of China [25] as well as many other infectious diseases including HIV [26], Chlamydia trachomatis and Neisseria gonorrhoea [27].

The increasing availability of a wide range of population-based variables allows a detailed analysis of demographic and socio-economic determinants of disease risk using spatial regression models at the ecological level $[24,28,29]$.

With respect to $\mathrm{HCV}$, it has been shown that not only prevalence varies between and within countries, but also the association between risk factors and HCV prevalence [13], highlighting the necessity to account for local variation in spatial regression models for HCV.

In settings where strong local variation of the association between disease risk and possible determinants can be expected, geographically weighted Poisson regression models (GWPR) have proven to be very effective to measure the spatially varying association between possible determinants and disease risk. This in turn, often led to the conclusion that the determinants of a specific disease depend largely where infected populations live, allowing public health preventions to be targeted directly at those population groups, that are most at risk in a specific location [30-32].

The aim of this paper is therefore to (i) determine hotspots for future screening interventions using the spatial scan statistic and (ii) to assess demographic and socio-economic determinants of HCV risk within these hotspots using GWPR to facilitate targeted, evidence-based screening interventions aimed directly at risk-groups.

\section{Data and Methods}

\section{Ethics Statement}

The medical ethics committee of the Maastricht University Medical Centre (Maastricht, the Netherlands) approved the study (11-4-136) and waived the need for consent to be collected from participants. Since retrospective data originated from standard care (in which one can opt-out for the use of their data for scientific research) and were analysed anonymously, no further informed consent for data analysis was obtained. 


\section{Dependent Variable}

The dependent variable consisted of the HCV diagnoses that were made in the southern part of the province Limburg, the Netherlands between January 1st, 2002 and December 31st, 2008, comprising an adult population of 500,955 in $2008[10,33]$. The diagnoses were retrieved from HCV test data that were provided by three hospital laboratories, which perform tests on HCV upon request of nearly all care providers serving the area. In total $23,800 \mathrm{HCV}$ tests were conducted of which 823 unique patients were tested positive. According to screening procedures in the Netherlands, HCV antibodies were detected with an ELISA. Confirmation was performed with an immunoblot and/or polymerase chain reaction (PCR). When an acute infection was suspected or when the patient was HIV positive or on haemodialysis, only PCR was used for screening. In the current study, we defined a positive confirmation test or PCR as a positive case. Of these 823 unique positive individuals, 781 had valid postal codes assigned and were included in the analysis. Next to postal code and HCV test result, the laboratory dataset included sex and age [10].

\section{Explanatory Variables}

We assessed several demographic and socio-economic variables for their association with HCV risk. The data for these variables were downloaded from the Central Bureau for Statistics Netherlands. In this study, we used data and map sources from the Statline database 2009 [33] (Table 1). The data were available on neighbourhood level and had to be matched to the four-digits postal codes of the HCV data. A neighbourhood is a part of a municipality with a homogenous socio-economic structure [33,34]. Due to privacy restrictions, socio-economic data on neighbourhood level is only available for neighbourhoods with more than 50 persons, 200 persons, 10 households and 70 households, depending on the respective variable [33]. We therefore aggregated to the four-digits postal codes based on those neighbourhoods, for which socio-economic data was made available.

\section{Table 1. Explanatory variables}

\begin{tabular}{lrrr} 
Variable & Average & Min & Max \\
Married (\%) & 44.7 & 1.0 & 62.0 \\
Unmarried (\%) & 40.9 & 15.0 & 96.0 \\
Divorced (\%) & 3.8 & 0.0 & 10.6 \\
Widowed (\%) & 6.8 & 0.0 & 48.0 \\
Non-western immigrants (\%) & 4.8 & 0.0 & 14.2 \\
One-person households (\%) & 36.4 & 7.0 & 71.8 \\
Households w/o children (\%) & 32.1 & 20.7 & 57.0 \\
Social welfare recipients (\%) & 1.2 & 0.5 & 14.6 \\
Average income (in 1000 Euro) & 20.5 & 14.2 & 29.1 \\
Persons with low income (\%) & 2.1 & 0.5 & 15.5 \\
HH with low purch. power (\%) & 8.9 & 0.0 & 20.0 \\
Households with low income (\%) & 45.9 & 17.0 & 67.0 \\
HH below social minimum (\%) & 9.3 & 0.0 & 22.0 \\
Mean prop. value (in 1000 Euro) & 213.6 & 116.7 & 433 \\
Males aged 36-45 (\%) & 6.4 & 0.0 & 12.2 \\
Males aged 46-55 (\%) & 8.2 & 0.0 & 11.2 \\
\hline
\end{tabular}


Demographic variables included stratified population data for 2012 on four-digits postal code level $[10,16]$. The population data was extracted from customised data by Statistics Netherlands (Extraction date: $20 / 02 / 2013$ ).

Socio-economic variables included marital status (proportion of residents that were married, unmarried, divorced, or widowed)[35], proportion of non-western immigrants [16], proportion of one-person households, proportion of households without children, average income [10,36], proportion of persons having low income [36] (defined as an income below 19,200 Euro per year [33]), households having low purchasing power (defined as households having less than 9,250 Euro available per year [33]), households having low income [36] (defined as households with an annual income below 25,100 Euro [33]), households below social minimum and mean property value as indicator for potential area deprivation $[10,33]$.

\section{Exploratory Disease Mapping}

We calculated the prevalence rate of $\mathrm{HCV}$ and the relative risk (RR) for the adult population aged between 16 and 65 .

The RR estimates provide useful information how common HCV infection in a specific location is as compared to the global baseline [37]. We additionally applied spatial empirical Bayes smoothing since the population at risk displayed strong regional variation. This leads to a large variance of the prevalence rate and the relative risk especially in areas where the underlying population is small [38]. Due to strong regional variation in the HCV prevalence, we applied a local smoothing approach. The prevalence rates and the RR were therefore smoothed towards a local mean where the neighbours were defined as areas sharing a common edge and a common boundary [39]. The calculation of the spatial empirical Bayes smoothing was carried out using OpenGeoDa 1.2.0 [40] and the results were then imported in ESRI ArcGIS 10.1.

\section{Global Cluster Detection}

To test whether there is spatial autocorrelation of the HCV prevalence, we used Moran ` $\mathrm{I}$. Moran ` $\mathrm{I}$ is a widely used global cluster test, which determines the degree of clustering or dispersion within a data set. The resulting values may range from 1 (perfect correlation), 0 (complete spatial randomness) to -1 (perfect dispersed) [41]. For the HCV data, a positive spatial autocorrelation means that postal code areas with high HCV prevalence are close to other postal code areas with high HCV prevalence. For this study, we defined adjacency as postal code areas sharing a common edge or corner. The presence of global clustering justified the subsequent local cluster analysis. The computation of Moran`s I was carried out in OpenGeoDa 1.2.0 [40]

\section{Local Cluster Detection}

The spatial scan statistic has been widely applied in several spatial-epidemiological studies to detect local clusters with statistically significant elevated risk of infectious diseases $[22,26,42,43]$. The spatial 
scan statistic is a local cluster test, which identifies the location and the statistical significance of local clusters [26]. We applied a Poisson purely spatial model where the number of HCV cases follows an inhomogeneous Poisson process [44]. The input data for this model consisted of the number of positive individuals per postal code, the number of adults aged between 16 and 65 and the centroid coordinates for each area. The spatial scan statistic imposes a circular scanning window, which is flexibly in size and position and gradually moves over all coordinates, evaluating all potential cluster locations and sizes up to either a user-defined maximum radius, a user defined maximum percentage of the population at risk or the default value of up to $50 \%$ of the population at risk [45].

In our study, the purpose of the spatial scan statistic was to detect areas with significantly elevated risk of diagnosed $\mathrm{HCV}$, which can serve as a basis for the prioritization of future screening interventions $[46,47]$. We set the maximum population at risk to not exceed $5 \%$ of the adult population. This was done to detect local clusters as precisely as possible since the default settings of $50 \%$ of the population at risk are more likely to produce clusters of no practical use [48]. The computation was carried out using the SaTScan software version 9.2 [45].

\section{Spatial Regression}

Ordinary Least Squares Regression. To specify a meaningful geographically weighted Poisson regression model, we conducted several steps: First, we performed a natural log-transformation of the dependent variable. We then used a data-mining tool called Exploratory Regression in ESRI ArcGIS 10.1. to determine potential candidate explanatory variables. This tool evaluates all possible variable combinations that form a properly specified ordinary least squares (OLS) regression model. Exploratory regression is comparable to a step-wise regression [31]. However, it evaluates all possible variable combinations based on following criteria: (i) the coefficients are statistically significant, (ii): the explanatory variables are free from multicollinearity, (iii): the residuals are normally distributed and (iv): the residuals do not display spatial autocorrelation $[31,49,50]$.

Based on the results of the exploratory regression, we determined overall model significance, the presence of heteroscedasticity and a wide range of diagnostics by creating an OLS regression model in OpenGeoDa 1.2.0 [40] with the same dependent and explanatory variables as suggested by the exploratory regression.

Geographically Weighted Regression. Since the OLS regression is a global regression model, it estimates the strength of the relationship between the dependent variable and the explanatory variables averaged over the whole study area. However, the larger the study area, the more unlikely it is that one single coefficient per explanatory variable reflects the true underlying spatial relationship between the dependent variable and the explanatory variable since spatial data tend to vary over space. Global statistics tend to lead to the conclusion that relationships between variables are equal across the entire study area whereas local statistics can show the falsity of this assumption by displaying how the relationships vary across space [51]. The geographically weighted regression (GWR) method is therefore an extension to the traditional standard regression methodology and estimates a 
wide range of local parameters and diagnostics.

The Poisson distribution within the GWR framework is currently the most suitable for disease data, especially if observed counts of cases are low in specific areas [52-54]. The dependent variable was specified within the geographically weighted Poisson regression (GWPR) as the observed number of $\mathrm{HCV}$ cases per postal code and the offset variable was specified as the number of adult persons per postal code. The GWPR model calculates an additional global Poisson regression model, which can be compared to the results of the global OLS model to test the hypothesis that a Poisson regression is more suitable for HCV than the traditional OLS regression. The explanatory variables for the global and local Poisson regression models were the same variables that were found to be significant as specified by the OLS model. The centroids of each postal code were used as input coordinates. The GWPR model then uses a kernel and fits for each coordinate a regression equation where the coordinate in the centre of the kernel is the regression point. The data points inside the kernel are weighted from the centre of the kernel towards the edge of the kernel. Data points outside the kernel receive a weight of zero and are not included in the regression equation. For each coordinate, the data points are weighted differently so that each regression point has a unique regression equation. We used an adaptive kernel size so that in rural areas where data points are sparse, the kernel bandwidth will increase in size and will decrease in urban areas where data points are plentiful. The size of the bandwidth for each kernel and regression point is optimized using Akaike`s Information Criterion (AIC) [51]. To facilitate interpretation of the regression coefficients of the GWPR, the coefficients were exponentiated to show an increase or decrease of the relative risk of the dependent variable per one-unit change in the respective explanatory variable [52]. Statistical significance for each coefficient per postal code was calculated using pseudo t-values [51]. The statistic behind the GWPR method is described in detail elsewhere [52]. The computation of the GWPR was carried out using the GWR4 software [55].

\section{Results}

\section{Spatial Distribution of Hepatitis C Prevalence among Adults}

The prevalence and the risk estimates between the postal code areas varied widely, ranging from 0 to $1.02 \%$ of the adult population per postal code. The overall prevalence rate among adults was $0.19 \%$ of the total adult population. There was a clear urban-rural divide within the study area. Areas with higher risks were strongly concentrated within the urban areas of Heerlen, Maastricht and to a lower extent in Sittard-Geleen (Fig 1). Moran `s I revealed significant positive global autocorrelation of the HCV prevalence (Moran` $s \mathrm{I}=0.43, p<0.001$ ), indicating that postal codes with higher risks are close to each other.

The spatial scan statistic detected five significant local clusters (Fig 1). These are postal codes with statistically significant elevated risk of diagnosed HCV. All clusters could be observed within the three urban areas of the study area (Table 2). In total, these clusters contain 268 (34\%) of all observed HCV infections in the study area. 


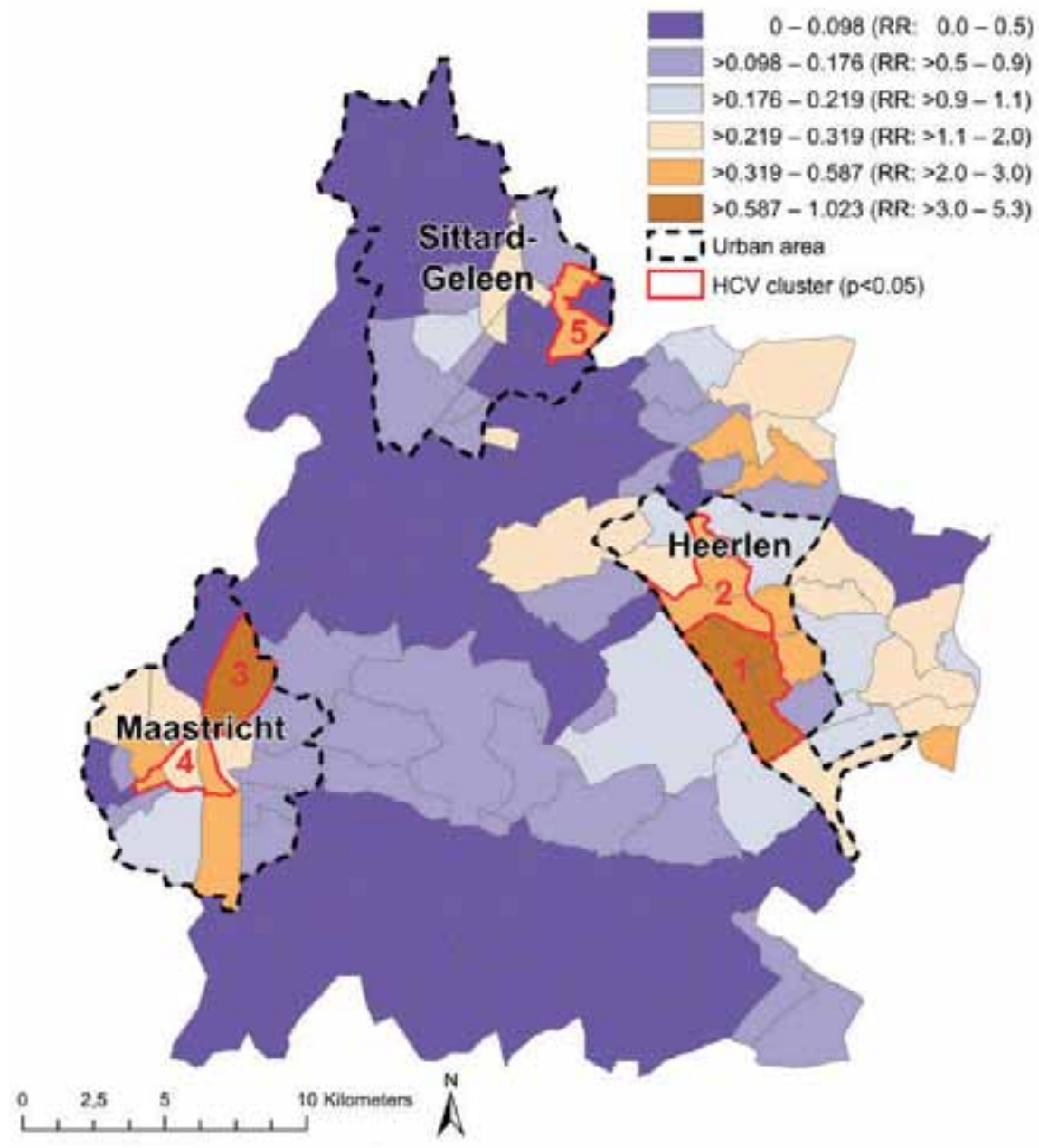

Figure 1. Spatial Distribution of HCV prevalence in \% of adult population and RR, 2002-2008

Table 2. Significant clusters with high HCV risk as determined by the spatial scan statistic

\begin{tabular}{lllll} 
Cluster nr. & Location & RR & Cases & P-value \\
1 & Southern part of Heerlen (3 postal codes) & 4.30 & 91 & $<0.001$ \\
2 & Northern part of Heerlen (2 postal codes) & 2.83 & 60 & $<0.001$ \\
3 & Northern part of Maastricht (1 postal code) & 4.03 & 31 & $<0.001$ \\
4 & Centre of Maastricht (3 postal codes) & 1.91 & 71 & $<0.001$ \\
5 & Eastern part of Sittard-Geleen (1 postal code) & 3.29 & 15 & $<0.05$ \\
\hline
\end{tabular}




\section{Demographic and Socio-economic Determinants of HCV}

As our analysis was exploratory in nature, we were interested in determining variable combinations based on population data that delivered a plausible explanation of HCV risk. We therefore identified two models that met all requirements for a properly specified OLS model that delivered a plausible explanation of the HCV prevalence. The AICc value of both OLS models differed only by 3, justifying a comparison of both models [56]. The first model consisted of the following explanatory variables that were overall positively associated with HCV risk: (i) proportion of divorced persons, (ii) proportion of oneperson households, (iii) proportion of non-western immigrants and (iv) proportion of males aged 36-45. The second model consisted of the variables (i) average income per person, (ii) one-person households, (iii) mean property value and (iv) males aged 36-45. Variables for the second model were overall positively associated with $\mathrm{HCV}$ risk except for average income and mean property value, that both showed an inverse association. The same variables that were found to be significant in the OLS models were then used for further analysis in the global and local Poisson models.

By comparing model performance in terms of the goodness-of-fit AlCc statistic (Table 3), the model with the lowest AICc value is the model with the best fit [24]. Based on this criterion, for both Model 1 and Model 2 the AICc value suggests that the global Poisson regression had a better fit than the OLS regression. However, the local Poisson regression outperformed both global regression approaches. The local Poisson regression of model 2 was the overall best-fitting regression model in terms of the $\mathrm{AICc}$ value as well as the percentage of local deviance explained.

\section{Table 3. Comparison of global and local models}

\begin{tabular}{lll} 
Model 1 & Local Deviance Explained & AlCc \\
OLS & & \\
Global Poisson & 0.50 & 495 \\
Local Poisson & 0.47 & 372 \\
Model 2 & 0.53 & 334 \\
OLS & & \\
Global Poisson & 0.50 & 498 \\
Local Poisson & 0.48 & 360 \\
\hline
\end{tabular}

\section{Results of the Geographically Weighted Poisson Regression}

Model 1. The results of the local Poisson model revealed strong local differences of the regression coefficients within the local clusters of elevated HCV risk (Table 4). The impact of the proportion of divorced persons on HCV risk was strongest in cluster 3 and 4 in Maastricht and cluster 5 in the northern part of Sittard-Geleen. In Heerlen, the impact of divorced persons was lowest (Fig 2). The impact of one-person households displayed intra-urban differences as well as regional differences. The association between the proportion of one-person households and HCV risk was strongest in the northern part of Heerlen (cluster 2) and the southern part of Sittard-Geleen (cluster 5). In cluster 3 and 4 in Maas- 
tricht, the impact of one-person households was overall lower than in the other urban areas and clusters. However, the northern part of Maastricht displayed a stronger association of one-person households to HCV risk than the southern part (Fig 2). The association between the proportion of non-western immigrants and HCV risk was only significant in cluster 3 and 4 in Maastricht and surrounding areas (Fig 2). Also, the association between the proportion of males aged $36-45$ years and HCV risk displayed large regional differences; its impact was only significant in cluster 5 in Sittard-Geleen, followed by clusters 3 and 4 in Maastricht and the rural areas in between (Fig 2).

Table 4. Significant $(p<0.05)$ coefficients per HCV cluster for model 1

\begin{tabular}{lll} 
HCV Cluster nr. & Determinants & Coefficient \\
\hline 1 & Divorced persons & 1.102 \\
2 & One-person households & 1.034 \\
3 & Divorced persons & 1.096 \\
& One-person households & 1.036 \\
& Divorced persons & 1.161 \\
& One-person households & 1.035 \\
& Non-western immigrants & 1.036 \\
4 & Males aged 36-45 & 1.157 \\
& Divorced persons & 1.164 \\
& One-person households & 1.034 \\
& Non-western immigrants & 1.035 \\
5 & Males aged 36-45 & 1.146 \\
& Divorced persons & 1.159 \\
& One-person households & 1.036 \\
& Males aged 36-45 & 1.161 \\
\hline
\end{tabular}

Model 2. Comparable to the first model, the second model revealed strong local differences of the coefficients within the HCV clusters (Table 5). The association of HCV risk to average income was overall negative, indicating that a lower income is associated with a higher HCV risk. The local coefficients however, revealed that this association is not in the whole study area significant and negative. Average income is only significant inversely associated with HCV risk in cluster 5 in Sittard-Geleen and one postal code area in Maastricht (Fig 3). The proportion of one-person households was positively associated with HCV risk in cluster 5 in Sittard-Geleen and the northern postal codes of Maastricht in cluster 3. This association decreased in strength towards cluster 1 and 2 in Heerlen (Fig 3). Mean property value was negatively associated to $\mathrm{HCV}$ risk in all areas but the association displayed strong regional and intra-urban differences and was strongest in the southern postal codes of Heerlen in cluster 1 (Fig 3). The association between the proportion of males aged 36-45 and HCV risk displayed a similar pattern as observed in model 1 . The association was only significant in the northern parts of Maastricht in cluster 3 and 4, the southwestern parts of Sittard-Geleen in cluster 5 and areas in between (Fig 3). 
a) Local coefficients for divorced persons

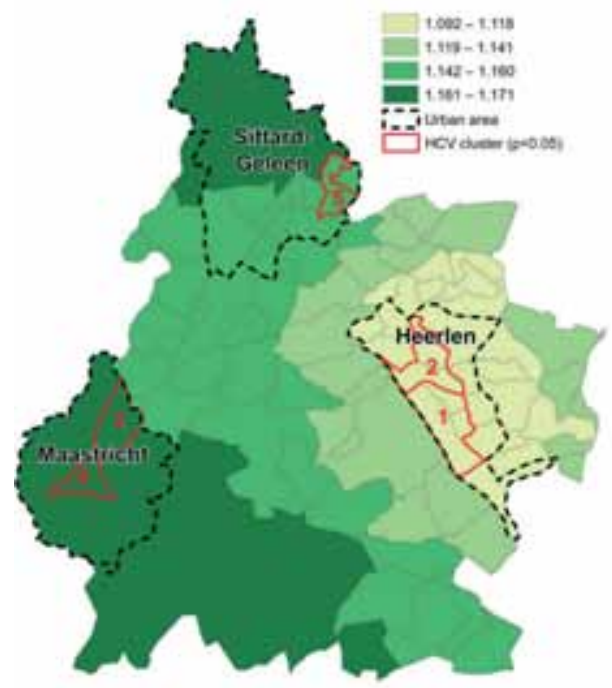

b) Local coefficients for one-person households

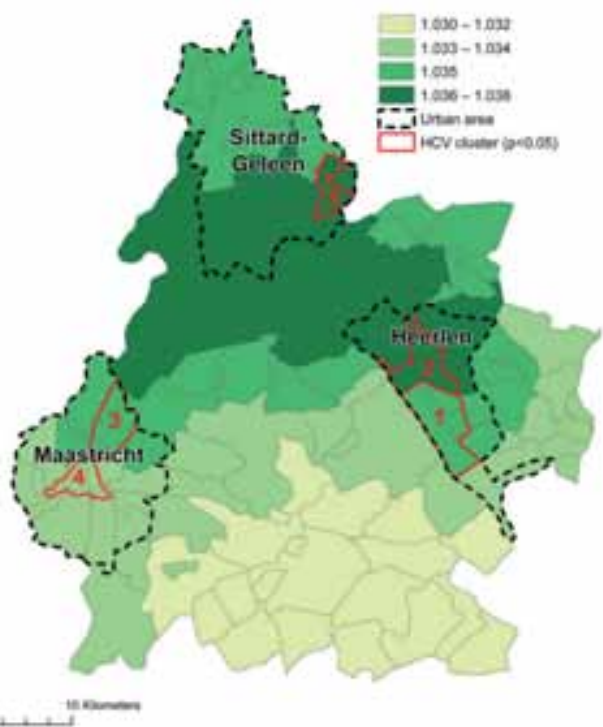

d) Local coefficients for males aged 36-45

c) Local coefficients for non-western immigrants

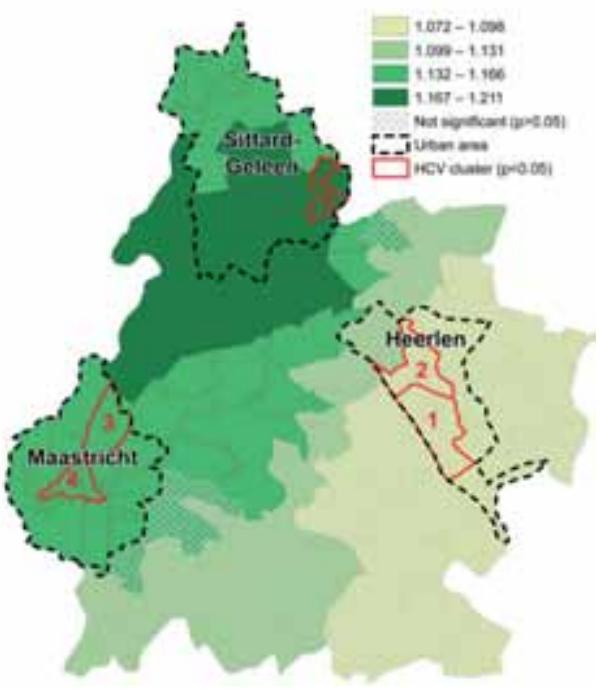

Figure 2. Local coefficients for model 1 
a) Local coefficients for average income per person

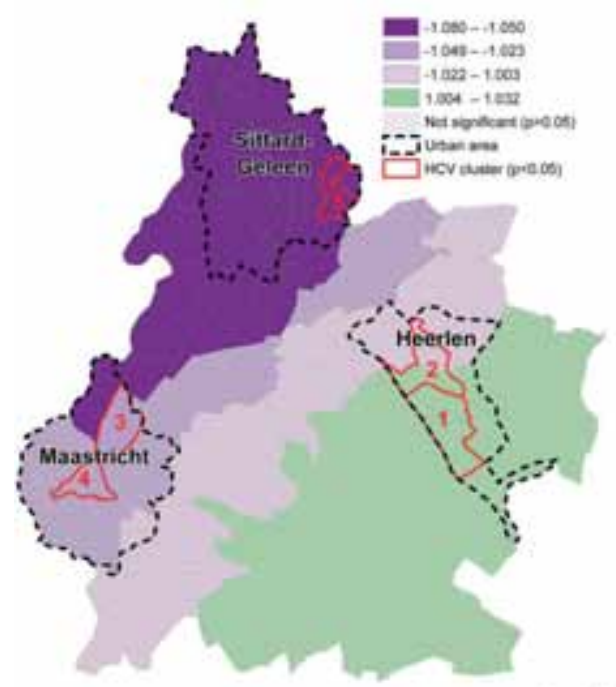

c) Local coefficients for mean property value

\section{b) Local coefficients for one-person households}

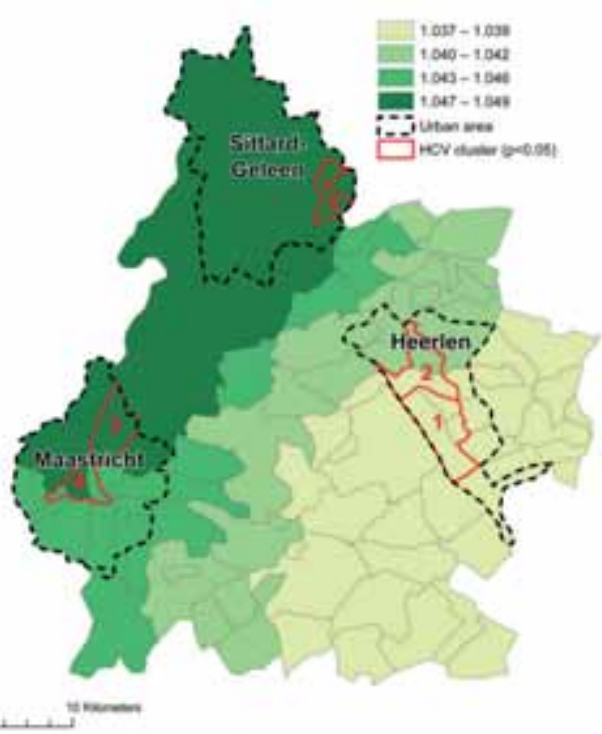

d) Local coefficients for males aged $36-45$
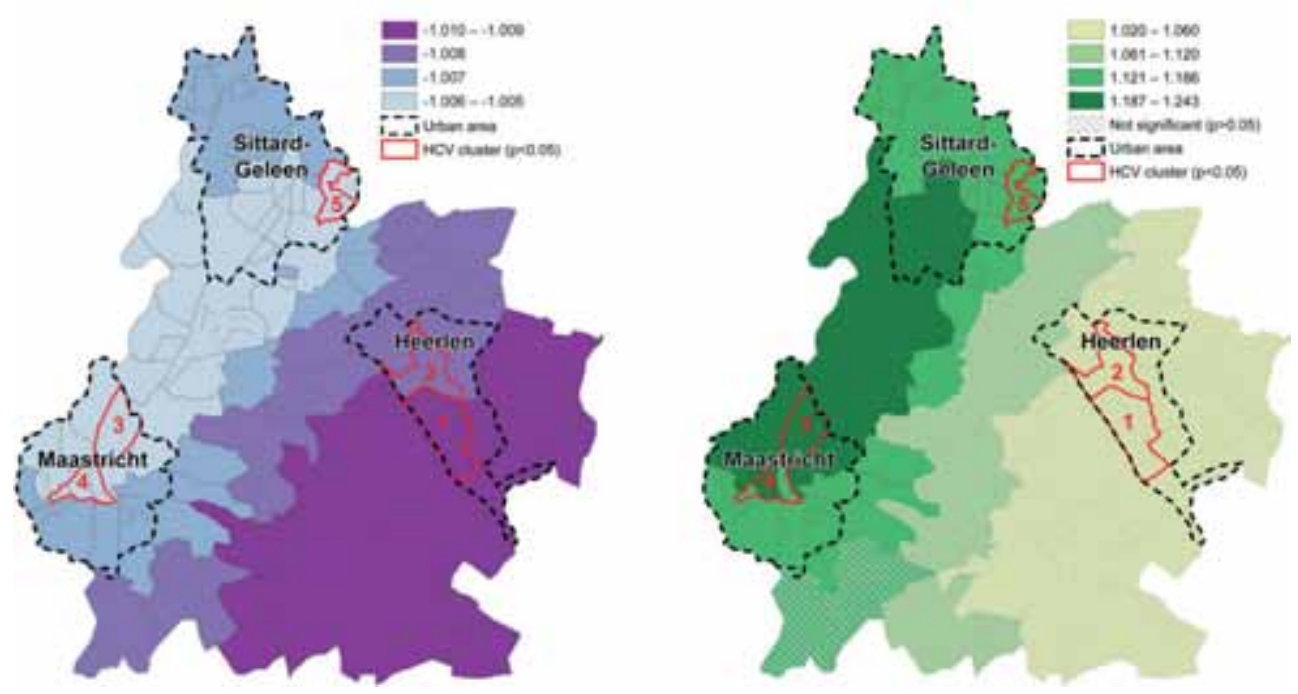

Figure 3. Local coefficients for model 2 
Table 5. Significant $(p<0.05)$ coefficients per HCV cluster for model 2

\begin{tabular}{llr} 
HCV Cluster nr. & Determinants & Coefficient \\
1 & One-person households & 1.038 \\
& Mean property value & -1.009 \\
2 & One-person households & 1.039 \\
& Mean property value & -1.008 \\
3 & One-person households & 1.047 \\
& Mean property value & -1.006 \\
& Males aged 36-45 & 1.213 \\
4 & One-person households & 1.045 \\
& Mean property value & -1.006 \\
& Males aged 36-45 & 1.186 \\
& Average income per person & -1.070 \\
& One-person households & 1.046 \\
& Mean property value & -1.006 \\
& Males aged 36-45 & 1.161 \\
\hline
\end{tabular}

\section{Discussion}

The prevalence of $\mathrm{HCV}$ varies geographically within the province of South Limburg and clusters were located in urban areas. The main population at risk were divorced persons, male residents aged 36-45 and non-western immigrants residing in the area. Socio-economic determinants associated with HCV risk included one-person households, low income at individual level and areas with low mean property value. The associations between these determinants and HCV risk displayed strong regional and intraurban differences.

The overall prevalence of diagnosed HCV cases was $0.19 \%$, which is in the range of previous overall estimations of the HCV prevalence within the Dutch population [7,57]. However, the prevalence showed strong local variations with prevalence ranging between 0 and $1.023 \%$.

Five local clusters of significantly elevated HCV risk were detected. These clusters were located in the three urban areas in the region. These results suggest that HCV risk is higher in urban areas than in rural areas and clusters geographically. Thereby, HCV prevalence does not only vary between countries, as was noted before $[13,14]$ but also on small geographic scales such as postal code areas. The smallscale variation of HCV prevalence corresponds with findings of another spatial analysis of HCV in a higher prevalence country [58]. Local clustering of HCV prevalence in urban areas is typical for a wide range of infectious diseases, including HIV [26], Neisseria gonorrhoea [42] and Chlamydia trachomatis [27]. The detection of local clusters in our study may serve as a basis for prioritization of areas for future targeted and evidence-based screening interventions [26,42]. However, it should be noted that only a third of all HCV cases were detected in these clusters. The other cases showed a more random distribution over the region. 
To what extent would these demographic and socio-economic determinants be of additional value to focus prevention strategies? When assuming that the population-based determinants represent the actual individual-based risk factors, then all determinants revealed here may indicate who are the key populations for HCV. Targeting these risk factors in the areas identified as clusters could serve as a practically applicable basis for prioritization of future screening interventions.

While there is a wide range of literature available about the prevalence of HCV infections and its associated risk factors [13,14], only a local analysis as employed here may help to understand the patterns of HCV infections and its associations to socio-economic determinants to effectively use available financial resources for targeted screening efforts.

The proportion of residents that were divorced was found to be associated with HCV risk over the complete study region. Marital status had been previously associated with HCV risk, yet findings were inconsistent [59-62]. Being divorced could be a proxy for sexual and economic instability. The found association between HCV risk and divorced persons may therefore serve as basis for future research on the role of marital status and potential high-risk sexual behaviour on HCV transmission in the study area. Non-western immigrants were identified as ethnic risk group in our study. Although this association corresponds well to previous studies focusing on risk factors of HCV in the Netherlands $[15,16]$, the association of non-western immigrants to HCV risk was only significant in Maastricht. Potentially, in the other cities, immigrants from eastern-European countries might be more relevant as ethnic risk group [13,15].

Males aged 36-45 were another main demographic risk group identified in our analysis confirming US findings [3]. It is considered unlikely that this association can be for a large part explained by HIV positive MSM, as they comprise an important but only small part of the HCV cases in the Netherlands. [63]. However, the association between males aged $36-45$ and HCV risk was only significant in the western part of the study area. One-person households were identified as a risk factor relating to household size. Although this association to HCV may not be obvious at first, it is in line with our findings that divorced persons are an overall risk factor for HCV and could be a potential additional proxy for sexual and economic instability. This finding may additionally serve as a basis for future research on the role of one-persons households and HCV transmission. Mean property value and low income at personal level were important socio-economic determinants associated with HCV risk [35] and are in line with other studies showing that low socio-economic status is an important risk factor for HCV $[10,13,36]$. However, our study demonstrated that low income at personal level was only significant in the urban area of Sittard-Geleen, while mean property value was found to be overall significant within the study area. Although this corresponds well to previous findings $[10,13,36]$, it highlights the importance of including several markers for low socio-economic status on personal, household and area level to understand how these different measures of low socio-economic status impact the prevalence of HCV infections.

Several determinants were associated with HCV risk in the complete study region while others were only associated in certain regions; but all associations showed regional variance. The strong spa- 
tial differences observed suggest that the importance of demographic and socio-economic determinants to characterize the HCV key population may depend largely on the area where the HCV infected individual lives. Our findings are therefore in line with other studies applying GWR for infectious diseases [24,30,64].

In all clusters, an association was observed between HCV risk and divorced persons, one-person households and low mean property value. The proportion of middle-aged males were only associated to $\mathrm{HCV}$ in the clusters $3-5$, and the proportion of non-western immigrants were only associated in the clusters 3 and 4. Income at personal level was only inversely associated in cluster 5 . Thus, the impact of demographic and socio-economic determinants differed across the study area for the identified clusters.

\section{Limitations}

First, the spatial analysis of this study was based on the four-digits postal code areas of the Netherlands. Although this spatial aggregation may be considered as a fine geographic scale [34], the prevalence rate of HCV follows the potentially arbitrary administrative boundaries of these postal codes. The results of our analysis might differ if a different level of aggregation had been chosen. This problem is often referred to as the modifiable areal unit problem (MAUP) and has not only an impact on the spatial distribution of HCV risk and the location of the detected clusters, but also on the results of the ecological regression analysis [65]. For our study, it would have been favourable to use street-level addresses of the HCV positive persons and underlying population at risk to analyse the spatial distribution of HCV without the limitation of arbitrary administrative boundaries [26]. This would not only allow a precise localization of HCV clusters, but could offer the chance to perform a geographically weighted logistic regression to provide more detailed insights on the spatially varying association between HCV risk and associated socio-economic and demographic determinants [51]. However, the HCV laboratory data as well as the population data used in this study were not available on this scale.

Second, it is unknown whether testing was motivated by the individuals due to symptoms related to HCV infection or was advised by a general practitioner due to prior knowledge of potential exposure factors of the tested individual. It is also unknown whether geographical, demographic or socio-economic determinants may have been associated with access to testing services (e.g. by distance, lack of knowledge, illiteracy) hence may have influenced the observed associations. The tested persons might therefore differ from the general population. During the initial data analysis, we tested the association of tested persons to demographic or socio-economic population characteristics through an additional exploratory regression model with the log-transformed percentage of tested persons as dependent variable. However, the exploratory regression analysis could not find demographic or socio-economic population characteristics that delivered a properly specified OLS regression model.

Additionally, we compared the spatial pattern of the ratio of HCV positive persons to tested persons with the ratio of positive persons to the adult population. Both approaches displayed a similar spatial pattern. An additional cluster analysis using a Bernoulli model in SaTScan with the number of negative 
tested persons as controls [45] could be used to test whether the location of spatial clusters will change when using the negative tested persons as denominator. This might additionally indicate, whether testing is performed randomly or follows different spatial patterns that cannot yet be explained by population or demographic characteristics that were available for this study. However, we applied only a Poisson model as our goal was to compare the HCV prevalence within our study area to previous estimates of the HCV prevalence in the Netherlands, which would not be possible when applying a case-control study design.

In our study, we consider the geographical spread of diagnosed $\mathrm{HCV}$ as a realistic representation of the diagnosed HCV prevalence among the adult population since the proportion of tested persons could not be properly explained by demographic or socio-economic population characteristics and the two compared ratios displayed a similar spatial pattern.

Third, the demographic and socio-economic determinants examined are practically applicable but are hampered by lack of precision as they are based on population data and not on an individual level. Population data provide population characteristics per neighbourhood. Therefore, additional research is needed to study whether the population-based determinants for key populations actually capture the individuals comprising such key population.

Fourth, we previously estimated that up to $66 \%$ of all HCV-positive patients in the study region were hidden to current screening practices [10]. As a result, cases that were diagnosed may differ from the cases that were still hidden with respect to the variables studied here.

Given the limitations outlined above, it is unknown to what extent the clusters and the demographic and socio-economic determinants really reflect the hidden population. A proof-of-principle intervention targeting postal codes in a detected cluster is currently being set up to reveal whether the hidden HCV infected individuals are appropriately addressed by our detected clusters and determinants. Additionally, we may have missed associations of potential determinants not captured in our analyses, as these were unavailable in the population databases such as educational level.

Also, the population-based determinants used in this study were taken from the Statline database 2009 as this was the earliest population data to include socio-economic variables and the customized stratified demographic data on sex and age were only available for 2012 but not for the years between 2002-2008. Although this might influence the results, it is unlikely that this has a strong impact as the demographic composition in the Netherlands remained relatively stable within the last few years [66].

The application of a Geographically Weighted Poisson regression clearly demonstrated spatial variability of the coefficients and underlined that future screening interventions for HCV clearly have to take into account the spatially varying association between demographic and socio-economic determinants. However, Paéz et al. point out that the use of GWPR delivers more robust results when applied on large datasets containing more than 160 administrative units [67]. Therefore, future research applying GWPR for HCV should focus on larger areas such as whole countries to gain more robust insights on the spatial variation of determinants for $\operatorname{HCV}[23,29,30]$. The reproducibility of our study would allow a similar analysis for the whole of the Netherlands. 


\section{Conclusions}

In this study, we used spatial epidemiological methods to analyse the spatial distribution of HCV and its associated demographic and socio-economic determinants. Our results revealed strong regional differences not only of the HCV prevalence but also of the association between demographic and socio-economic determinants and HCV risk. These findings underline that a one-size-fits-all approach is not appropriate and that future screening interventions need to take into account the spatially varying demographic and socio-economic determinants for HCV. Our approach may not only be useful for South-Limburg, but may be useful in other countries as well.

\section{Acknowledgments}

The authors acknowledge the three medical microbiology laboratories for providing the laboratory data: Dick van Dam and Monique Manders (Orbis Medical Centre, Sittard, the Netherlands), Frans Stals and Jos Bus (Atrium Medical Center Parkstad, Heerlen, The Netherlands), and Inge van Loo and Gert Grauls (Maastricht University Medical Centre, Maastricht, The Netherlands). The authors would also like to thank Jennifer Ilius for enhancing the maps using Adobe Illustrator. The authors received no specific funding for this work. 


\section{References}

1. Shepard CW, Finelli L, Alter MJ (2005) Global epidemiology of hepatitis $C$ virus infection. Lancet Infect Dis 5: 558-567. pmid:16122679 doi: 10.1016/s1473-3099(05)70216-4

2. Perz J. Estimated global prevalence of hepatitis $C$ virus infection; 2004. Idsa.

3. Centers for Disease Control and Prevention (1998). Recommendations for prevention and control of hepatitis $\mathrm{C}$ virus (HCV) infection and HCV-related chronic disease. MMWR Recomm Rep 47: 1-39. pmid:9809743 doi: 10.1037/ e547602006-001

4. Gebo KA, Bartlett JG (2002) Management of hepatitis C: a review of the NIH Consensus Development Conference. Hopkins HIV Rep 14: suppl i-iv.

5. Alter MJ, Margolis HS, Bell BP, Bice SD, Buffington J, et al. (1998) Recommendations for prevention and control of hepatitis C virus (HCV) infection and HCV-related chronic disease. MMWR Morb Mortal Wkly Rep 47. pmid:9790221

6. Desenclos J (2003) The challenge of hepatitis C surveillance in Europe. Euro surveillance: bulletin Europeen sur les maladies transmissibles $=$ European communicable disease bulletin 8 : 99-100.

7. Slavenburg $S$, Verduyn-Lunel $F$, Hermsen J, Melchers W, Te Morsche R, et al. (2008) Prevalence of hepatitis $C$ in the general population in the Netherlands. Neth J Med 66: 13-17. pmid:18219062

8. Culver DH, Alter MJ, Mullan RJ, Margolis HS (2000) Evaluation of the effectiveness of targeted lookback for HCV infection in the United States-interim results. Transfusion 40: 1176-1181. pmid:11061852 doi: 10.1046/j.15372995.2000.40101176.x

9. Singer ME, Younossi ZM (2001) Cost effectiveness of screening for hepatitis $C$ virus in asymptomatic, average-risk adults. The American journal of medicine 111: 614-621. pmid:11755504 doi: 10.1016/s0002-9343(01)00951-2

10. Vermeiren AP, Dukers-Muijrers $\mathrm{NH}_{\text {, van }} \mathrm{Loo} \mathrm{IH}_{\text {, }}$ Stals F, van Dam DW, et al. (2012) Identification of Hidden Key Hepatitis C Populations: An Evaluation of Screening Practices Using Mixed Epidemiological Methods. PloS one 7: e51194. doi: 10.1371/journal.pone.0051194. pmid:23236452

11. Dore GJ, Matthews GV, Rockstroh J (2011) Future of hepatitis $C$ therapy: development of direct-acting antivirals. Curr Opin HIV AIDS 6: 508-513. doi: 10.1097/COH.0b013e32834b87f8. pmid:21897228

12. Ghany $M G$, Nelson $D R$, Strader DB, Thomas DL, Seeff LB (2011) An update on treatment of genotype 1 chronic hepatitis $C$ virus infection: 2011 practice guideline by the American Association for the Study of Liver Diseases. Hepatology 54: 1433-1444. doi: 10.1002/hep.24641. pmid:21898493

13. Cornberg M, Razavi HA, Alberti A, Bernasconi E, Buti $M$, et al. (2011) A systematic review of hepatitis $C$ virus epidemiology in Europe, Canada and Israel. Liver International 31: 30-60. doi: 10.1111/j.1478-3231.2011.02539.x. pmid:21651702

14. Hahné SJ, Veldhuijzen IK, Wiessing L, Lim T-A,

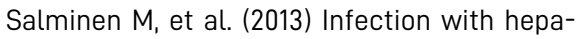
titis $B$ and $C$ virus in Europe: a systematic review of prevalence and cost-effectiveness of screening. BMC infectious diseases 13: 181. doi: 10.1186/1471-2334-13-181. pmid:23597411

15. Vriend HJ, de Coul ELO, Van De Laar TJ, Urbanus AT, Van Der Klis FR, et al. (2012) Hepatitis C virus seroprevalence in The Netherlands. The European Journal of Public Health 22: 819-821. doi: 10.1093/eurpub/cks013. pmid:22461704

16. Vriend $H$, Van Veen $M$, Prins $M$, Urbanus $A$, Boot $H$, et al. (2013) Hepatitis $C$ virus prevalence in The Netherlands: migrants account for most infections. Epidemiology and infection 141: 1310-1317. doi: 10.1017/S0950268812001884. pmid:22963908

17. Zuure FR, Urbanus AT, Langendam MW, Helsper $\mathrm{CW}$, van den Berg CH, et al. (2014) Outcomes of hepatitis $\mathrm{C}$ screening programs targeted at risk groups hidden in the general population: a systematic review. BMC Public Health 14: 66. doi: 10.1186/1471-2458-14-66. pmid:24450797 
18. World Health Organization (2014) Guidelines for the screening, care and treatment of persons with hepatitis $\mathrm{C}$ infection.

19. Smith BD, Yartel AK (2014) Comparison of Hepatitis C Virus Testing Strategies: Birth Cohort Versus Elevated Alanine Aminotransferase Levels. American journal of preventive medicine 47: 233-241. doi: 10.1016/j.amepre.2014.05.011. pmid:25145616

20. Smith BD, Morgan RL, Beckett GA, Falck-Ytter $Y$, Holtzman D, et al. (2012) Recommendations for the identification of chronic hepatitis $C$ virus infection among persons born during 1945-1965. MMWR Recomm Rep 61: 1-32. pmid:22895429

21. Du $P$, Lemkin $A$, Kluhsman $B$, Chen J, Roth RE, et al. (2010) The roles of social domains, behavioral risk, health care resources, and chlamydia in spatial clusters of US cervical cancer mortality: not all the clusters are the same. Cancer Causes Control 21: 1669-1683. doi: 10.1007/ s10552-010-9596-4. pmid:20532608

22. Kauhl B, Pilot E, Rao R, Gruebner O, Schweikart $J$, et al. (2015) Estimating the spatial distribution of acute undifferentiated fever (AUF) and associated risk factors using emergency call data in India. A symptom-based approach for public health surveillance. Health Place 31: 111-119. doi: 10.1016/j.healthplace.2014.11.002. pmid:25463924

23. Shoff C, Yang TC (2012) Spatially varying predictors of teenage birth rates among counties in the United States. Demogr Res 27: 377-418. pmid:23144587 doi: 10.4054/demres.2012.27.14

24. Weisent J, Rohrbach B, Dunn JR, Odoi A (2012) Socioeconomic determinants of geographic disparities in campylobacteriosis risk: a comparison of global and local modeling approaches. Int J Health Geogr 11: 45. doi: 10.1186/1476072X-11-45. pmid:23061540

25. Wang $L$, Xing J, Chen F, Yan R, Ge L, et al. (2014) Spatial Analysis on Hepatitis C Virus Infection in Mainland China: From 2005 to 2011. PLoS One 9: e110861. doi: 10.1371/journal.pone.0110861. pmid:25356554

26. Tanser F, Barnighausen T, Cooke GS, Newell ML
(2009) Localized spatial clustering of HIV infections in a widely disseminated rural South African epidemic. Int J Epidemiol 38: 1008-1016. doi: 10.1093/ije/dyp148. pmid:19261659

27. Bush KR, Henderson EA, Dunn J, Read RR, Singh A (2008) Mapping the core: chlamydia and gonorrhea infections in Calgary, Alberta. Sex Transm Dis 35: 291-297. doi: 10.1097/OLQ. 0b013e31815cledb. pmid:18490871

28. Zheng S, Cao CX, Cheng JQ, Wu YS, Xie X, et al. (2014) Epidemiological features of hand-footand-mouth disease in Shenzhen, China from 2008 to 2010. Epidemiol Infect 142: 1751-1762. doi: $10.1017 /$ S0950268813002586. pmid:24139426

29. Tsai PJ (2013) Scrub typhus and comparisons of four main ethnic communities in taiwan in 2004 versus 2008 using geographically weighted regression. Glob J Health Sci 5: 101-114. doi: 10.5539/gjhs.v5n3p101. pmid:23618480

30. Hu M, Li Z, Wang J, Jia L, Liao $Y$, et al. (2012) Determinants of the incidence of hand, foot and mouth disease in China using geographically weighted regression models. PLoS One 7: e38978. doi: 10.1371/journal.pone.0038978. pmid:22723913

31. Haque $U$, Scott LM, Hashizume M, Fisher $E$,

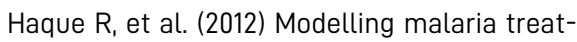
ment practices in Bangladesh using spatial statistics. Malar J 11: 63. doi: 10.1186/1475-287511-63. pmid:22390636

32. Lin $\mathrm{CH}$, Wen TH (2011) Using geographically weighted regression (GWR) to explore spatial varying relationships of immature mosquitoes and human densities with the incidence of dengue. Int J Environ Res Public Health 8: 27982815. doi: 10.3390/ijerph8072798. pmid:21845159

33. Centraal Bureau voor de Statistiek (CBS) (2015) Statline.

34. Dijkstra A, Janssen F, De Bakker M, Bos J, Lub

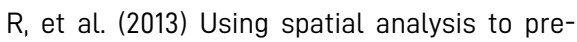
dict health care use at the local level: a case study of type 2 diabetes medication use and its association with demographic change and socioeconomic status. PLoS One 8: e72730. doi: 10.1371/journal.pone.0072730. pmid:24023636

35. Garfein RS, Vlahov D, Galai N, Doherty MC, Nel- 
son KE (1996) Viral infections in short-term injection drug users: the prevalence of the hepatitis $C$, hepatitis $B$, human immunodeficiency, and human T-lymphotropic viruses. American Journal of Public Health 86: 655-661. pmid:8629715 doi: 10.2105/ajph.86.5.655

36. Meffre C, Le Strat $Y$, Delarocque-Astagneau E, Dubois F, Antona D, et al. (2010) Prevalence of hepatitis $B$ and hepatitis $C$ virus infections in France in 2004: social factors are important predictors after adjusting for known risk factors. J Med Virol 82: 546-555. doi: 10.1002/ jmv.21734. pmid:20166185

37. Berke 0, Grosse Beilage E (2003) Spatial relative risk mapping of pseudorabies-seropositive pig herds in an animal-dense region. J Vet Med B Infect Dis Vet Public Health 50: 173-182. doi: 10.1046/j.1439-0450.2003.00689.x

38. Lawson $A B$, Biggeri $A B$, Boehning $D$, Lesaffre $E$, Viel JF, et al. (2000) Disease mapping models: an empirical evaluation. Disease Mapping Collaborative Group. Stat Med 19: 2217-2241. pmid: 10960849 doi:10.1002/10970258(20000915/30)19:17/18<2217:

aid$\operatorname{sim} 565>3.0 . c 0 ; 2-\mathrm{e}$

39. Waller L, Gotway C (2004) Applied spatial statistics for public health data. Hoboken, NJ: John Wiley and Sons, Inc.

40. Anselin L (2005) Exploring Spatial Data with GeoDaTM: A Workbook. Urbana, Illinois, USA: Spatial Analysis Laboratory, Department of Geography, University of Illinois at Urbana-Champaign.

41. Moran PA (1950) Notes on continuous stochastic phenomena. Biometrika: 17-23. pmid:15420245 doi: 10.1093/biomet/37.1-2.17

42. Jennings JM, Curriero FC, Celentano D, Ellen JM (2005) Geographic identification of high gonorrhea transmission areas in Baltimore, Maryland. Am J Epidemiol 161: 73-80. pmid:15615917 doi: 10.1093/aje/kwi012

43. Alencar $\mathrm{CH}$, Ramos AN Jr., dos Santos ES, Richter J, Heukelbach J (2012) Clusters of leprosy transmission and of late diagnosis in a highly endemic area in Brazil: focus on different spatial analysis approaches. Trop Med Int Health
17: 518-525. doi: 10.1111/j.1365-3156.2011.02945.x. pmid:22248041

44. Kulldorff M (1997) A Spatial Scan Statistic. Commun Stat Theory Methods 26: 1481-1496. doi: 10.1080/03610929708831995

45. Kulldorff M (2013) SaTScanTM User Guide for version 9.2 .

46. Coleman $M$, Coleman $M$, Mabuza AM, Kok $G$, Coetzee $M$, et al. (2009) Using the SaTScan method to detect local malaria clusters for guiding malaria control programmes. Malar I 8: doi: 10.1186/1475-2875-8-68. pmid:19374738

47. Jones RC, Liberatore M, Fernandez JR, Gerber SI (2006) Use of a prospective space-time scan statistic to prioritize shigellosis case investigations in an urban jurisdiction. Public Health Rep 121: 133. pmid: 16528945

48. Chen J, Roth RE, Naito AT, Lengerich EJ, Maceachren AM (2008) Geovisual analytics to enhance spatial scan statistic interpretation: an analysis of U.S. cervical cancer mortality. Int J Health Geogr 7: 57. doi: 10.1186/1476-072X-7-57. pmid:18992163

49. Poole MA, O'Farrell PN (1971) The assumptions of the linear regression model. Transactions of the Institute of British Geographers: 145-158. doi: $10.2307 / 621706$

50. ESRI (2013) How Exploratory Regression works.

51. Fotheringham AS, Brunsdon $C$, Charlton $M$ (2003) Geographically weighted regression: the analysis of spatially varying relationships: John Wiley \& Sons.

52. Nakaya T, Fotheringham AS, Brunsdon C, Charlton M (2005) Geographically weighted Poisson regression for disease association mapping. Stat Med 24: 2695-2717. pmid:16118814 doi: 10.1002/sim.2129

53. Lovett AA, Bentham C, Flowerdew R (1986) Analysing geographic variations in mortality using poisson regression: the example of ischaemic heart disease in England and Wales 19691973. Social Science \& Medicine 23: 935-943. pmid:3823977 doi: 10.1016/0277-9536(86)902510

54. Lovett A, Flowerdew R (1989) Analysis of count 
data using poisson regression*. The Professional Geographer 41: 190-198. doi: 10.1111/j.00330124.1989.00190.x

55. Nakaya T (2012) GWR4 user manual. WWW document, http://www.st-andrewsacuk/geoinformatics/wp-content/uploads/GWR4manual_201311.pdf.

56. Burnham KP, Anderson DR (2002) Model selection and multimodel inference: a practical information-theoretic approach: Springer Science \& Business Media.

57. Veldhuijzen IK, van Driel HF, Vos D, de Zwart 0 , van Doornum GJ, et al. (2009) Viral hepatitis in a multi-ethnic neighborhood in the Netherlands: results of a community-based study in a low prevalence country. International Journal of Infectious Diseases 13: e9-e13. doi: 10.1016/j. ijid.2008.05.1224. pmid:18678518

58. Mujeeb SA, Shahab S, Hyder AA (2000) Geographical display of health information: study of hepatitis $C$ infection in Karachi, Pakistan. Public Health 114: 413-415. pmid:11035468 doi: 10.1016/s0033-3506(00)00375-9

59. Alter MJ, Kruszon-Moran D, Nainan OV, McQuillan GM, Gao F, et al. (1999) The prevalence of hepatitis $C$ virus infection in the United States, 1988 through 1994. New England journal of medicine 341: 556-562. pmid:10451460 doi: 10.1056/nejm199908193410802

60. Bao YP, Liu ZM, Lian Z, Li JH, Zhang RM, et al. (2012) Prevalence and correlates of HIV and $\mathrm{HCV}$ infection among amphetamine-type stimulant users in 6 provinces in China. J Acquir Immune Defic Syndr 60: 438-446. doi: 10.1097/ QAI.0b013e31825694f2. pmid:22481605

61. Rodrigues Neto J, Cubas MR, Kusma SZ, Olandoski M (2012) Prevalence of hepatitis $C$ in adult users of the public health service of Sao Jose dos Pinhais-Parana. Rev Bras Epidemiol 15: 627-638. pmid: 23090309 doi: 10.1590/s1415$790 \times 2012000300016$

62. Cavlek TV, Margan IG, Lepej SZ, Kolaric B, Vince A (2009) Seroprevalence, risk factors, and hepatitis $C$ virus genotypes in groups with highrisk sexual behavior in Croatia. J Med Virol 81: 1348-1353. doi: 10.1002/jmv.21530. pmid:19551819
63. van de Laar TJ, van der Bij AK, Prins M, Bruisten

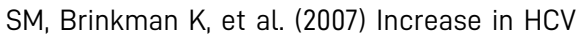
incidence among men who have sex with men in Amsterdam most likely caused by sexual transmission. Journal of Infectious Diseases 196: 230-238. pmid:17570110 doi: 10.1086/518796

64. Tsai PJ, Yeh HC (2013) Scrub typhus islands in the Taiwan area and the association between scrub typhus disease and forest land use and farmer population density: geographically weighted regression. BMC Infect Dis 13: 191. doi: 10.1186/1471-2334-13-191. pmid:23627966

65. Fotheringham AS, Wong DW (1991) The modifiable areal unit problem in multivariate statistical analysis. Environment and planning A 23: 1025-1044. doi: 10.1068/a231025

66. OECD (2013) Demographic Change in the Netherlands: Strategies for resilient labour markets. The Netherlands: OECD.

67. Páez A, Farber S, Wheeler D (2011) A simulation-based study of geographically weighted regression as a method for investigating spatially varying relationships. Environment and Planning-Part A 43: 2992. doi: 10.1068/a44111 




\section{Chapter 6}

\section{Detecting Hepatitis B and C by Combined Public Health and Primary Care Birth Cohort Testing}

Jeanne Heil, Christian J.P.A. Hoebe, Jochen W.L. Cals, Henriëtte L.G. ter Waarbeek, Inge H.M. van Loo, Nicole H.T.M. Dukers-Muijrers 


\section{Abstract}

\section{Purpose}

Both chronic hepatitis $C$ (HCV) and B virus (HBV) infections are generally asymptomatic, and many remain undetected or are diagnosed at a late stage. Studies that evaluate best practice hepatitis testing strategies are needed to better detect this hidden population.

\section{Methods}

In this prospective cohort study, we aimed to determine the diagnostic yield (test uptake and rate of positive test results) of a combined public health and primary care birth cohort testing strategy in detecting hidden cases of HCV and HBV infections. We invited all patients aged between 40 and 70 years $(n=6,743)$ registered with 11 family practices serving 2 higher prevalence areas, or hotspots (i.e., estimated HCV prevalence of $1 \%$; national estimated prevalence is $0.1-0.4 \%$ ), in the south of the Netherlands.

\section{Results}

Test uptake was $50.9 \%$ ( $n=3,434$ patients). No active or chronic HCV infection was detected: $0.00 \%$ (95\% Cl, 0.00\%-0.11\%). Positive test rates were $0.20 \%$ (95\% Cl, 0.08\%-0.42\%) for anti-HCV $(n=7), 0.26 \%$ $(95 \% \mathrm{Cl}, 0.12 \%-0.50 \%)$ for hepatitis B surface antigen $(\mathrm{n}=9)$, and $4.14 \%(95 \% \mathrm{Cl}, 3.49 \%-4.86 \%)$ for anti-hepatitis B core $(n=142)$.

\section{Conclusions}

This best practice testing strategy was effective in achieving a high test uptake. It completely failed, however, to detect hidden chronic HCV infections and is not recommended for countries with a low prevalence of the disease. 


\section{Introduction}

Chronic hepatitis $\mathrm{C}$ virus (HCV) and B virus (HBV) infections, major causes of chronic liver disease worldwide, are generally asymptomatic, and many infections remain hidden to care or are diagnosed at a late stage.[1-5] Because treatment for HCV infection has greatly improved, identification of HCVinfected individuals has become even more imperative.[6] Yet, strategies to detect cases of HCV infection hidden in the general population have been disappointing. Currently, it is universally recommended to offer testing to individuals who are part of a population with a high prevalence of HCV or HBV infection or who have a history of risk exposure or behavior.[7-10] Risk groups include injection drug users, recipients of infected blood products, children of HCV-positive mothers, and human immunodeficiency virus (HIV)-infected persons.[11-14] Past drug users or recipients of blood transfusions will remain hidden, however, as they may not remember or report these behaviors.[15]

To capture all persons who have HCV infection, prospective studies are needed that evaluate the diagnostic yield of HCV testing strategies not based on exposure risk factors.[16] Birth cohort screening, as currently recommended in the United States (HCV prevalence of 2.0\%), has also been suggested for European countries.[9,17,18] In simulation models, onetime HCV testing in the 1945-1965 birth cohort with subsequent treatment was likely cost-effective in the United States.[19] Yet again, primary care clinicians faced with the increasing societal need to screen for HCV infections encounter practical challenges in diagnosis and linking patients to appropriate care.[20] There is also debate on whether expanded screening will lead to net clinical benefit or harm, given the lack of evidence regarding screening efficacy.[21] Whether the birth cohort approach is a useful strategy for countries with low estimated HCV prevalence, such as the United Kingdom (0.7\%) and the Netherlands (0.1-0.4\%), needs to be demonstrated in practice.[15,22-25]

In countries with a low prevalence of HCV infection, a high test uptake is crucial to increase the number of diagnoses and thereby the diagnostic yield of a birth cohort approach. According to a meta-analysis, targeted practitioner-based studies are most effective in increasing test uptake and cases detected.[26] Diagnostic yield could be further optimized by focusing on areas of higher prevalence. Based on spatial-epidemiological analyses of laboratory data, the estimated prevalence of HCV infection in the south of the Netherlands is $0.5 \%$, and $\mathrm{HCV}$ infections are found to cluster in urban areas, with a prevalence of up to $1 \% .[27,28]$ These so-called hotspots are postal codes where there is a statistically significant elevated risk of diagnosed HCV infection (relative risk >4). In addition, an estimated $66 \%$ of HCV-infected persons are estimated to be untested and thus hidden to care.[27]

We developed a best practice approach by combining public health and primary care in a birth cohort testing strategy. We applied this approach in 2 identified Dutch hotspots to detect cases of HCV and HBV infection that are hidden in the general population. Our current study describes the development of this strategy and an evaluation of its diagnostic yield to provide insights on possible implementation in low-prevalence countries. 


\section{Methods}

\section{Testing Strategy Development}

The strategy was developed and implemented in a collaboration between public health and primary care.

All family physicians located in the hotspots were approached by a peer family physician. Family physicians agreeing to take part personally invited their eligible patients by means of a letter, which was developed by a multidisciplinary team of family physicians, behavioural scientists, epidemiologists, and language ambassadors. Testing was advertised in local newspapers and through waiting room posters.

The regional public health service (PHS) facilitated the practical organization of the testing by distributing the letters of invitation and reminders, arranging the testing location, and planning and collecting measurements. They organized 3 testing days with different time slots (September 2014 to April 2015) at 2 local community centres. Alternatively, patients could be tested at their family practice, the PHS clinic, at home, or at the hospital. Tests were free of charge. Patients not tested received a reminder letter for testing 1 week later. Both participants tested and patients who declined to be tested were invited to complete a short questionnaire. Participants provided written informed consent, and the study was approved by the university medical ethics committee (MUMC;14-4-042).

\section{Testing Strategy Implementation}

Two hotspots were targeted because of their highest regional estimated prevalence of HCV infection. [28] The family practices agreeing to participate invited patients aged between 40 and 70 years for a $\mathrm{HCV}$ and $\mathrm{HBV}$ test. Blood samples were transported within 3 hours of collection to the laboratory. Initial screening included anti-HCV and anti-hepatitis B core (anti-HBc) (Anti-HCV II and Anti-HBc, Roche Diagnostics). When a screening test was positive, subsequent tests included the following: HCV ribonucleic acid (RNA) (COBAS, Ampliprep/COBAS, Taqman HCV Quantitative Test, version 2.0, Roche Diagnostics) and/or immunoblot (Mikrogen), a hepatitis B surface antigen (HBsAg) test, and an anti-hepatitis B surface (anti-HBs) test (HBsAg II and Anti-HBs, Roche Diagnostics) (see Figure 1).

In HBsAg-positive samples additional tests were performed, including hepatitis $B$ e antigen (HBeAg), anti-HBeAg, anti-HBc immunoglobulin M (IgM), HBV deoxyribonucleic acid (DNA), and alanine aminotransferase (ALT) (HBeAg, Anti-HBe, Anti-HBc IgM, COBAS, Ampliprep/COBAS, Taqman HBV Test, ALT, Roche Diagnostics). In solitary anti-HBc $\square$ positive samples, $\mathrm{HBeAg}$, anti-HBeAg, and HBV DNA tests were performed (Roche Diagnostics). Samples with weak positive anti-HBc, HBsAg, or anti-HCV test results (between 1 and $2 x$ cut-off value) were confirmed with a second screening test (BioMerieux).

Within 3 weeks after testing, the family physician informed the patient about the test results. In the case of an active $\mathrm{HCV}$ or HBV infection, the family physician referred the patient to a gastroenterologist at the academic hospital, who ensured routine care and treatment when needed. For those with HBsAg-positive tests, follow-up testing was conducted after 6 months to discriminate between acute 

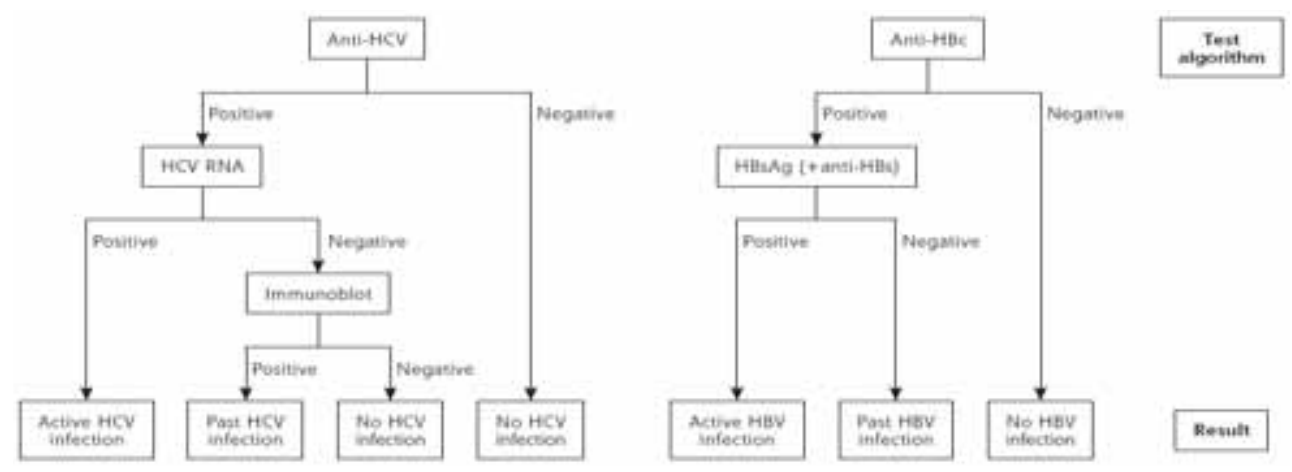

Figure 1. The laboratory testing algorithm used for identifying hepatitis $C$ virus and hepatitis $B$ virus infections

$\mathrm{HBV}=$ hepatitis $\mathrm{B}$ virus, $\mathrm{HBC}=$ hepatitis $\mathrm{B}$ core; $\mathrm{HBS}=$ hepatitis B surface; $\mathrm{HCV}=$ hepatitis $\mathrm{C}$ virus; RNA = ribonucleic acid

and chronic infections. The regional public health service performed contact tracing for all cases of active infections and offered hepatitis A virus (HAV) vaccination for the patient and $\mathrm{HBV}$ vaccination for close contacts to prevent further spread.

\section{Data Collection}

For this prospective cohort study, coded data on sex, age, postal code, and referral to a gastroenterologist were retrieved from the family physician registry, and test results were obtained from the laboratory. Questionnaires included the following determinants: country of birth (participant, mother, and father), educational level, working situation, living situation, and previous HCV or HBV infection. Education was categorized into low (no, primary, and lower vocational education), intermediate (intermediate vocational, higher secondary, and vocational education), and high (higher professional education and university). The participants questionnaire also included HCV exposure risk factors (i.e., surgery abroad, blood transfusion or organ transplant before 1992, diagnosis of HIV infection, or a history of intravenous drug use), as well as reasons for participating. The questionnaire for those who declined testing included reasons for not participating. The PHS data included the number of close contacts of all active infections and the number of vaccinations of both the patients (for HAV) and their contacts (for HBV).

\section{Statistical Analysis}

The diagnostic yield of the testing strategy was evaluated in terms of achieved rates of test uptake and positive test results. A priori, we expected a test uptake of $40 \%$ based on international targeted-testing studies and Dutch studies using personal letter invitations.[29-34] A positive anti-HCV test rate higher than the estimated Dutch prevalence of $0.1 \%-0.4 \%$ would be considered promising to explore further assessment and implementation of the testing strategy.[23-25] Test uptake and rates of positive test results were calculated among the patients invited and participants, and associated determinants 
were assessed using multivariate logistic regression analyses; determinants included hotspot, sex, age, educational level, and hepatitis exposure risk factors as non-Western migrant, surgery abroad, blood transfusion or organ transplant before 1992, HIV positive, or a history of intravenous drug use. Analyses were performed using SPSS 21.0 (IBM Inc).

\section{Results}

All 11 family practices in the targeted areas agreed to take part, and 6,743 patients (excluding failed delivery) between the ages of 40 and 70 years were sent invitations to participate in the study.

\section{Diagnostic Yield: Test Uptake}

In total, 3,434 of the 6,743 patients invited were tested for HCV and HBV infection. The test uptake was $50.9 \%$ ( $95 \% \mathrm{Cl}, 49.7 \%-52.1 \%$ ) (Figure 2). Of those participating, 54.3\% were women, the mean age was 57.3 years ( $\mathrm{SD}=8.1$ years), $47.4 \%$ had a low education level, and $17.2 \%$ had at least 1 hepatitis exposure risk factor.

\section{Diagnostic Yield: Rate of Positive Test Results}

No active HCV infection was diagnosed $(95 \% \mathrm{Cl}, 0.00 \%-0.11 \%)$. The rate of positive tests for anti-HCV, confirmed by immunoblot, was $0.20 \%(95 \% \mathrm{Cl}, 0.08 \%-0.42 \%)(\mathrm{n}=7)$, for HBsAg was $0.26 \%(95 \% \mathrm{Cl}$, $0.12 \%-0.50 \%)(n=9)$, and for anti-HBc was $4.14 \%(95 \% \mathrm{Cl}, 3.49 \%-4.86 \%)(n=142)$ (Figure 2). The numbers screened needed to detect 1 case of a positive anti-HCV, HBsAg, or anti-HBc test were 491,382, and 24 , respectively. Seventy-one percent $(n=5)$ of the anti-HCV positive tests results, $22 \%(n=2)$ of the HBsAg positive tests results, and $9 \%(n=13)$ of the anti-HBc positive findings were associated with a history of HCV or HBV infection. All $9 \mathrm{HBsAg}$-positive participants had negative HBeAg and IgM anti$\mathrm{HBc}$ findings and had an ALT level of $<45 \mathrm{U} / \mathrm{L}$. All were referred to a gastroenterologist. Seven of 9 active HBV infections were undiagnosed and were further assessed by the hospital and the PHS. Six participants were chronically infected with HBV, i.e., their HBsAg tests remained positive after 6 months. Treatment was not indicated for any of these patients according to their serum ALT levels, HBV DNA load, or signs of liver fibrosis and status on hepatocellular carcinoma. The PHS traced 13 close contacts of HBsAg-positive participants, and HBV vaccination was needed and given in 9 (Figure 2).

\section{Determinants of Test Uptake}

No differences in test uptake between the 2 hotspots were observed. Test uptake was higher among women (54.4\%) and older participants, with an uptake of $61.2 \%$ among those aged 60 to 70 years (Table 1). Participants had a lower educational level than those not tested (Supplemental Appendix 1). The reported reasons to get tested were because of the invitation by the family physician $(62 \%, n=2,120)$ or 


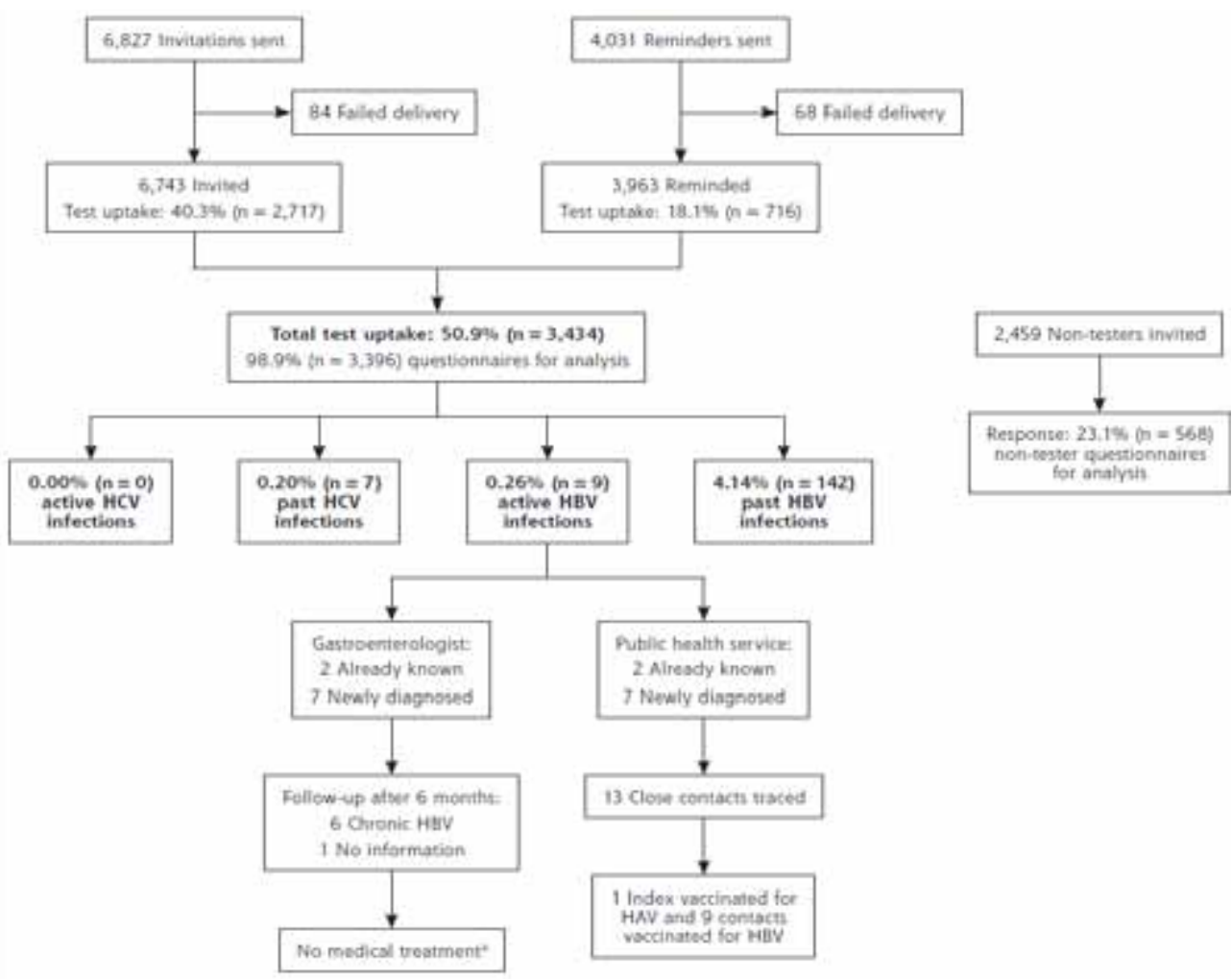

Figure 2. Flow diagram of the birth cohort testing for hepatitis $C$ virus and hepatitis $B$ virus infections

$\mathrm{ALT}=$ alanine aminotransferase; DNA = deoxyribonucleic acid; HAV = hepatitis A virus; HBV = hepatitis B virus, HCV $=$ hepatitis $\mathrm{C}$ virus.

a Medical treatment is not indicated in active HBV infections. In chronic HBV infections, treatment is indicated if the HBV DNA level is $>1.0 \times 10^{5}$ copies $/ \mathrm{mL}$ combined with an elevated ALT level or major liver fibrosis.

to rule out hepatitis $(33 \%, n=1,132)$. Patients declining to be tested reported reasons for not testing as a low risk perception ( $33 \%, n=133)$, practical reasons $(24 \%, n=94)$, and being vaccinated or tested in the past $(14 \%, n=55)$. Reasons based on stigma or fear were rare $(3 \%, n=12)$. 
Table 1. Sociodemographic Determinants of Test Uptake of the Public Health and Primary Care Birth Cohort Testing Strategy

\begin{tabular}{|c|c|c|c|}
\hline \multirow[t]{2}{*}{ Determinant } & Test Uptake & Not Tested & \\
\hline & $\%$ (No.) & $\%$ (No.) & OR $(95 \% \mathrm{Cl})^{\mathrm{a}}$ \\
\hline \multicolumn{4}{|l|}{ Higher prevalence area } \\
\hline Hotspot A $(n=2,891)$ & $50.2(1,450)$ & $49.8(1,441)$ & $1.05(0.95-1.16)$ \\
\hline Hotspot B $(n=3,949)$ & $50.2(1,984)$ & $49.8(1,965)$ & 1 [Reference] \\
\hline \multicolumn{4}{|l|}{ Sex } \\
\hline Male $(n=3,417)$ & $46.0(1,571)$ & $54.0(1,846)$ & 1 Reference] $^{\mathrm{b}}$ \\
\hline Female $(n=3,423)$ & $54.4(1,863)$ & $45.6(1,560)$ & $1.41(1.28-1.55)$ \\
\hline \multicolumn{4}{|l|}{ Age, y } \\
\hline $40-49^{c}(n=1,891)$ & $35.0(662)$ & $65.0(1,229)$ & $1[\text { Reference }]^{\mathrm{b}}$ \\
\hline $50-59(n=2,531)$ & $51.0(1,292)$ & $49.0(1,239)$ & $1.93(1.71-2.18)$ \\
\hline $60-70^{d}(n=2,418)$ & $61.2(1,480)$ & $38.8(938)$ & $2.95(2.60-3.34)$ \\
\hline
\end{tabular}

$\mathrm{OR}=$ odds ratio.

adjusted for higher prevalence area, sex, and age.

${ }^{\mathrm{b}} P \leq .001$.

${ }^{c}$ Includes 2 aged $<40$ years.

${ }^{d}$ Includes 9 aged $>70$ years.

\section{Determinants of Positive Test Results}

Rates of positive test results were higher in those individuals with an exposure risk factor for anti-HCV, $\mathrm{HBsAg}$, and anti-HBc $(0.68 \%, 1.19 \%$, and $11.02 \%$, respectively) than in those without such a risk factor $(0.11 \%, 0.07 \%$, and $2.71 \%$, respectively). Logistic regression analyses assessing additional determinants for past HBV infection found the highest positive anti-HBc test rate among non-Western migrants (27.6\%, $\mathrm{n}=48$ of 174) (OR [odds ratio] $=16.1 ; 95 \% \mathrm{Cl}, 10.4-24.9$ ), HIV-positive patients ( $22.2 \%, \mathrm{n}=2$ of 9) (OR $=6.7 ; 95 \% \mathrm{Cl}, 1.4-33.3)$, and individuals with a history of intravenous drug use $(28.6 \%, \mathrm{n}=2$ of 7$)(\mathrm{OR}=8.2$; $95 \% \mathrm{Cl}, 1.5-43.2)$, when adjusted for a higher prevalence area, sex, and age.

\section{Discussion}

A combined public health and primary care birth cohort testing strategy to detect hidden HCV and HBV infections in higher prevalence areas in the Netherlands had a limited diagnostic yield. This best practice approach was able to gain a higher than expected test uptake of $51 \%$, but it completely failed to detect hidden HCV infections.

The current test uptake of $51 \%$ was higher compared with international studies targeted to risk factors (10\% to $49 \%$ ) and other Dutch studies with a personal invitation ( $18 \%$ to $42 \%$ ).[29-36] The family physicians' personal invitation appeared key for achieving this high uptake, as confirmed by the reported main reason to get tested. Test uptake in specific settings, such as the emergency department, may be even higher (up to 65\%),[37] as here tests can be offered and performed within the routine diagnostic work-up. 
The main result is that no active HCV infections were detected. A higher prevalence was expected based on previous estimations in these hotspots $(0.5 \%$ to $1 \%),[27,28]$ or other Dutch studies focusing on risk groups $(0.3 \%$ to $4.8 \%),[32,34,38,39]$ and on (inter)national estimations that a substantial population is untested.[2-5] Estimates of the hidden HCV-infected population, however, are largely derived from mathematical models ( $43 \%$ to $72 \%$ ). The number of hidden cases of chronic HCV infection seems to be overestimated compared with a real-life setting. The detected rate of tests positive for anti-HCV is $0.2 \%$ and for HBsAg is $0.3 \%$, which is comparable to the general prevalence in the Netherlands $(0.1 \%$ to $0.4 \%) .[23-25,40,41]$ The rate of positive anti-HBc test results $(4.1 \%)$ was higher compared with the Dutch estimated prevalence of 2.1\%.[41] Yet, this finding has no implications for patient care. Higher positive rates and lower numbers needed to screen to detect 1 case have been found in birth cohort studies in higher prevalence settings and countries, such as the United States.[15,26,37,42]

Detected positive rates were higher in those with a hepatitis exposure risk factor, a finding in line with studies targeting risk factors.[15,26] Using a risk group instead of the birth cohort, however, would have missed $22 \%$ to $54 \%$ of all positive cases in this study ( 3 of 7 anti-HCV-positive cases, 2 of 9 HBsAg-positive cases, and 77 of 142 anti-HBc-positive cases).[7-10] For chronic HBV infections specifically, several studies state that systematic screening among migrants is likely to be cost-effective or at least increases its efficiency.[43,44] This is in line with family physician guidelines in the United Kingdom and the Netherlands, as well as the recommendations of the Dutch Health Council to target HBV testing, such as to non-Western migrants.[7,8,45]

Our study is the first in Europe to develop a public health and primary care birth cohort testing strategy to detect hidden cases of HCV and HBV infection in identified hotspots and evaluate its diagnostic yield. Our study has some limitations. First, selection bias cannot be ruled out, as many HCV-infected patients are at a disadvantage in terms of health literacy.[46] In the Netherlands, health insurance is obligatory, and family physicians function as a gatekeeper to specialist care, but some individuals might have been less likely to get tested. Nevertheless, those who were tested and those who were not did not differ in assessed characteristics, such as working or living situation, or migrant status. Moreover, study participants had an even lower educational level compared with those declining to be tested, and national estimates support that we were able to reach intravenous drug users.[47,48]

Second, behavioural data are self-reported and could be influenced by recall bias and social desirability bias. Third, questions on sexual exposure risk were not included, based on feasible questionnaire length. Fourth, the data from those not tested might be less generalizable to the general population because of low response (23\%). Fifth, hotspots were determined based on laboratory data of the tested population. We assumed that the hidden, untested population follows the same geographical pattern. Finally, as no active HCV infections and only small numbers of past HCV and active HBV infections were detected, we were able to assess more detailed determinants only for past HBV infections.

Because no active HCV infections were found in the identified hotspots, it is likely that the strategy taken would not be effective in other areas of the Netherlands and other low-prevalence countries. Our testing strategy can be applied to detecting HCV and HBV infections, as well as other infectious 
diseases, in high-endemic countries, such as the United States. If the test is not offered for free, however, a lack of health insurance could be a limiting factor in the United States. Considering the different health care system in the United States, the test uptake of a similar testing strategy might be lower in certain groups at risk, such as intravenous drug users or patients co-infected with HIV. Lessons learned can also be applied to future studies aimed at retracing patients previously diagnosed with HCV and HBV. The success factor of our high test uptake is the combination of a personal invitation accompanied by reminders, and the cooperation between public health care and primary care. Moreover, our findings informed the Dutch Health Council in their recommendation not to screen the general population for HCV and HBV infection.[45]

\section{Acknowledgments}

We wish to thank Peter HA Jacobs (GGD Limburg-Noord, Venlo), Arjan ER Bos (Open University, Heerlen), Boris Kauhl, Gerjo Kok, Karlijn Massar, and Stefan LK Gruijters (Maastricht University Medical Centre, Maastricht), all participating family practices, community nurses, community centres, language ambassadors (Arcus College, Heerlen), laboratory analysts (laboratory of Medical Microbiology, Maastricht), medical specialists (Maastricht University Medical Centre, Maastricht), and the staff of the regional public health service (GGD Zuid-Limburg), for their advice, cooperation, and contribution to the design of this study. This work was supported by the National Institute for Public Health and the Environment [0037-2014] and AbbVie Inc. [A14-989]. None of the sponsors had any role in the study design or conduct of the study; in the collection, management, analysis, or interpretation of the data; the preparation of the manuscript; or in the decision to submit the manuscript for publication. 


\section{References}

1. Stanaway JD, Flaxman $A D$, Naghavi $M$, et al. The global burden of viral hepatitis from 1990 to 2013: findings from the Global Burden of Disease Study 2013. Lancet. 2016; 388(10049): 1081-1088.

2. Spradling $P R$, Rupp L, Moorman AC, et al; Chronic Hepatitis Cohort Study Investigators. Hepatitis B and C virus infection among 1.2 million persons with access to care: factors associated with testing and infection prevalence. Clin Infect Dis. 2012; 55(8): 1047-1055.

3. Hagan $H$, Campbell J, Thiede $H$, et al. Self-reported hepatitis $\mathrm{C}$ virus antibody status and risk behavior in young injectors. Public Health Rep. 2006; 121(6): 710-719.

4. Brouard C, Le Strat $Y$, Larsen $C$, Jauffret-Roustide $M$, Lot $F$, Pillonel J. The undiagnosed chronically-infected HCV population in France. Implications for expanded testing recommendations in 2014. PLoS One. 2015; 10(5): e0126920.

5. Denniston MM, Klevens RM, McQuillan GM, Jiles RB. Awareness of infection, knowledge of hepatitis $\mathrm{C}$, and medical follow-up among individvals testing positive for hepatitis C: National Health and Nutrition Examination Survey 20012008. Hepatology. 2012; 55(6): 1652-1661.

6. Tran TT. A review of standard and newer treatment strategies in hepatitis C. Am J Manag Care. 2012; 18(14)(Suppl): S340-S349.

7. National Institute for Health and Care Excellence (NICE). Public health guideline 43: Hepatitis $B$ and $C$ testing: people at risk of infection. https: //www.nice.org.uk/guidance/ph43. Published Dec 2012. Updated Mar 2013. Accessed May 9, 2016.

8. NHG. NHG-Standaard Virushepatitis en andere leveraandoeningen (derde herziening). Huisarts Wet. 2016. https: //www.nhg.org/standaarden/volledig/nhg-standaard-virushepatitis-en-andereleveraandoeningen.

9. Smith BD, Morgan RL, Beckett GA, et al; Centers for Disease Control and Prevention. Recommendations for the identification of chronic hepatitis $C$ virus infection among persons born during 1945-1965. MMWR Recomm Rep. 2012; 61(RR-4): 1-32.

10. Guidelines for the screening, care and treatment of persons with chronic hepatitis $\mathrm{C}$ infection. Geneva, Switzerland: World Health Organization; 2016.

11. Nelson PK, Mathers BM, Cowie B, et al. Global epidemiology of hepatitis $B$ and hepatitis $C$ in people who inject drugs: results of systematic reviews. Lancet. 2011; 378(9791): 571-583.

12. Shepard CW, Finelli L, Alter MJ. Global epidemiology of hepatitis $C$ virus infection. Lancet Infect Dis. 2005; 5(9): 558-567.

13. Benova L, Mohamoud YA, Calvert C, Abu-Raddad LJ. Vertical transmission of hepatitis $C$ virus: systematic review and meta-analysis. Clin Infect Dis. 2014; 59(6): 765-773.

14. Taylor LE, Swan T, Mayer KH. HIV coinfection with hepatitis $\mathrm{C}$ virus: evolving epidemiology and treatment paradigms. Clin Infect Dis. 2012; 55(Suppl 1): S33-S42.

15. Zuure FR, Urbanus AT, Langendam MW, et al. Outcomes of hepatitis $\mathrm{C}$ screening programs targeted at risk groups hidden in the general population: a systematic review. BMC Public Health. 2014; 14: 66.

16. Chou R, Cottrell EB, Wasson N, Rahman B, Guise JM. Screening for hepatitis $C$ virus infection in adults: a systematic review to update the 2004 U.S. Preventive Services Task Force Recommendation. Ann Intern Med. 2013; 159(5): 349-357.

17. Moyer VA, Force USPST; U.S. Preventive Services Task Force. Screening for hepatitis $\mathrm{C}$ virus infection in adults: U.S. Preventive Services Task Force recommendation statement. Ann Intern Med. 2013; 159(5): 349-357.

18. Alfaleh FZ, Nugrahini $N$, Maticic $M$, et al. Strategies to manage hepatitis $C$ virus infection disease burden - volume 3. J Viral Hepat. 2015; 22(Suppl 4): 42-65.

19. McEwan $P$, Ward $T$, Yuan $Y$, Kim R, L'italien G. The impact of timing and prioritization on the 
cost-effectiveness of birth cohort testing and treatment for hepatitis $\mathrm{C}$ virus in the United States. Hepatology. 2013; 58(1): 54-64.

20. Lebovics E, Torres R, Porter LK. Primary care perspectives on hepatitis $C$ virus screening, diagnosis and linking patients to appropriate care. Am J Med. 2017; 130(2): S1-S2.

21. Koretz $R L$, Lin $K W$, loannidis $J P$, Lenzer J. Is widespread screening for hepatitis $C$ justified? BMJ. 2015; 350: g7809.

22. Harris RJ, Ramsay M, Hope VD, et al. Hepatitis C prevalence in England remains low and varies by ethnicity: an updated evidence synthesis. Eur J Public Health. 2012; 22(2): 187-192.

23. Kok A, Zuure FR, Weegink CJ, Coutinho RA, Prins M. Hepatitis C in Nederland: schaarse gegevens over actuele prevalentie en de noodzaak van epidemiologisch onderzoek en innovatieve opsporingsmethoden. Ned Tijdschr Geneeskd. 2007; 151(43): 2367-2371.

24. Slavenburg S, Verduyn-Lunel FM, Hermsen JT, Melchers WJ, te Morsche RH, Drenth JP. Prevalence of hepatitis $C$ in the general population in the Netherlands. Neth J Med. 2008; 66(1): 13-17.

25. Vriend HJ, Op de Coul EL, van de Laar TJ, Urbanus $A T$, van der Klis FR, Boot HJ. Hepatitis C virus seroprevalence in the Netherlands. Eur J Public Health. 2012; 22(6): 819-821.

26. Aspinall EJ, Doyle JS, Corson S, et al. Targeted hepatitis $C$ antibody testing interventions: a systematic review and meta-analysis. Eur J Epidemiol. 2015; 30(2): 115-129.

27. Vermeiren $A P$, Dukers-Muijrers $N H_{\text {, van }} L o o I H_{\text {, }}$ et al. Identification of hidden key hepatitis $C$ populations: an evaluation of screening practices using mixed epidemiological methods. PLoS One. 2012; 7(12): e51194.

28. Kauhl B, Heil J, Hoebe CJ, Schweikart J, Krafft T, Dukers-Muijrers NH. The spatial distribution of hepatitis $C$ virus infections and associated determinants-an application of a geographically weighted Poisson regression for evidence-based screening interventions in hotspots. PLoS One. 2015; 10(9): e0135656.

29. Reilley B, Leston J, Hariri S, et al. Birth Cohort
Testing for Hepatitis C Virus - Indian Health Service 2012-2015. MMWR Morb Mortal Wkly Rep. 2016; 65(18): 467-469.

30. Cullen W, Stanley J, Langton D, Kelly Y, Staines $A$, Bury $G$. Hepatitis $C$ infection among injecting drug users in general practice: a cluster randomised controlled trial of clinical guidelines' implementation. Br J Gen Pract. 2006; 56(532): 848-856.

31. Litwin $A H, S$ smith $B D$, Drainoni ML, et al. Primary care-based interventions are associated with increases in hepatitis $C$ virus testing for patients at risk. Dig Liver Dis. 2012; 44(6): 497-503.

32. Richter $C$, Ter Beest G, Gisolf EH, et al. Screening for chronic hepatitis $B$ and $C$ in migrants from Afghanistan, Iran, Iraq, the former Soviet Republics, and Vietnam in the Arnhem region, The Netherlands. Epidemiol Infect. 2014; 142(10): 2140-2146.

33. Menger $H$, Neve G. 'Vietnam tussen de tulpen' Screening op hepatitis B van Vietnamese inwoners van Noord-Holland. Infectieziekten Bulletin. 2013; 24(2): 45-47.

34. Grintjes K, Dofferhoff ASM, Stelma F, et al. Hepatitis $\mathrm{C}$-opsporing onder migranten in Nijmegen (HECOM). Tijdschrift voor Infectieziekten. 2014; 9(5): 126-133.

35. Niessen W, Benne R, van Zeijl J, van der Have J, Broer J. Is het schriftelijk oproepen van immigranten voor hepatitis B-onderzoek effectief? Infectieziekten Bulletin. 2013; 24(4): 107-111.

36. van der Veen YJJ, van Empelen $P$, de Zwart 0 , Visser $\mathrm{H}$, Mackenbach JP, Richardus JH. Cultural tailoring to promote hepatitis $B$ screening in Turkish Dutch: a randomized control study. Health Promot Int. 2013;29(4):692-704.

37. Galbraith JW, Franco RA, Donnelly JP, et al. Unrecognized chronic hepatitis $C$ virus infection among baby boomers in the emergency department. Hepatology. 2015; 61(3): 776-782.

38. Zuure FR, Davidovich U, Coutinho RA, et al. Using mass media and the Internet as tools to diagnose hepatitis $C$ infections in the general population. Am J Prev Med. 2011; 40(3): 345-352.

39. Zuure FR, Bouman J, Martens M, et al. Screen- 
ing for hepatitis $\mathrm{B}$ and $\mathrm{C}$ in first-generation Egyptian migrants living in the Netherlands. Liver Int. 2013; 33(5): 727-738.

40. Marschall $T$, Kretzschmar $M$, Mangen MJ, Schalm S. High impact of migration on the prevalence of chronic hepatitis B in the Netherlands. Eur J Gastroenterol Hepatol. 2008; 20(12): 1214-1225.

41. van Marrewijk $C M$, Velshuijzen IK, Conyn-van Spaendonck MAE, Kooy $H$, van den Hof $S$, Dorigo-Zetsma JW. Prevalence of hepatitis $B$ viral markers in the Dutch population: a population-based serosurveillance study (Pienter project). Prevalentie van hepatitis B virale markers in de Nederlandse bevolking: een population-based seroprevalentie studie (Pienter project) 1999. http: //www.rivm.nl/bibliotheek/ rapporten/243680001.html.

42. Orkin $C$, Flanagan $S$, Wallis $E$, et al. Incorporating HIV/hepatitis $B$ virus/hepatitis $C$ virus combined testing into routine blood tests in nine UK Emergency Departments: the "Going Viral" campaign. HIV Med. 2016; 17(3): 222-230.

43. Hutton DW, Tan D, So SK, Brandeau ML. Cost-effectiveness of screening and vaccinating Asian and Pacific Islander adults for hepatitis B. Ann Intern Med. 2007; 147(7): 460-469.

44. Veldhuijzen IK, Toy M, Hahné SJ, et al. Screening and early treatment of migrants for chronic hepatitis B virus infection is costeffective. Gastroenterology. 2010; 138(2): 522-530.

45. Gezondheidsraad. Screening Risk Groups for Hepatitis B and C. The Hague: Health Council of the Netherlands; 2016.

46. Clark PJ, Muir AJ. Overcoming barriers to care for hepatitis C. N Engl J Med. 2012; 366(26): 2436-2438.

47. Cruts AAN, Van Laar M, Buster M. Aantal en kenmerken van problematische opiatengebruikers in Nederland. Utrecht: Trimbos-instituut; 2013.

48. Van Laar M, Van Gageldonk $A$, Ketelaars T, Van Ooyen M, Cruts G, Croes E. Report to the EMCDDA by the Reitox National Focal Point. The Netherlands Drug Situation 2005. Utrecht: Trimbos-instituut; 2006. https: //www.wodc.nl/ binaries/1226-full-text_tcm28-68365.pdf. 


\section{Supplemental material}

Supplemental Appendix 1. Comparing the distribution of socio-demographic characteristics of the testers and non-testers

\begin{tabular}{|c|c|c|c|c|}
\hline & Testers ( $\mathrm{N}=3396$ ) & Non-testers ( $N=568)$ & & \\
\hline & $\%(n)$ & $\%(n)$ & $\mathbf{O R}^{\mathrm{a}}$ & $95 \% \mathrm{Cl}$ \\
\hline \multicolumn{5}{|l|}{ Educational level } \\
\hline $\begin{array}{l}\text { - Low } \\
\text { - Medium } \\
\text { - High }\end{array}$ & $\begin{array}{l}47.4(1609) \\
23.1(783) \\
28.5(969)\end{array}$ & $\begin{array}{l}30.8(175) \\
24.3(138) \\
41.4(235)\end{array}$ & $\begin{array}{l}1.67 \\
1.28 \\
\text { ref }\end{array}$ & $\begin{array}{l}1.33-2.10 \\
1.01-1.61 \\
* * *\end{array}$ \\
\hline \multicolumn{5}{|l|}{ Working situation } \\
\hline $\begin{array}{l}\text { - Working (part-time or full-time) } \\
\text { - Retired }{ }^{b} \\
\text { - Not working (unemployed/ receiving social } \\
\text { welfare) }{ }^{c}\end{array}$ & $\begin{array}{l}47.8(1623) \\
26.5(899)\end{array}$ & $\begin{array}{l}54.2(308) \\
22.2(126)\end{array}$ & $\begin{array}{l}\text { ref } \\
1.21\end{array}$ & $\begin{array}{l}\text { ref } \\
0.89-1.65 \\
0.98-1.58\end{array}$ \\
\hline \multicolumn{5}{|l|}{ Living situation } \\
\hline $\begin{array}{l}\text { - Alone } \\
\text { - With partner/ children/ parents }\end{array}$ & $\begin{array}{l}24.1(819) \\
75.3(2557)\end{array}$ & $\begin{array}{l}25.4(144) \\
71.1(404)\end{array}$ & $\begin{array}{l}\text { ref } \\
1.04\end{array}$ & $\begin{array}{l}\text { ref } \\
0.85-1.29\end{array}$ \\
\hline \multicolumn{5}{|l|}{ Migrant } \\
\hline $\begin{array}{l}\text { - Non-western migrant } \\
\text { - Autochthonous } \\
\text { - Western migrant }\end{array}$ & $\begin{array}{l}5.1(174) \\
80.4(2732) \\
13.1(444)\end{array}$ & $\begin{array}{l}5.8(33) \\
78.2(444) \\
13.6(75)\end{array}$ & $\begin{array}{l}\text { ref } \\
1.15 \\
1.14\end{array}$ & $\begin{array}{l}\text { ref } \\
0.77-1.71 \\
0.72-1.79\end{array}$ \\
\hline
\end{tabular}

Abbreviation: $n$, number of participants; OR, odds ratio; $\mathrm{Cl}$, confidence interval.

${ }^{* * *} \mathrm{p} \leq 0.001$

adjusted for higher prevalence area, gender, and age.

${ }^{b}$ Including all retired persons (with/without work).

${ }^{\circ}$ Including housewives. 




\section{Chapter 7}

\section{Hepatitis E prevalence in a sexual high-risk population compared to the general population}

Jeanne Heil, Christian J.P.A. Hoebe, Inge H.M. van Loo, Jochen W.L. Cals, Geneviève A.F.S. van Liere, Nicole H.T.M. Dukers-Muijrers 


\section{Abstract}

Transmission routes of the hepatitis E virus (HEV) are under debate. Here, we studied possible sexual transmission by comparing HEV prevalence in a Dutch sexual high-risk population $(n=1,482)$ with that in a general population ( $n=1,487$ ) while assessing sociodemographic and sexual risk factors. Overall prevalence of anti-HEV IgG of $18.9 \%(n=562)$ was, adjusting for confounders, similar between the two populations $(p=0.44)$. Prevalence was higher with each year's increase in age (adjusted OR: $1.03,95 \% \mathrm{Cl}$ : 1.02-1.04, $\mathrm{p}<0.01$ ), among men (adjusted OR: 1.24, 95\%Cl: 1.02-1.50, $\mathrm{p}=0.03$ ) and among individuals diagnosed with sexually transmitted infections (adjusted OR: 1.60,95\% Cl: 1.02-2.49, $\mathrm{p}=0.04$ ). Our results only hint at the possibility of a sexual transmission route for HEV given higher rates in those with chlamydia and/or gonorrhoeal infections. Sexual transmission is not a dominant transmission route, as its prevalence was not higher for the sexual high-risk population than for the general population. 


\section{Introduction}

Recently, the hepatitis E virus (HEV) has become a global public health concern, as an increase of autochthonous HEV infections was observed in developed countries. HEV is considered to be endemic in developing countries, where it is transmitted mainly through contaminated water and the faecal-oral route, causing epidemic outbreaks of genotypes 1 and $2[1,2]$. Traditionally, HEV was considered to be a travel-related disease in developed countries, associated with genotypes 1 and 2. For genotypes 1 and 2 , the mortality rate is usually low $(0.07-0.6 \%)$; it is particularly severe among pregnant women, with mortality rates between $15-25 \%$ [3]. However, reported cases of patients that have not travelled to endemic areas - so-called autochthonous hepatitis infections - have increased in developed countries [4-10]. These infections are mainly caused by HEV genotype 3, symptomatic HEV genotype 3 infections are more common among middle-aged and older individuals as well as among men [10-12]. HEV infections are usually asymptomatic, but genotype 3 infections may cause chronic hepatitis in immunocompromised patients. This group includes patients who have received an organ transplant, patients receiving chemotherapy and HIV-infected individuals [13-16].

Transmission routes continue to be one of the most debated aspects of HEV. The most recent evidence suggest that HEV caused by genotypes 3 and 4 is transmitted zoonotically. In Europe, North America and Japan, HEV genotype 3 is widespread among pigs [17-19]. In these countries, domestic pigs and wild boars act as a reservoir [20]. It is proven that HEV is transmitted by ingesting uncooked or poorly cooked pork or game meat [21-23].

Studies are needed to identify all transmission routes of $\mathrm{HEV}$, so appropriate preventive and control measures can be taken. The hepatitis A virus (HAV) and HEV genotypes 1 and 2 are both single-stranded RNA viruses with similar incubation periods and a faecal-oral transmission route. Sexual activity, including oral-anal contact, as the major transmission route among men who have sex with men (MSM) is another widely documented aspect of $\operatorname{HAV}[24,25]$, but only a limited number of studies have focused on the possible sexual transmission route of HEV infections [26-30]. This study could contribute to policy on the prevention and control of $\mathrm{HEV}$ infections, to be targeted at vulnerable individuals who are at highest risk. To explore the possible role of sexual transmission, we compared the HEV prevalence of a population with higher sexual risk to the general population. In addition, we assessed potential risk factors of sexual transmission through a cross-sectional study in the south of the Netherlands.

\section{Methods}

\section{Study population}

The STI clinic study and the GP study were approved by the Maastricht University Medical Centre Medical Ethical Committee (11-4-108 for the STI clinic cohort and 14-4-042 for the GP cohort). No informed consent was needed because of prevailing laws in the Netherlands, as it concerns an observational 
study using anonymous data only. Our study population consisted of two populations: a sexual highrisk population from a STI clinic cohort and the general population from a GP cohort. Venous blood samples were tested on HEV IgG. All individuals from the two study populations lived in urban areas in South Limburg. In the study period (December 2011 to November 2015), no clusters or outbreaks of HEV were reported in the study region.

First, the sexual high-risk study population (STI clinic cohort; $n=1,482$ ) was compiled as a sample from a cohort of individuals aged 20-70, all of whom were tested for a sexually transmitted infection (STI) at the STI clinic between December 2011 and November 2015 (original cohort size about 24,500 individuals). This sample included women $(n=350)$; female swingers, heterosexuals who as a couple practise partner-swapping or group sex, or who visit sex clubs for couples [31] ( $n=184)$; heterosexual men $(n=480)$; and men who have sex with men (MSM; $n=468)$. This STI clinic cohort represented a high-risk population, as $75.2 \%$ reported anal sex, had three or more sexual partners in the past six months or tested positive for Chlamydia trachomatis (CT), Neisseria gonorrhoeae (NG), syphilis or HIV (see S1 Table).

Second, the general study population (GP cohort; $n=1,487$ ) was compiled as a sample from a cohort of individuals aged 40-70, all of whom were tested by general practitioners (GPs) for a study of the hepatitis B virus (HBV) and the hepatitis C virus (HCV) between September 2014 and April 2015 (original study size $n=3,434)$. The prevalence of past $\mathrm{HCV}$ infections was $0.27 \%(4 / 1,487)$. This is comparable to the prevalence in the general population [32-34]. No active HCV infections were diagnosed in the GP cohort. The prevalence of active and past HBV infections was $0.5 \%(7 / 1,487)$ and $8.9 \%(132 / 1,487)$ respectively. Overall, the prevalence of active and past $\mathrm{HBV}$ infections is $0.2-0.3 \%[35,36]$ and $2.1 \%[36]$ in the Netherlands. This GP cohort represented a general population of both man and women from two urban areas, without any further exclusion criteria.

\section{Data collection}

Data on the test year, age, gender, ethnicity, HIV positivity and anti-HEV test results were available for all samples. In the STI clinic cohort, HIV and syphilis positivity was based on the testing of high-risk groups such as MSM. In the GP cohort, HIV positivity was based on self-reported data.

Additional data on sexual preference, reported anal sex, number of sexual partners in the past six months and diagnosis of CT/NG/syphilis were only available for the STI clinic cohort. Additional data on educational level, HBV and HCV positivity were only available for the GP cohort. Reporting anal sex, having three or more sexual partners in the past six months and being CT positive, NG positive, Syphilis positive or HIV positive were categorised as risk factors of sexual transmission.

\section{Serological testing}

Stored sera from the participants of the two study populations were tested for HEV IgG (recomWell hepatitis E virus IgG, Mikrogen GmbH, Neuried, Germany) at the Department of Medical Microbiology at Maastricht University Medical Centre. HEV IgG was measured in $\mathrm{U} / \mathrm{ml}$ : results below $20 \mathrm{U} / \mathrm{ml}$ were 
reported as negative, $20-24 \mathrm{U} / \mathrm{ml}(\mathrm{n}=41)$ were reported as grey areas (considered as negative in current analyses) and results above $24 \mathrm{U} / \mathrm{ml}$ were reported as positive. In a recent study, the Wantai assay detected more positives (prevalence of $48.2 \%$ compared to $17.3 \%$ with the Mikrogen assay) and had a lower detection limit. However, it is likely that this included more false positives and the Mikrogen assay had the highest correlation to the estimated overall IgG (prevalence of $18.7 \%$ ). Therefore, we chose for the Mikrogen assay.

\section{Statistical analysis}

The prevalence of HEV was based on the number of positive HEV test results, divided by the total number of HEV tests and multiplied by 100 . Three different models were constructed, including an overall model, a model for the STI clinic cohort and a model for the GP cohort. Univariate logistic regression analyses were used to assess the unadjusted associations between potential risk factors and HEV prevalence. All previously described variables (see the Data collection section) were included in the analyses as potential risk factors. However, we identified several known confounders on the basis of the literature, which led to adjustments in the multivariate logistic regression analyses. These confounders include the test year, age and gender. We used the Enter method to assess the OR and the $95 \%$ confidence intervals $(p \leq 0.05)$. The age curves in Fig 1 were designed on the basis of a seconddegree polynomial fit.

\section{Results}

A total of 2,969 individuals were tested on HEV IgG antibodies: 1,482 from the STI clinic cohort and 1,487 from the GP cohort. The study population had a median age of 44 (IQR 30-54), 54.9\% were men ( $n=$ $1,630)$ and $11.0 \%(n=326)$ had a non-western ethnicity (see S1 Table). Anti-HEV IgG was detected in 562 samples (18.9\%, 95\%Cl: 17.5-20.4).

\section{Univariate risk factors}

In univariate analyses, the overall HEV prevalence was higher with each year's increase in age $(p<0.01)$ as well as for individuals from the GP cohort ( $p<0.01$; see Table 1). For the STI clinic cohort, HEV prevalence was higher with each year's increase in age $(p<0.01)$, for MSM $(p=0.04)$, for individuals who reported anal $\operatorname{sex}(p=0.02)$, for individuals who had three or more sexual partners $(p=0.05)$ and with a diagnosis of CT or NG $(p=0.05)$. For the GP cohort, the HEV prevalence was higher with each year's increase in age $(p<0.01)$ and borderline significant for men $(p=0.10)$. 


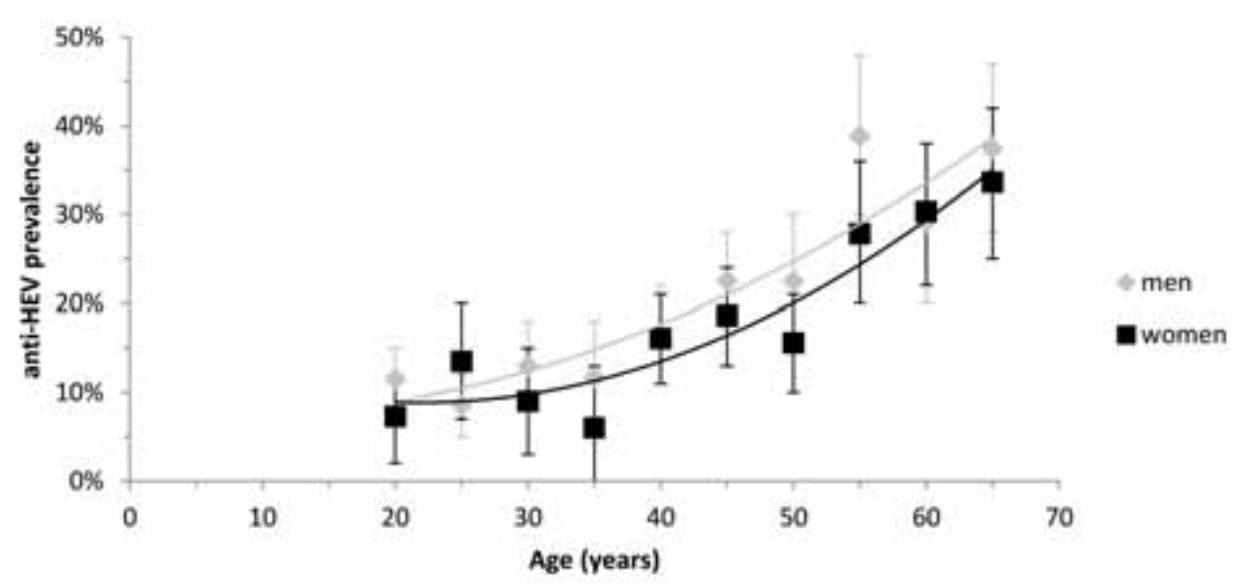

Figure 1. Anti-HEV IgG prevalence in five-year age groups $(n=2,969)$, south Netherlands, Dec 2011 to Nov 2015

\section{Independent risk factors}

In multivariate analyses, the overall HEV prevalence was higher with each year's increase in age (adjusted OR: $1.03,95 \% \mathrm{Cl}: 1.02-1.04, \mathrm{p}<0.01$ ) and for men as compared to women (adjusted OR: $1.24,95 \% \mathrm{Cl}$ : 1.02-1.50, $\mathrm{p}=0.03$; see Table 1 and Fig 1). HEV prevalence was similar among the STI clinic cohort and the GP cohort, after adjusting for confounding factors (see Table 1).

For the STI clinic cohort, most univariate sexual risk factors attenuated and became statistically non-significant after adjusting for test year, age and sexual preference. Independent predictors for HEV prevalence were older age (adjusted OR: 1.02, 95\% Cl: 1.01-1.04, $\mathrm{p}<0.01$ ) and a diagnosis of CT or NG (adjusted OR: $1.60,95 \% \mathrm{Cl}: 1.02-2.49, \mathrm{p}=0.04)$.

For the GP cohort, HEV prevalence was higher with each year's increase in age (adjusted OR: 1.04, $95 \% \mathrm{Cl}: 1.03-1.05, \mathrm{p}<0.01)$. 
Table 1. Determinants of anti-HEV IgG prevalence, south Netherlands, Dec 2011 to Nov 2015

\begin{tabular}{|c|c|c|c|}
\hline & \multicolumn{2}{|c|}{ Univariate anti-HEV IgG prevalence } & $\begin{array}{l}\text { Multivariate } \mathrm{OR}(95 \% \mathrm{CI}) \\
\text { adjusted for test yeara, age, gender }\end{array}$ \\
\hline \multicolumn{4}{|l|}{ Total study population $(n=2,969)$} \\
\hline Age (median=44, IQR=30-54) & & *** & $1.03^{* * *}(1.02-1.04)$ \\
\hline \multicolumn{4}{|l|}{ Gender } \\
\hline - Men & $309 / 1,630$ & $19.0 \%$ & $1.24^{*}(1.02-1.50)$ \\
\hline - Women & $253 / 1,339$ & $18.9 \%$ (ref) & 1.00 \\
\hline \multicolumn{4}{|l|}{ Population } \\
\hline - High sexual risk (STI clinic cohort) & $176 / 1,482$ & $11.9 \%$ (ref) & 1.00 \\
\hline - General (GP cohort) & $386 / 1,487$ & $26.0 \% \%^{* * *}$ & $1.19(0.76-1.87)$ \\
\hline STI clinic cohort $(n=1,482)$ & & & adjusted for test year ${ }^{a}$, age, sexual preference \\
\hline Age (median=30, IQR=24-39) & & *** & $1.02^{* *}(1.01-1.04)$ \\
\hline \multicolumn{4}{|l|}{ Gender } \\
\hline - Men & $118 / 948$ & $12.4 \%$ & $1.23(0.88-1.73)$ \\
\hline - Women & $58 / 534$ & $10.9 \%$ (ref) & 1.00 \\
\hline \multicolumn{4}{|l|}{ Sexual preference } \\
\hline - Women & $33 / 350$ & $9.4 \%$ (ref) & 1.00 \\
\hline - Female swinger & $25 / 184$ & $13.6 \%$ & $1.17(0.65-2.11)$ \\
\hline - Heterosexual men & $52 / 480$ & $10.8 \%$ & $1.19(0.75-1.89)$ \\
\hline - MSM & $66 / 468$ & $14.1 \% \%^{*}$ & $1.41(0.90-2.23)$ \\
\hline \multicolumn{4}{|l|}{ Reported anal sex } \\
\hline - Yes & $87 / 629$ & $13.8 \% *$ & $1.27(0.86-1.88)$ \\
\hline - No & $81 / 812$ & $10.0 \%$ (ref) & 1.00 \\
\hline - Unknown & $8 / 41$ & $19.5 \% \%^{\#}$ & $2.11^{\#}(0.92-4.83)$ \\
\hline \multicolumn{4}{|c|}{ Number of sexual partners (median=3, IQR=2-5) } \\
\hline - $<3$ in past 6 months & $61 / 617$ & $9.9 \%$ (ref) & 1.00 \\
\hline - $\geq 3$ in past 6 months & $114 / 856$ & $13.3 \% *$ & $1.31(0.93-1.85)$ \\
\hline - Unknown & $1 / 9$ & $11.1 \%$ & $1.09(0.13-9.03)$ \\
\hline \multicolumn{4}{|l|}{ Chlamydia and/or gonorrhoeae positive } \\
\hline - Yes & $28 / 171$ & $16.4 \% *$ & $1.60 *(1.02-2.49)$ \\
\hline - $\mathrm{No}^{\mathrm{b}}$ & $148 / 1,311$ & $11.3 \%$ (ref) & 1.00 \\
\hline \multicolumn{4}{|l|}{ Syphilis positive } \\
\hline - Yes & $1 / 4$ & $25.0 \%$ & $1.75(0.16-18.72)$ \\
\hline - No & $14 / 114$ & $12.3 \%$ (ref) & 1.00 \\
\hline - Untested & $161 / 1,364$ & $11.8 \%$ & $0.88(0.46-1.68)$ \\
\hline \multicolumn{4}{|l|}{ HIV positive } \\
\hline - Yes & $6 / 37$ & $16.2 \%$ & $1.08(0.43-2.74)$ \\
\hline - No & $167 / 1,427$ & $11.7 \%$ (ref) & 1.00 \\
\hline - Untested & $3 / 18$ & $16.7 \%$ & $1.48(0.42-5.22)$ \\
\hline GP cohort $(n=1,487)$ & & & adjusted for test year , age, gender \\
\hline Age (median=53, IQR=46-62) & & ${ }^{* * *}$ & $1.04^{* * *}(1.03-1.05)$ \\
\hline \multicolumn{4}{|l|}{ Gender } \\
\hline - Men & $191 / 682$ & $28.0 \% \%^{\#}$ & $1.25^{\#}(0.99-1.58)$ \\
\hline - Women & $195 / 805$ & $24.2 \%$ (ref) & 1.00 \\
\hline \multicolumn{4}{|l|}{ Educational level } \\
\hline - Low & $185 / 676$ & $27.4 \%$ & $1.12(0.82-1.51)$ \\
\hline - Medium & $94 / 371$ & $25.3 \%$ & $1.11(0.80-1.55)$ \\
\hline - High & $102 / 427$ & $23.9 \%($ ref $)$ & 1.00 \\
\hline - Unknown & $5 / 13$ & $38.5 \%$ & $1.43(0.45-4.55)$ \\
\hline \multicolumn{4}{|l|}{ HIV positive } \\
\hline - Yes & $1 / 5$ & $20.0 \%$ (ref) & 1.00 \\
\hline - No & $352 / 1,374$ & $25.6 \%$ & $1.46(0.16-13.42)$ \\
\hline - Untested & $33 / 108$ & $30.6 \%$ & $1.91(0.20-18.21)$ \\
\hline \multicolumn{4}{|l|}{ HBV positive } \\
\hline - Yes (active or past infection) & $43 / 139$ & $30.9 \%$ & $1.15(0.78-1.70)$ \\
\hline - No (no infection or vaccinated) & $343 / 1348$ & $25.4 \%$ (ref) & 1.00 \\
\hline HCV positive & & & \\
\hline - Yes (past infection) & $3 / 4$ & & $8.77^{\#}(0.89-86.40)$ \\
\hline - No (no infection) & $383 / 1483$ & $25.8 \%$ (ref) & 1.00 \\
\hline a Test year of 2012 includes two te & m Decer & & \\
\hline${ }^{b}$ Including 14 individuals not teste & CT and 13 & s not teste & vG. \\
\hline${ }^{*} p \leq 0.05$ & & & \\
\hline${ }^{* *} \mathrm{p} \leq 0.01$ & & & \\
\hline$* * * 0 \leq 0.001$ & & & \\
\hline$\# 0.05 \leq p \leq 0.10$ & & & \\
\hline
\end{tabular}




\section{Discussion}

No firm conclusions can be drawn about sexual transmission of HEV from this study given that the overall prevalence of anti-HEV IgG was the same between the sexual high-risk population and the general population. Our results only hint at the possibility of sexual transmission of HEV as having a sexually transmitted infection (CT and/or NG) was found to be associated with a higher HEV prevalence. Though this may lead to occasional HEV outbreaks, as is the case for HAV, sexual HEV transmission is unlikely to influence the prevalence at the population level. More research is needed on possible sexual transmission of HEV.

Anti-HEV IgG was detected in $18.9 \%$ of the 2,969 blood samples from individuals either attending an STI clinic or belonging to the general population. The adjusted HEV prevalence was similar among the two cohorts. This observed prevalence is similar to the figure of $17 \%$ found in a German study among persons aged 18-79 years, which used the same HEV assay [37]. The observed prevalence is lower than a study among Dutch blood donors with a prevalence of $27 \%$ [11]. This difference in HEV prevalence is unlikely only explained by the use of the Wantai assay with a slightly higher sensitivity [38], it is more likely explained by the older study population. The identification of age and gender factors with relation to HEV prevalence confirms the results from several previous studies [10-12, 39]. HEV prevalence is thought to be related to age, because of the cumulative effect of lifetime exposure. However, no clear and thorough explanation has as yet been found for its connection with gender.

Interestingly, HEV prevalence was higher for individuals who tested positive for CT and/or NG. This higher prevalence is unlikely explained by the zoonotic transmission route of HEV. The ingestion of HEV-infected food is not believed to be more common among individuals who tested positive for CT and/or NG. Furthermore, a similar trend is seen in other risk factors of sexual transmission such as being an MSM, reporting anal sex, having three or more sexual partners in the past six months and being tested positive for syphilis. This may suggest that sex may be a possible transmission route for HEV. Whether HEV could be transmitted via the faecal-oral route, via blood contact during risky sexual behaviour or via person-to-person contact remains unknown and should be the subject of further study.

To our knowledge, this is the first study to explore the possible sexual transmission of HEV and its impact at the population level in the Netherlands. However, the following limitations must be considered. First, no data on sexual risk behaviour were available for individuals from the GP cohort and data on parenteral risk behaviour, injective drug use, were not included due to its low prevalence. However, we compared the sexual risk behaviour of the STI clinic cohort to the general population in the Netherlands. In our study $40 \%$ of the individuals reported anal sex in the past six months compared to $7-18 \%$ in the general population [40,41]. Overall more sexual risk behaviour was reported in the STI clinic cohort compared to the general population. Second, the age distribution differs between the STI clinic cohort and the GP cohort. Age was included as confounder in the multivariate logistic regression analyses. Additionally, we assessed the HEV prevalence in the 40-50 year olds. No difference was detected between the STI clinic cohort and the GP cohort in this age group too, $p=0.678$. Matching cases and 
controls on age and/or sex is desirable for future studies[26, 27]. Third, the comparison to HEV prevalence in other studies is difficult to make, as sensitivity and specificity are highly variable between the different serological assays $[42,43]$. Fourth, no data on occupational exposure to swine, as a known risk factor of HEV, were available. Finally, using this cross-sectional design we were unable to assess causal associations, a longitudinal study including genotyping would have been the ideal design. Our results only hint at the possibility of a sexual transmission route for HEV given higher rates in those with chlamydia and/or gonorrhoeal infections. Sexual transmission is not a dominant transmission route, as its prevalence was not higher for the STI clinic cohort than for the GP cohort. Whether sexual transmission of HEV occurs, and whether it could consequently lead to outbreaks in the same vein as HAV, should preferably be studied at the individual level in future prospective research. Considering the limited clinical impact of HEV infections, we do not recommend increased HEV testing in sexual high risk clinical settings, with the possible exception of patients who are immunocompromised. 


\section{References}

1. Balayan MS, Andjaparidze AG, Savinskaya SS, Ketiladze ES, Braginsky DM, Savinov AP, et al. Evidence for a virus in non-A, non-B hepatitis transmitted via the fecal-oral route. Intervirology. 1983; 20(1):23-31. Epub 1983/01/01. PMID: 6409836 .

2. Purcell RH, Emerson SU. Hepatitis E: an emerging awareness of an old disease. J Hepatol. 2008; 48(3):494-503. Epub 2008/01/15. https://doi.org/10.1016/j.jhep.2007.12.008 PMID: 18192058.

3. Aggarwal R, Krawczynski K. Hepatitis E: an overview and recent advances in clinical and laboratory research. J Gastroenterol Hepatol. 2000; 15(1):9-20. Epub 2000/03/17. PMID: 10719741.

4. Zanetti AR, Schlauder GG, Romano L, Tanzi E, Fabris $P$, Dawson GJ, et al. Identification of a novel variant of hepatitis $E$ virus in Italy. J Med Virol. 1999; 57(4):356-60. Epub 1999/03/24. https://doi.org/10.1002/(SICI)10969071(199904)57:4<356::AID-JMV5>3.0.C0;2-D PMID: 10089046.

5. Garbuglia AR, Scognamiglio $P$, Petrosillo $N$, Mastroianni CM, Sordillo $P$, Gentile $D$, et al. Hepatitis E virus genotype 4 outbreak, Italy, 2011. Emerg Infect Dis. 2012; 19(1):110-4. Epub 2012/12/25. https://doi.org/10.3201/ eid1901.120983 PMID: 23260079.

6. Dalton HR, Stableforth W, Thurairajah $\mathrm{P}, \mathrm{Ha}-$ zeldine S, Remnarace R, Usama W, et al. Autochthonous hepatitis $E$ in Southwest England: natural history, complications and seasonal variation, and hepatitis E virus IgG seroprevalence in blood donors, the elderly and patients with chronic liver disease. Eur J Gastroenterol Hepatol. 2008; 20(8):784-90. Epub 2008/07/12. https://doi.org/10.1097/MEG. 0b013e3282f5195a PMID: 18617784.

7. Dalton $H R$, Fellows $H J$, Gane EJ, Wong $P$, Gerred S, Schroeder B, et al. Hepatitis E in new zealand. J Gastroenterol Hepatol. 2007; 22(8):1236-40. Epub 2007/05/11. https://doi. org/10.1111/j.1440-1746. 2007.04894.x PMID: 17489963.
8. Mansuy JM, Peron JM, Abravanel $F$, Poirson $H_{\text {, }}$ Dubois $M$, Miedouge $M$, et al. Hepatitis $E$ in the south west of France in individuals who have never visited an endemic area. J Med Virol. 2004; 74(3):419-24. Epub 2004/09/16. https://doi. org/10.1002/jmv.20206 PMID: 15368508.

9. Drobeniuc J, Greene-Montfort T, Le NT, Mixson-Hayden TR, Ganova-Raeva L, Dong C, et al. Laboratory-based surveillance for hepatitis E virus infection, United States, 20052012. Emerg Infect Dis. 2013; 19(2):218-22; quiz 353. Epub 2013/01/26. https://doi.org/10.3201/ eid1902.120961 PMID: 23347695.

10. Koot $H$, Hogema BM, Koot $M$, Molier $M$, Zaaijer $\mathrm{HL}$. Frequent hepatitis $\mathrm{E}$ in the Netherlands without traveling or immunosuppression. J Clin Virol. 2015; 62:38-40. https://doi.org/10.1016/j. jcv.2014.11.020 PMID: 25542468.

11. Slot $E$, Hogema BM, Riezebos-Brilman A, Kok TM, Molier M, Zaaijer HL. Silent hepatitis E virus infection in Dutch blood donors, 2011 to 2012. Euro Surveill. 2013; 18(31). Epub 2013/08/10. PMID: 23929229.

12. Dalton HR, Bendall RP, Rashid M, Ellis V, Ali $R$, Ramnarace $R$, et al. Host risk factors and autochthonous hepatitis $E$ infection. Eur J Gastroenterol Hepatol. 2011; 23(12):1200-5. Epub 2011/09/24. https://doi.org/10.1097/MEG. Ob013e32834ca4da PMID: 21941192.

13. Kamar N, Selves J, Mansuy JM, Ouezzani L, Peron $J M$, Guitard J, et al. Hepatitis E virus and chronic hepatitis in organ-transplant recipients. $\mathrm{N}$ Engl J Med. 2008; 358(8):811-7. Epub 2008/02/22. https://doi.org/10.1056/NEJMoa0706992 PMID: 18287603.

14. Dalton HR, Bendall RP, Keane FE, Tedder RS, ljaz S. Persistent carriage of hepatitis E virus in patients with HIV infection. N Engl J Med. 2009; 361(10):1025-7. Epub 2009/09/04. https:// doi.org/10.1056/NEJMc0903778 PMID: 19726781.

15. Kamar N, Garrouste C, Haagsma EB, Garrigue V, Pischke $\mathrm{S}$, Chauvet $\mathrm{C}$, et al. Factors associated with chronic hepatitis in patients with hepatitis E virus infection who have received solid organ transplants. Gastroenterology. 2011; 140(5):1481- 
9. Epub 2011/03/01. https://doi.org/10.1053/j. gastro.2011.02.050 PMID: 21354150.

16. Pas SD, de Man RA, Mulders C, Balk AH, van Hal PT, Weimar W, et al. Hepatitis E virus infection among solid organ transplant recipients, the Netherlands. Emerg Infect Dis. 2012; 18(5):86972. Epub 2012/04/21. https://doi.org/10.3201/ eid1805.111712 PMID: 22516170.

17. Rutjes SA, Lodder WJ, Bouwknegt $M$, de Roda Husman AM. Increased hepatitis E virus prevalence on Dutch pig farms from 33 to $55 \%$ by using appropriate internal quality controls for RT-PCR. J Virol Methods. 2007; 143(1):112-6. Epub 2007/02/27. https://doi.org/10.1016/j.jviromet.2007.01.030 PMID: 17320980.

18. Dalton HR, Bendall R, ljaz S, Banks M. Hepatitis $E$ : an emerging infection in developed countries. Lancet Infect Dis. 2008; 8(11):698-709. Epub 2008/11/11. https://doi.org/10.1016/S14733099(08)70255-X PMID: 18992406.

19. Van Der Poel WH, Koopmans M, De Roda Husman AM. Hepatitis E virus in Nederland. Inf Bulletin. 2002; 13(8):299-303.

20. Pavio N, Meng XJ, Doceul V. Zoonotic origin of hepatitis E. Curr Opin Virol. 2015; 10:34-41. https://doi.org/10.1016/j.coviro.2014.12.006 PMID: 25588602.

21. Wichmann 0 , Schimanski S, Koch J, Kohler M, Rothe C, Plentz A, et al. Phylogenetic and case-control study on hepatitis $E$ virus infection in Germany. J Infect Dis. 2008; 198(12):1732-41. Epub 2008/11/06. https://doi. org/10.1086/593211 PMID: 18983248.

22. Colson $P$, Borentain $P$, Queyriaux $B$, Kaba $M$, Moal V, Gallian $P$, et al. Pig liver sausage as a source of hepatitis $E$ virus transmission to humans. J Infect Dis. 2010; 202(6):825-34. Epub 2010/08/11. https://doi.org/10.1086/655898 PMID: 20695796.

23. Hazards EPanel oB, Ricci $A$, Allende A, Bolton $D$, Chemaly $M$, Davies $R$, et al. Public health risks associated with hepatitis E virus (HEV) as a food-borne pathogen. EFSA Journal. 2017; 15(7):e04886-n/a. https://doi.org/10.2903/j. efsa.2017.4886

24. Gorgos L. Sexual transmission of viral hepati- tis. Infect Dis Clin North Am. 2013; 27(4):811-36. https://doi.org/10.1016/j.idc.2013.08.002 PMID: 24275272.

25. Freidl GS, Sonder GJ, Bovee LP, Friesema IH, van Rijckevorsel GG, Ruijs WL, et al. Hepatitis A outbreak among men who have sex with men (MSM) predominantly linked with the EuroPride, the Netherlands, July 2016 to February 2017. Euro Surveill. 2017; 22(8). https://doi. org/10.2807/1560-7917.ES.2017.22.8.30468 PMID: 28251892.

26. Sazzad HMS, Luby SP, Labrique AB, Kamili $S$, Hayden TM, Kamili NA, et al. Risk Factors Associated with Blood Exposure for Sporadic Hepatitis E in Dhaka, Bangladesh. Am J Trop Med Hyg. 2017. https://doi.org/10.4269/ajtmh.17-0261 PMID: 28820721.

27. Abravanel F, Lhomme S, Fougere M, Saune $K, A l-$ varez $M$, Peron $J M$, et al. HEV infection in French HIV-infected patients. J Infect. 2017; 74(3):310-3. https://doi.org/10.1016/j.jinf.2016.12.004 PMID: 27998748.

28. Eker A, Tansel O, Kunduracilar H, Tokuc B, Yulugkural Z, Yuksel P. [Hepatitis E virus epidemiology in adult population in Edirne province, Turkey]. Mikrobiyol Bul. 2009; 43(2):251-8. PMID: 19621610.

29. Christensen $P B$, Engle RE, Jacobsen $S E$, Krarup HB, Georgsen J, Purcell RH. High prevalence of hepatitis $E$ antibodies among Danish prisoners and drug users. J Med Virol. 2002; 66(1):49-55. PMID: 11748658.

30. Thomas DL, Yarbough PO, Vlahov D, Tsarev SA, Nelson KE, Saah AJ, et al. Seroreactivity to hepatitis $E$ virus in areas where the disease is not endemic. J Clin Microbiol. 1997; 35(5):1244-7. PMID: 9114415.

31. Dukers-Muijrers NH, Niekamp AM, Brouwers $\mathrm{EE}$, Hoebe CJ. Older and swinging; need to identify hidden and emerging risk groups at STI clinics. Sex Transm Infect. 2010; 86(4):3157. https://doi.org/10.1136/sti.2009.041954 PMID: 20577016.

32. Kok A, Zuure FR, Weegink CJ. Hepatitis $C$ in Nederland: schaarse gegevens over actuele prevalentie en de noodzaak van epidemiolo- 
gisch onderzoek en innovatieve opsporingsmethoden. Nederlands Tijdschrift voor Geneeskunde 2007; 151:2367-71. PMID: 18019212

33. Slavenburg $S$, Verduyn-Lunel FM, Hermsen JT, Melchers WJ, te Morsche RH, Drenth JP. Prevalence of hepatitis $C$ in the general population in the Netherlands. Neth J Med. 2008; 66(1):13-7. Epub 2008/01/26. PMID: 18219062

34. Vriend HJ, Op de Coul EL, van de Laar TJ, Urbanus AT, van der Klis FR, Boot HJ. Hepatitis $C$ virus seroprevalence in the Netherlands. Eur J Public Health. 2012; 22(6):819-21. https://doi. org/10.1093/eurpub/cks013 PMID: 22461704.

35. Marschall $T$, Kretzschmar $M$, Mangen $M J$, Schalm S. High impact of migration on the prevalence of chronic hepatitis B in the Netherlands. Eur J Gastroenterol Hepatol. 2008; 20(12):1214-25. Epub 2008/10/24. https://doi. org/10.1097/MEG.0b013e32830e289e PMID: 18946359.

36. van Marrewijk $\mathrm{CM}$, Velshuijzen IK, Conyn-van Spaendonck MAE, Kooy $H_{\text {, van }}$ den Hof $S$, Dorigo-Zetsma JW. Prevalence of hepatitis $B$ viral markers in the Dutch population: a population-based serosurveillance study (Pienter project) Bilthoven: Rijksinstituut voor Volksgezondheid en Milieu; 1999 [updated 199903-11]. http://www.rivm.nl/bibliotheek/rapporten/243680001.html.

37. Faber MS, Wenzel JJ, Jilg W, Thamm M, Hohle M, Stark K. Hepatitis E virus seroprevalence among adults, Germany. Emerg Infect Dis. 2012; 18(10):1654-7. https://doi.org/10.3201/ eid1810.111756 PMID: 23018055.

38. Pas SD, Streefkerk RH, Pronk $M$, de Man RA, Beersma MF, Osterhaus $A D$, et al. Diagnostic performance of selected commercial HEV $\lg M$ and IgG ELISAs for immunocompromised and immunocompetent patients. J Clin Virol. 2013; 58(4):629-34. https://doi.org/10.1016/j. jcv.2013.10.010 PMID: 24210958.

39. RIVM. LCl-richtlijn Hepatitis E. 2007.

40. Heijne JC, van Liere GA, Hoebe CJ, Bogaards $J A$, van Benthem $B H$, Dukers-Muijrers $\mathrm{NH}$. What explains anorectal chlamydia infection in women? Implications of a mathematical model for test and treatment strategies. Sex Transm Infect. 2016. https://doi.org/10.1136/ sextrans-2016-052786 PMID: 27986968.

41. National Survey of Sexual Attitudes and Lifestyles (Natsal-3). http://www.natsal.ac.uk/ media/3935/natsal-3-reference-tables.pdf.

42. Bendall R, Ellis V, ljaz S, Ali R, Dalton H. A comparison of two commercially available anti-HEV IgG kits and a re-evaluation of anti-HEV IgG seroprevalence data in developed countries. J Med Virol. 2010; 82(5):799-805. https:// doi.org/10.1002/jmv.21656 PMID: 20336757.

43. Rossi-Tamisier M, Moal V, Gerolami R, Colson P. Discrepancy between anti-hepatitis $E$ virus immunoglobulin $G$ prevalence assessed by two assays in kidney and liver transplant recipients. J Clin Virol. 2013; 56(1):62-4. https://doi. org/10.1016/j.jcv.2012.09.010 PMID: 23089569. 


\section{Supporting information}

S1 Table. Characteristics of total samples tested for HEV $(n=2,969)$, south Netherlands, Dec 2011 to Nov 2015a

\begin{tabular}{|c|c|c|c|}
\hline & $\begin{array}{l}\text { Sexual high-risk } \\
\text { population } \\
\mathrm{N}=1,482\end{array}$ & $\begin{array}{l}\text { General population } \\
N=1,487\end{array}$ & $\begin{array}{l}\text { Total } \\
\mathrm{N}=2,969\end{array}$ \\
\hline & $\%(n)$ & $\%(n)$ & $\%(n)$ \\
\hline Age & $\begin{array}{l}\text { median=30, } \\
\mathrm{IQR}=24-39\end{array}$ & $\begin{array}{l}\text { median=53, } \\
\mathrm{IQR}=46-62\end{array}$ & $\begin{array}{l}\text { median=44, } \\
\mathrm{IQR}=30-54\end{array}$ \\
\hline \multicolumn{4}{|l|}{ Gender } \\
\hline $\begin{array}{l}\text { - Men } \\
\text { - Women }\end{array}$ & $\begin{array}{l}64.0(948) \\
36.0(534)\end{array}$ & $\begin{array}{l}45.9(682) \\
54.1(805)\end{array}$ & $\begin{array}{l}54.9(1,630) \\
45.1(1,339)\end{array}$ \\
\hline \multicolumn{4}{|l|}{ Non-western ethnicity ${ }^{b}$} \\
\hline $\begin{array}{l}\text { - Yes } \\
\text { - No }\end{array}$ & $\begin{array}{l}13.4(199) \\
86.6(1,283)\end{array}$ & $\begin{array}{l}8.5(127) \\
91.5(1360)\end{array}$ & $\begin{array}{l}11.0(326) \\
89.0(2,643)\end{array}$ \\
\hline \multicolumn{4}{|c|}{ Additional variables only available for STI clinic cohort } \\
\hline \multicolumn{4}{|l|}{ Sexual preference } \\
\hline $\begin{array}{l}\text { - Women } \\
\text { - Female swinger } \\
\text { - Heterosexual men } \\
\text { - MSM }\end{array}$ & $\begin{array}{l}23.6(350) \\
12.4(184) \\
32.4(480) \\
31.6(468)\end{array}$ & - & \\
\hline \multicolumn{4}{|c|}{ Sexual transmission risk factor ${ }^{c}$} \\
\hline $\begin{array}{l}\text { - } Y e s \\
\text { - } \mathrm{No}^{d}\end{array}$ & $\begin{array}{l}75.2(1,114) \\
24.8(368)\end{array}$ & - & \\
\hline \multicolumn{4}{|c|}{ Additional variables only available for GP cohort } \\
\hline \multicolumn{4}{|l|}{ Educational level } \\
\hline $\begin{array}{l}\text { - Low } \\
\text { - Medium } \\
\text { - High } \\
\text { - Unknown }\end{array}$ & - & $\begin{array}{l}45.5(676) \\
24.9(371) \\
28.7(427) \\
0.9(13)\end{array}$ & \\
\hline
\end{tabular}

a Test year of 2012 includes two tests from December 2011.

${ }^{b}$ Individuals who were born in or who had at least one parent born in Africa, Asia (excluding Indonesia and Japan) or Latin-America.

${ }^{\circ}$ Including reporting anal sex, having three or more sexual partners in the past six months and being CT positive, NG positive, Syphilis positive or HIV positive.

${ }^{\mathrm{d}}$ Including five tests for which the risk factor was unknown. 



\section{Chapter 8}

General discussion 
The studies presented in this thesis aimed to identify and address hidden infections and evaluate current infectious disease prevention, surveillance and control. Better insight into hidden infections allows for example more targeted and effective testing practices in order to eventually protect the most vulnerable and susceptible groups at risk. In this chapter, I will discuss the main findings of this thesis and provide recommendations for future policy and research on hidden infections, by reflecting on recent literature and research on pertussis and hepatitis.

\subsection{Hidden pertussis infections}

Pertussis surveillance aims to monitor the impact of the vaccination programme, identify high-risk areas, detect outbreaks and monitor case management in order to take timely preventive measures [1]. To avoid morbidity and mortality in young infants, pertussis surveillance data based on notifications is currently used to guide pertussis control measures. However, there is a discrepancy between the number of pertussis notifications and the number of pertussis infections. In sero-surveys antibody levels against pertussis toxin (PT) are used to estimate the prevalence of pertussis infections in the population [2]. The Dutch seroprevalence of PT-IgG levels $\geq 50 \mathrm{IU} / \mathrm{mL}$ increased from 4\% in 1995-1996 to $9 \%$ in 2006-2007 [3,4]. Results of the third Dutch pertussis seroprevalence study conducted in 2016-2017 are expected this year. In 2006-2007, the estimated seroprevalence of pertussis infections was 100-fold higher than the reported notifications at that time $[5,6]$.

\section{Study aim and methods}

Therefore, more insight was needed into the accuracy of pertussis surveillance and control, including the identification of spatial clusters of infections (Chapter 3) and studying impeding factors in the medical care (healthcare provider and laboratory) and public healthcare (Chapter 2 and 4). We studied a unique combination of data sources from one region (1.1 million residents), including online GPs questionnaires, laboratory registries and public health care registries. In this thesis we used geographical analyses and a surveillance study as methods to give more insight into the factors that hamper the identification of hidden pertussis infections.

\section{Main findings}

Pertussis surveillance and control is hampered by, for example, under-ascertainment as individuals with mild symptoms or who are asymptomatic may not present to healthcare for diagnosis [7,8]. Clinically, the disease resembles other respiratory diseases, particularly in the early catarrhal phase when an individual is already highly contagious [7]. Also, the classical pertussis symptoms are often absent in adolescents and adults, therefore these cases may not be recognized by HCPs $[7,9,10]$. Clinical recognition, perceived barriers in testing, and a lack of being familiar with testing protocols influence the testing behaviour of physicians [11]. In contrast to national guidelines, in our study GPs reported to 
perform laboratory diagnostic tests for pertussis mainly in patients with clinical symptoms. This practice is in accordance with expressed facilitators and barriers to test for pertussis among GPs [12]. Laboratory diagnostic procedures, especially interpretation of serology, are complicated because of changing cut-off value recommendations, in cases of recent immunisation and because of limitations of the available diagnostic tests $[8,11,13]$. As the pertussis diagnostic process is quite challenging, not all cases presenting to healthcare are diagnosed (underdiagnosis) or notified (under-notification) [14]. Our studies revealed that the current pertussis incidence is largely the result of testing, possible misdiagnosis, substantial under-notification (18\%) and a large delay between patient symptoms and notification to the local public health services (median 34 days) precluding timely preventive actions $[15,16]$. Hidden pertussis infections are likely not unique for this area of the Netherlands and are generalizable to the rest of Europe. These countries are likely to encounter varying guidelines, difficulties in pertussis diagnostics and unexplained local differences in notification data too. It is not feasible and desirable to identify all pertussis infections. Ideally, the accuracy of surveillance would be improved by focusing on the factors identified in this thesis. This contributes to optimisation of the surveillance system and more importantly, to improved pertussis control by preventing young infants from being infected with pertussis and avoiding morbidity and mortality in this risk group.

\section{Recommendations for practice and future research}

Based upon this thesis and recent literature we have several recommendations on how to improve current practice and policy. We were able to give more insight into the factors that hamper the identification of hidden pertussis infections. These findings function as an important input for the discussion on how to reduce the workload of PHS and the debate on how to reduce the overall delay until notification to improve pertussis control [17,22].

First, to reduce misdiagnosis and the variation in pertussis diagnostics, we recommend laboratories and HCPs to improve adherence to national guidelines concerning timing and choice of test. For laboratories, a national uniform and standardised guideline on cut-off values in serology and the use of $\lg A$ and/or IgG is desirable. Single serological testing is not suitable to detect recent pertussis infection in individuals vaccinated with an acellular pertussis vaccine within the past year. Multiple serology is also recommended when the first titre is below the cut-off value specific for a pertussis infection. Among infants younger than 1 year of age and individuals with less then three weeks of coughing, PCR testing is recommended [23-25]. Testing all patients presenting with cough is not feasible, as only $3 \%$ of adult patients presenting with acute cough in primary care had evidence of an acute pertussis infection in Europe [26]. Moreover, testing for pertussis follows to an extent the general healthcare seeking behaviour for common respiratory infections, whereas the current pertussis incidence is largely the result of testing. Increased testing would thus not necessarily improve pertussis control. Therefore, HCPs should focus pertussis testing on family members surrounding incompletely vaccinated infants $<1$ year of age, women $>34$ weeks pregnant and children with severe comorbidities such as heart or lung failure. In addition, they are advised of whooping cough have vulnerable groups at risk in their 
household. As such, GPs could play a more prominent role in contact tracing (now carried out by the public health authorities in the Netherlands) in order to minimise the disease burden in infants.

Second, to reduce under-notification, laboratories and HCPs could benefit from introducing automated notification systems [15]. In an endemic situation with severe underreporting, the obligatory notification of pertussis is not effective for the protection of unvaccinated children [22]. On the other hand, the notification of pertussis infections is of great value to national policy on pertussis surveillance and control [17,18] although we showed the limitations of pertussis surveillance [15]. Pertussis has to remain a notifiable disease as it is necessary to prohibit a pertussis-positive patient to go to work when he/she works with vulnerable young infants. The detection of outbreaks using space-time cluster detection is feasible and could help to facilitate an early and appropriate public health response. However, this approach has to be adjusted for the strong dependency to testing and is probably most efficient when using test-positivity as indicator [16].

Third, as public health is almost always too late to intervene, delays need to be reduced and we need earlier preventive measures by healthcare providers [19]. Patient delays due to late presentation to healthcare may be unavoidable, however delays in reporting once a patient presents can be reduced [21]. GPs, midwives and day nursery employees could play a major role here. Creating awareness among these professionals as well as patients themselves about taking timely preventive measures could lead to lower individual disease burden and to a higher cost-effectiveness of pertussis care.

At last, we also need additional preventive measures for the most vulnerable and susceptible group of unvaccinated infants, as the Dutch national vaccination program starts at the age of two months. In the first few months young infants are unprotected as vaccination is only effective after at least three doses. The efficacy of pertussis vaccines has been debated because of waning immunity, incomplete protection of infants below 5 months, genetic changes in Bordetella pertussis and limited duration of protection. Currently, maternal immunisation has been recommended by the WHO and the ECDC. In England, maternal immunisation was found to provide $91 \%$ protection against infant disease (vaccine-effectiveness), whilst no important side effects were observed. The Dutch health council advised the introduction of maternal vaccination to the national vaccination program (December 2015) and pertussis vaccinations for healthcare workers (June 2017). The practical implementation of these recommendations into the Dutch healthcare system is undecided yet. 


\subsection{Hidden hepatitis infections}

Chronic hepatitis $\mathrm{C}$ virus (HCV) and B virus (HBV) infections, major causes of chronic liver disease worldwide, are generally asymptomatic and many infections remain hidden to care or are diagnosed at a late stage [27-31]. A national serosurvey in 2006-2007 in the Netherlands estimated a weighted HBsAg seroprevalence of $0.2 \%$ and $0.3 \%$ of anti-HCV antibodies in the general Dutch population [32,33]. However, because HBV and HCV infections are concentrated within high-risk groups such as migrants, men who have sex with men (MSM), and people who inject drugs (PWID), groups which are often underrepresented in (voluntary) national serosurveys, these estimations are possibly an underestimation. Three studies using a risk group approach estimated a prevalence of chronic HBV of 0.36-0.53\% in 2006 [34], a prevalence of anti-HCV antibodies of $0.22 \%$ in 2009 [35], and a prevalence of chronic HCV infection of $0.11 \%$ in 2015 [36]. The chronic HBV and HCV prevalence estimates were updated in 2016, stratified by country-of-origin for first-generation migrants. The estimated chronic HBV infection prevalence is $0.34 \%$ and the estimated chronic HCV infection prevalence is $0.16 \%$ [37]. Approximately $20 \%$ of people with untreated chronic HBV and $15-30 \%$ of people with chronic HCV infection are estimated to develop cirrhosis within 20 years [38,39]. In the Netherlands approximately 500 people died annually between 2002 and 2015 due to the consequences of chronic HBV or HCV infection [40]. These deaths are to a large extent avoidable as effective antiviral treatment is available for chronic HBV infections and direct-acting antivirals (DAA's) are accessible for all patients with chronic HCV infection in the Netherlands [41-43].

Unlike HBV and HCV infections, transmission routes of hepatitis E virus (HEV) are under debate. Recently, HEV has become a global public health concern, as an increase of autochthonous HEV infections was observed in developed countries. The most recent evidence suggests HEV caused by genotypes 3 and 4 is transmitted zoonotically. HEV is proven to be transmitted by ingesting uncooked or poorly cooked pork or game meat [44-46]. The hepatitis A virus (HAV) and HEV genotypes 1 and 2 are both single-stranded RNA viruses with similar incubation periods and a faecal-oral transmission route. Sexual activity, including oral-anal contact, as the major transmission route among men who have sex with men (MSM) is another widely documented aspect of HAV $[47,48]$, but only a limited number of studies have focused on the possible sexual transmission route of HEV infections [49-53].

\section{Study aim and methods}

Because treatment for $\mathrm{HBV}$ and $\mathrm{HCV}$ infection has greatly improved, identification of infected individuals has become even more important. Yet, strategies to detect cases of HCV infection hidden in the general population have been disappointing. To capture all persons who have HCV infection, prospective studies are needed to evaluate the diagnostic yield of HCV testing strategies not based on exposure risk factors [54]. Birth cohort screening, as currently recommended in the United States (HCV prevalence of 2.0\%), has also been suggested for European countries [55-57]. In simulation models, onetime HCV testing in the 1945-1965 birth cohort with subsequent treatment was likely cost-effective 
in the United States [58]. According to a meta-analysis, targeted practitioner-based studies are most effective in increasing test uptake and cases detected [59]. Diagnostic yield could be further optimized by focusing on areas of higher prevalence. In this thesis we used geographical analyses and we examined this model and estimates in a real-life setting to identify hidden hepatitis $B$ and $C$ infections.

To explore the possible role of sexual transmission, in Chapter 7 we compared the HEV prevalence in a Dutch sexual high-risk population with the prevalence in a general population while assessing sociodemographic and sexual risk factors. In this thesis we used a seroprevalence study as method to identify hidden hepatitis $E$ infections.

\section{Main findings}

Based on spatial-epidemiological analyses of laboratory data, the estimated prevalence of HCV infection in the south of the Netherlands is $0.5 \%$, and we identified HCV clusters in urban areas, with a prevalence of up to $1 \%$, as described in Chapter 5 [60,61]. In addition, an estimated $66 \%$ of HCV-infected persons were estimated to be untested and thus hidden to care [60]. All of this, made us develop a best practice approach by combining public health and primary care efforts in a birth cohort testing strategy as described in Chapter 6. We applied this approach in two identified hotspots in the Netherlands to detect hidden HCV and HBV infections in the general population. However, this best practice approach had a limited diagnostic yield. We were able to gain a higher than expected test uptake of $51 \%$, but our approach completely failed to detect hidden HCV infections [62].

A higher prevalence was expected based on previous estimations in these hotspots $(0.5 \%$ to $1 \%)$ [60,61], other Dutch studies focusing on risk groups (0.3\% to 4.8\%) [63-66], and (inter)national estimations of a substantial untested population ( $43 \%$ to $72 \%$ ) [28-31]. The low positivity rate can be due to the possibility of selection bias. This cannot be ruled out, as many HCV-infected patients are at a disadvantage in terms of health literacy [67]. In the Netherlands, health insurance is obligatory, and general practitioners function as a gatekeeper to specialist care, but some individuals might have been less likely to get tested. Nevertheless, those who were tested and those who were not did not differ in assessed characteristics, such as working or living situation, or migrant status. Moreover, study participants had an lower educational level compared with those declining to be tested, and national estimates support our ability to reach intravenous drug users $[68,69]$. Another explanation for the low positivity rate can be found in the fact that estimates of the hidden HCV-infected population are largely derived from mathematical models. Additionally, the hotspots were determined based on laboratory data of the tested population. We assumed the hidden, untested population to follow the same geographical pattern as the tested population. Therefore, the number of hidden cases of chronic HCV infection seems to be overestimated within a real-life setting.

\section{Recommendations for practice and future research}

Lessons learned from this evidence-based practice can be applied to future studies. At first, as no active HCV infections were found in the identified hotspots, the hotspot strategy would probably not work 
in other areas of the Netherlands as well and this also account for other countries with low HCV prevalence. Our findings partly informed the Dutch Health Council in their advice against screening of the general Dutch population for HCV and HBV (November 2016). This advice is part of the national hepatitis elimination plan, developed by specialists, doctors of the public health service and GPs, aimed at the prevention of transmission and reduction of hepatitis related disease burden and deaths. The committee recommends case finding by GPs for people in risk groups and by institutions who are responsible for delivering care to people in risk groups or for accommodating these people. The GP guidelines in the UK and the Netherlands advice to focus more on targeted HBV testing, especially among non-western migrants. This is in line with the recommendation of the Dutch Health Council on regional HBV screening programmes in areas with relatively large groups of first-generation migrants from high-endemic countries ( $\geq 2 \%$ chronic HBV infection). In the Netherlands, PWID and HIV-positive MSM are tested for $\mathrm{HBV}$ and/or HCV as part of comprehensive health care programs (i.e., HIV treatment, HBV vaccination, and harm reduction programs for PWID) [70-72]. However, for migrants who account for a relatively large proportion of HBV and HCV infections [73], there are no structural screening programs. This may partly be caused by the heterogeneity of this population, in terms of ethnic origin, risk for infection and awareness of infection status. Some screening interventions in the Netherlands have targeted different migrant groups $[63,64,66,74-76]$. These interventions, however, were limited in geographical coverage, and uptake was often low/moderate depending on the screening model. Structural screening programs for (subgroups of) migrants are needed to substantially reduce chronic viral hepatitis related morbidity and mortality among migrants, and the sustainability, linkage to care and access to treatment has to be ensured. Several interventions to further optimize the continuum of care have been described [77]. In addition, the feasibility and cost-effectiveness of introducing HCV to the prenatal screening program among first generation migrants could be studied. Future studies could also focus at the knowledge gap on the effectiveness of HBV/HCV screening among asylum seekers.

Additionally, our testing strategy could be applied to detecting HCV and HBV in high-endemic countries, to other infectious diseases and high-endemic settings. Higher positivity rates have been found in studies of countries with higher prevalence and in settings other than the general population with higher prevalence, such as the emergency department. An American study showed that HCV-infected individuals are more likely to use the emergency department (ED) for care than any other health care setting [78]. HCV testing in the ED was found acceptable by $63 \%$ [79]. Testing in this setting reveals hidden infections as this testing could reach those who do not respond to screening projects, do not feel at risk or avoid health care in general. Furthermore, test-uptake in this setting may be very high as tests can be offered and performed within routine diagnostic work-up. Several studies in the UK and US support routine testing on HCV in the ED setting with test-uptake varying from 27 to $66 \%$ and anti-HCV prevalence from 2 to $11 \%$ [80-83]. In the context of applicability, it is shown that routinely offering HCV testing to patients who are undergoing laboratory testing had no effect on length of stay at the emergency department [82]. 
Consciousness of health care providers, for example to prompt viral hepatitis testing when people present with abnormal liver function, is needed to identify those infected who do not belong to one of the risk groups. Automated screening alerts for ALAT elevation at the GP clinic can be a tool to detect hidden HCV infections, although this is a challenging process. The risk of HCV infection is substantially elevated in Dutch primary care patients with an ALAT elevation between $50 \mathrm{IU} / \mathrm{L}$ and $100 \mathrm{IU} / \mathrm{L}$, whereas the risk of HBV infection is not [84]. Therefore, diagnostic follow-up for HCV is recommended in all these patients, particularly in those for whom no clear explanation for the ALAT elevation is found [84,85]. Among HBV patients without an indication for referral, ALAT should be checked during three years, both the GP and the patient should be reminded for these check-ups [86].

Future projects aimed at detecting chronic $\mathrm{HBV}$ and $\mathrm{HCV}$ infections hidden to care should focus on retrieval projects. This includes retracing and evaluating patients previously diagnosed with HBV or $\mathrm{HCV}$ who are eligible for (new) treatment. In the Netherlands, there is evidence for patients diagnosed with HBV or HCV who are eligible for treatment still remain untreated [87]. These patients were lost to follow-up as they stopped treatment because of the side effects, were not able to start treatment because of contra-indications, or did not attend their follow-up appointments. The Health Council of the Netherlands recommend retracing people who have been diagnosed with HBV or HCV in the past but are no longer receiving care [88]. This retracing should focus on giving patients the opportunity to make use of the new treatment options. Once they have been retraced, they must promptly be given appropriate care. Studies on detection of chronic hepatitis B and C patients who were lost to follow up, enables evaluation of the indication for current treatment options $[89,90]$.

Currently, a national registry of all HBV and HCV infected patients is in development and will include patients characteristics and treatment data. HBV infections and recent HCV infections are notifiable diseases. Until now, chronic HCV infections are not notifiable. Therefore, there is no national surveillance system nor a database for chronic HCV infections. The surveillance of HCV could be improved by introducing chronic HCV infections into the notification policy. This would also make the current HBV and HCV estimated prevalence more precise.

At last, our results only hint at the possibility of a sexual transmission route for HEV given higher rates in those with chlamydia and/or gonorrhoeal infections. Sexual transmission is not a dominant transmission route, however, as its prevalence was not higher for the sexual high-risk population than for the general population. Whether sexual transmission of HEV occurs, and whether it could consequently lead to outbreaks such as HAV in MSM, should preferably be studied the individual level in future prospective research. Considering the limited clinical impact of HEV infections, we do not recommend increased HEV testing in sexual high-risk clinical settings, with the possible exception of patients who are immunocompromised. 


\subsection{Concluding remarks}

In conclusion, several methodologies can be used to detect hidden infections. This thesis showed the value of the surveillance pyramid as a tool to determine the different levels in infectious disease control and factors influencing its accuracy. Both epidemiological and geographical analyses compliment each other in identifying risk groups and estimating the prevalence of infectious diseases including hidden infections. However, there is no one-size-fits-all approach which can be applied to every infectious disease. Furthermore, this thesis demonstrates the importance of examining models and estimates in a real-life setting. 


\section{References}

1. WHO, WHO-recommended surveillance standards for surveillance of selected vaccine-preventable diseases. 2003, WHO: Geneva, Switzerland. p. 28-31.

2. Barkoff, A.M., K. Grondahl-Yli-Hannuksela, and Q. He, Seroprevalence studies of pertussis: what have we learned from different immunized populations. Pathog Dis, 2015. 73(7).

3. de Melker, H.E., et al., The incidence of Bordetella pertussis infections estimated in the population from a combination of serological surveys. J Infect, 2006. 53(2): p. 106-13.

4. De Greeff, S.C., et al., Seroprevalance of Pertussis in the NEtherlands: Evidence for Increased Circulation of Bordetella pertussis. PLoS ONE, 2010. 5(12).

5. de Greeff, S.C., et al., Seroprevalence of pertussis in The Netherlands: evidence for increased circulation of Bordetella pertussis. PLoS One, 2010. 5(12): p. e14183.

6. de Greeff, S.C., et al., Pertussis disease burden in the household: how to protect young infants. Clin Infect Dis, 2010. 50(10): p. 1339-45.

7. Wood, N. and P. Mclntyre, Pertussis: review of epidemiology, diagnosis, management and prevention. Paediatr Respir Rev, 2008. 9.

8. He, Q., et al., High heterogeneity in methods used for the laboratory confirmation of pertussis diagnosis among European countries, 2010: integration of epidemiological and laboratory surveillance must include standardisation of methodologies and quality assurance. Euro Surveill, 2012. 17(32).

9. Winter, K., et al., California Pertussis Epidemic, 2010. J Pediatr, 2012. 161(6).

10. Barret, A.S., et al., Pertussis outbreak in northwest Ireland, January - June 2010. Euro Surveill, 2010. 15(35).

11. Dempsey, A.F., et al., Diagnosis and testing pratices for adolescents pertussis among a national sample of primary care physicians. Prev Med, 2009. 48.

12. Heil, J., et al., Pertussis diagnostic practices of general practitioners in the Netherlands: a cross-sectional study Fam Pract, 2018. submitted.

13. Crowcroft, N.S. and R.G. Pebody, Recent developments in pertussis. Lancet, 2006. 367.

14. Solano, R., et al., Underdetection and underreporting of pertussis in children attended in primary health care centers: Do surveillance systems require improvement? Am J Infect Control, 2016. 44(11): p. e251-e256.

15. Heil, J., et al., Pertussis surveillance and control: exploring variations and delays in testing, laboratory diagnostics and public health service notifications, the Netherlands, 2010 to 2013. Euro Surveill, 2017. 22(28).

16. Kauhl, B., et al., Is the current pertussis incidence only the results of testing? A spatial and space-time analysis of pertussis surveillance data using cluster detection methods and geographically weighted regression modelling. PLoS One, 2017. 12(3): p. e0172383.

17. de Gier, B., et al., Verschillen in GGD-werkwijzen rond kinkhoestmeldingen. Infectieziekten Bulletin, 2016. 27(2): p. 54-56.

18. Niessen, W.J., J. Broer, and J. Schellekens, Onderzoek naar verschillen in GGD-werkwijzen rond kinkhoestmeldingen voor beleid ter bescherming van zuigelingen niet nodig. Infectieziekten Bulletin, 2016. 27(3): p. 103-105.

19. Bonacic Marinovic, A., et al., Quantifying reporting timeliness to improve outbreak control. Emerg Infect Dis, 2015. 21(2): p. 209-16.

20. Kraaij - Dirkzwager, M., et al., Melding op tijd of te laat? Terugkoppelingsrapportages aan GGD hebben meerwaarde. Infectieziekten Bulletin, 2015. 26(8).

21. Crabbe, H., et al., Are pertussis cases reported too late for public health interventions? Retrospective analysis of cases in London and South East England, 2010 to 2015. Euro Surveill, 2017. 22(29).

22. Niessen, W.J., J. Broer, and J.F. Schellekens, [The obligatory notification of pertussis is not 
effective for the protection of unvaccinated children]. Ned Tijdschr Geneeskd, 2008. 152(2): p. 86-90.

23. LCI, Richtlijn Pertussis - kinkhoest. 2012, RIVM: Bilthoven.

24. Guiso, N., et al., What to do and what not to do in serological diagnosis of pertussis: recommendations from EU reference laboratories. Eur $J$ Clin Microbiol Infect Dis, 2011. 30(3): p. 307-12.

25. Verheij, T.J.M., et al., NHG-Standaard Acuut hoesten (eerste herziening). Huisarts Wet, 2011. 54(2): p. 68-92.

26. Teepe, J., et al., Prevalence, diagnosis, and disease course of pertussis in adults with acute cough: a prospective, observational study in primary care. Br J Gen Pract, 2015. 65(639): p. e662-7.

27. Stanaway, J.D., et al., The global burden of viral hepatitis from 1990 to 2013: findings from the Global Burden of Disease Study 2013. Lancet, 2016.

28. Spradling, P.R., et al., Hepatitis $B$ and $C$ virus infection among 1.2 million persons with access to care: factors associated with testing and infection prevalence. Clin Infect Dis, 2012. 55(8): p. 1047-55.

29. Hagan, H., et al., Self-reported hepatitis $C$ virus antibody status and risk behavior in young injectors. Public Health Rep, 2006. 121(6): p. 710-9.

30. Brouard, C., et al., The undiagnosed chronically-infected HCV population in France. Implications for expanded testing recommendations in 2014. PLoS One, 2015. 10(5): p. e0126920.

31. Denniston, M.M., et al., Awareness of infection, knowledge of hepatitis $C$, and medical follow-up among individuals testing positive for hepatitis C: National Health and Nutrition Examination Survey 2001-2008. Hepatology, 2012. 55(6): p. 1652-61.

32. Hahne, S.J., et al., Prevalence of hepatitis B virus infection in The Netherlands in 1996 and 2007. Epidemiol Infect, 2012. 140(8): p. 1469-80.

33. Vriend, H.J., et al., Hepatitis $C$ virus seroprevalence in the Netherlands. Eur J Public Health, 2012. 22(6): p. 819-21.
34. Marschall, T., et al., High impact of migration on the prevalence of chronic hepatitis $B$ in the Netherlands. Eur I Gastroenterol Hepatol, 2008. 20(12): p. 1214-25.

35. Vriend, H.J., et al., Hepatitis C virus prevalence in The Netherlands: migrants account for most infections. Epidemiol Infect, 2012. 141(6): p. 13107.

36. The European Union HCV Collaborators, Hepatitis $C$ virus prevalence and level of intervention required to achieve the WHO targets for elimination in the European Union by 2030: a modelling study. Lancet Gastroenterol Hepatol, 2017. 2(5): p. 325-336.

37. Koopsen, J., et al., Chronic hepatitis B and C infections in the Netherlands: estimated prevalence in high-risk groups and the general population. Submitted, 2018.

38. Ganem, D. and A.M. Prince, Hepatitis B virus infection--natural history and clinical consequences. N Engl J Med, 2004. 350(11): p. 1118-29.

39. Thein, H.H., et al., Estimation of stage-specific fibrosis progression rates in chronic hepatitis $C$ virus infection: a meta-analysis and meta-regression. Hepatology, 2008. 48(2): p. 418-31.

40. Hofman, R., et al., [Mortality due to chronic viral hepatitis $B$ and $C$ infections in the Netherlands]. Ned Tijdschr Geneeskd, 2016. 160(0): p. D511.

41. Tran, T.T., A review of standard and newer treatment strategies in hepatitis C. Am J Manag Care, 2013. 18(14 Suppl): p. S340-9.

42. Dienstag, J.L., Hepatitis B virus infection. N Engl J Med, 2008. 359(14): p. 1486-500.

43. Arends, P. and H.L.A. Janssen, Behandelmogelijkheden van chronische hepatitis B. Nederlands Tijdschrift voor Medische Microbiologie, 2011. 19(1): p. 16-20.

44. Wichmann, 0. , et al., Phylogenetic and case-control study on hepatitis E virus infection in Germany. J Infect Dis, 2008. 198(12): p. 1732-41.

45. Colson, P., et al., Pig liver sausage as a source of hepatitis $E$ virus transmission to humans. J Infect Dis, 2010. 202(6): p. 825-34. 
46. Hazards, E. et al., Public health risks associated with hepatitis E virus (HEV) as a food-borne pathogen. EFSA Journal, 2017. 15(7): p. e04886n/a.

47. Gorgos, L., Sexual transmission of viral hepatitis. Infect Dis Clin North Am, 2013. 27(4): p. 811-36.

48. Freidl, G.S., et al., Hepatitis A outbreak among men who have sex with men (MSM) predominantly linked with the EuroPride, the Netherlands, July 2016 to February 2017. Euro Surveill, 2017. 22(8).

49. Sazzad, H.M.S., et al., Risk Factors Associated with Blood Exposure for Sporadic Hepatitis E in Dhaka, Bangladesh. Am J Trop Med Hyg, 2017.

50. Abravanel, F., et al., HEV infection in French HIV-infected patients. J Infect, 2017. 74(3): p. 310-313.

51. Eker, A., et al., [Hepatitis E virus epidemiology in adult population in Edirne province, Turkey]. Mikrobiyol Bul, 2009. 43(2): p. 251-8.

52. Christensen, P.B., et al., High prevalence of hepatitis $E$ antibodies among Danish prisoners and drug users. J Med Virol, 2002. 66(1): p. 49-55.

53. Thomas, D.L., et al., Seroreactivity to hepatitis $E$ virus in areas where the disease is not endemic. J Clin Microbiol, 1997. 35(5): p. 1244-7.

54. Chou, R., et al., Screening for Hepatitis C Virus Infection in Adults: A Systematic Review to Update the 2004 U.S. Preventive Services Task Force Recommendation. ann Intern Med, 2013. 158.

55. Smith, B.D., et al., Recommendations for the identification of chronic hepatitis $C$ virus infection among persons born during 1945-1965. MMWR Recomm Rep, 2012. 61(RR-4): p. 1-32.

56. Moyer, V.A. et al., Screening for hepatitis $\mathrm{C}$ virus infection in adults: U.S. Preventive Services Task Force recommendation statement. Ann Intern Med, 2013. 159(5): p. 349-57.

57. Alfaleh, F.Z., et al., Strategies to manage hepatitis $C$ virus infection disease burden - volume 3 . J Viral Hepat, 2015. 22 Suppl 4: p. 42-65.

58. McEwan, P., et al., The impact of timing and prioritization on the cost-effectiveness of birth cohort testing and treatment for hepatitis $\mathrm{C}$ virus in the United States. Hepatology, 2013. 58(1): p. 54-64.

59. Aspinall, E.J., et al., Targeted hepatitis $C$ antibody testing interventions: a systematic review and meta-analysis. Eur J Epidemiol, 2015. 30(2): p. 115-29.

60. Vermeiren, A.P., et al., Identification of hidden key hepatitis $C$ populations: an evaluation of screening practices using mixed epidemiological methods. PLoS One, 2012. 7(12): p. e51194.

61. Kauhl, B., et al., The Spatial Distribution of Hepatitis C Virus Infections and Associated Determinants-An Application of a Geographically Weighted Poisson Regression for Evidence-Based Screening Interventions in Hotspots. PLoS One, 2015. 10(9): p. e0135656.

62. Heil, J., et al., Detecting Hepatitis B and C by Combined Public Health and Primary Care Birth Cohort Testing. Ann Fam Med, 2018. 16(1): p. 21-27.

63. Richter, C., et al., Screening for chronic hepatitis $B$ and $C$ in migrants from Afghanistan, Iran, Iraq, the former Soviet Republics, and Vietnam in the Arnhem region, The Netherlands. Epidemiol Infect, 2014. 142(10): p. 2140-6.

64. Grintjes, K., et al., Hepatitis C-opsporing onder migranten in Nijmegen (HECOM). Tijdschrift voor Infectieziekten, 2014. 9(5): p. 126-133.

65. Zuure, F.R., et al., Using mass media and the Internet as tools to diagnose hepatitis $C$ infections in the general population. Am J Prev Med, 2011. 40(3): p. 345-52.

66. Zuure, F.R., et al., Screening for hepatitis B and $\mathrm{C}$ in first-generation Egyptian migrants living in the Netherlands. Liver Int, 2013. 33(5): p. 727-38.

67. Clark, P.J. and A.J. Muir, Overcoming barriers to care for hepatitis C. N Engl J Med, 2012. 366(26): p. 2436-8.

68. Cruts, A.A.N., M. Van Laar, and M. Buster, Aantal en kenmerken van problematische opiatengebruikers in Nederland. 2013, Trimbos-instituut: Utrecht.

69. Van Laar, M., et al., report to the EMCDDA by the Reitox National Focal Point. The Netherlands 
drug situation 2005. 2006, Trimbos-instituut: Utrecht.

70. Dutch Association of HIV-treating physicians. [HIV treatment guidelines for the Netherlands] [Cited August 22, 2017]. [cited 2017 August 22]; Available from: http://richtlijnhiv.nvhb.nl/index. php/Inhoud.

71. Loth, C., et al., [Guidline opiate maintenance treatment (RIOB) rivesed version]. 2012: Amersfoort.

72. van Rijckevorsel, G., et al., Targeted vaccination programme successful in reducing acute hepatitis $B$ in men having sex with men in Amsterdam, the Netherlands. J Hepatol, 2013. 59(6): p. 1177-83.

73. European Centre for Disease Prevention and Control, Epidemiological assessment of hepatitis $\mathrm{B}$ and $\mathrm{C}$ among migrants in the EU/EEA. 2016, ECDC: Stockholm.

74. Coenen, S., et al., Clinical impact of five largescale screening projects for chronic hepatitis $B$ in Chinese migrants in the Netherlands. Liver Int, 2016.

75. Richter, C., et al., Hepatitis B prevalence in the Turkish population of Arnhem: implications for national screening policy? Epidemiol Infect, 2012. 140(4): p. 724-30.

76. Veldhuijzen, I.K., et al., Viral hepatitis in a multi-ethnic neighborhood in the Netherlands: results of a community-based study in a low prevalence country. Int J Infect Dis, 2009. 13(1): p. e9-e13.

77. Zhou, K., et al., Interventions to optimise the care continuum for chronic viral hepatitis: a systematic review and meta-analyses. Lancet Infect Dis, 2016. 16(12): p. 1409-1422.

78. Stepanova, M., et al., Insurance status and treatment candidacy of hepatitis $C$ patients: analysis of population-based data from the United States. Hepatology, 2011. 53(3): p. 737-45.

79. Allison, W.E., et al., Knowledge about Hepatitis $C$ Virus Infection and Acceptability of Testing in the 1945-1965 Birth Cohort (Baby Boomers) Presenting to a Large Urban Emergency Department: A Pilot Study. J Emerg Med, 2016.

80. Allison, W.E., et al., Hepatitis C virus infection in the 1945-1965 birth cohort (baby boomers) in a large urban ED. Am J Emerg Med, 2016. 34(4): p. 697-701.

81. Galbraith, J.W., et al., Unrecognized chronic hepatitis $C$ virus infection among baby boomers in the emergency department. Hepatology, 2015. 61(3): p. 776-82.

82. White, D.A., et al., Results of a Rapid Hepatitis $C$ Virus Screening and Diagnostic Testing Program in an Urban Emergency Department. Ann Emerg Med, 2016. 67(1): p. 119-28.

83. Orkin, C., et al., Incorporating HIV/hepatitis B virus/hepatitis $C$ virus combined testing into routine blood tests in nine UK Emergency Departments: the "Going Viral" campaign. HIV Med, 2016. 17(3): p. 222-30.

84. Helsper, C., et al., Follow-up of mild alanine aminotransferase elevation identifies hidden hepatitis C in primary care. Br J Gen Pract, 2012. 62(596): p. e212-6.

85. Wolffram, l., et al., Prevalence of elevated ALT values, $\mathrm{HBsAg}$, and anti-HCV in the primary care setting and evaluation of guideline defined hepatitis risk scenarios. J Hepatol, 2015. 62(6): p. 1256-64.

86. Hofman, R., et al., Vervolgdiagnostiek, follow-up en verwijzing van patiënten met hepatitis $B$ en C. Ned Tijdschr Geneeskd, 2018. 162(D2047).

87. Niessen, W., et al., Evaluatie van de zorg voor mensen met chronische hepatitis $B$ in de provincie Groningen. Infectieziekten Bulletin, 2014. 25(3): p. 64-68.

88. Gezondheidsraad, Screening risk groups for hepatitis B and C. 2016, Health Council of the Netherlands: The Hague.

89. Spruijt, A.G., et al., [Tracing patients with chronic viral hepatitis]. Ned Tijdschr Geneeskd, 2016. 160(0): p. D414.

90. Beekmans, N. and M. Klemt-Kropp, Re-evaluation of chronic hepatitis $B$ and hepatitis $C$ patients lost to follow-up: results of the Northern Holland hepatitis retrieval project. Hepatology, Medicine and Policy, 2018. 3(1): p. 5. 



\section{Chapter 9}

\section{Appendices}



Summary 
The studies presented in this thesis aimed to identify and address hidden infections and evaluate current prevention, surveillance and control of infectious diseases.

In order to avoid pertussis-related infant morbidity and mortality, pertussis surveillance data are used to guide pertussis control measures. Chapter 2 provides more insight into the accuracy of pertussis surveillance and control, and into the range of healthcare and public health-related factors that hamper the identification of hidden pertussis infections. We analysed a unique combination of data sources from one Dutch region of 1.1 million residents, including data from laboratory databases and local public health notifications. This large surveillance study (12,090 pertussis tests) reveals possible misdiagnoses, substantial under-notification (18\%) and a delay between patient symptoms and notification to the local public health services (median 34 days, IQR: 27-54). In addition to the introduction of maternal immunisation, based on current findings, we further recommend greater adherence to testing guidelines, standardisation of test interpretation guidelines, use of automatic notification systems and earlier preventive measures.

In Chapter $\mathbf{3}$ we used geographical analyses to identify clusters of pertussis infections. We analysed laboratory registry data including all geocoded pertussis tests in the southern area of the Netherlands. Socio-demographic and infrastructure related population data were matched to the geo-coded laboratory data. Testing for pertussis follows to an extent the general healthcare seeking behaviour for common respiratory infections, whereas the current pertussis incidence is largely the result of testing. More testing would thus not necessarily improve pertussis control. Detecting outbreaks using space-time cluster detection is feasible but needs to be adjusted for the strong impact of testing on the detection of pertussis cases.

Chapter 4 describes, additional to Chapter 2, healthcare-related factors that hamper the identification of hidden pertussis infections. A total of $122 \mathrm{GPs}(21 \%)$ completed an online questionnaire on their diagnostic practices and perceived facilitators, barriers and intention towards pertussis testing. In contrast to national guidelines, that advise to perform laboratory testing for pertussis in patients at risk for (causing) complications from pertussis infections, general practitioners report to mainly perform laboratory diagnostic tests for pertussis in patients with clinical symptoms. This is in accordance with GPs' expressed facilitators and barriers to test for pertussis. We recommend GPs to focus pertussis testing more on family members surrounding incompletely vaccinated infants $<1$ year of age, women $>34$ weeks pregnant and children with severe comorbidities such as heart or lung failure.

In Chapter $\mathbf{5}$ hotspots of HCV infections and risk factors within these hotspots were identified to facilitate targeted, evidence-based testing strategies. We analysed $23,800 \mathrm{HCV}$ tests performed in the southern area of the Netherlands. Population data were matched to the geocoded HCV test data. Based on spatial-epidemiological analyses of laboratory data, the estimated prevalence of HCV infection in the south of the Netherlands is $0.5 \%$, and we identified HCV hotspots in urban areas, with a prevalence of up to $1 \%$. The main population at risk were middle-aged males, non-western immigrants and divorced persons. Socio-economic determinants consisted of one-person households, persons with low income and mean property value. However, the association between HCV risk and demo- 
graphic as well as socio-economic determinants displayed strong regional and intra-urban differences. These results underline that a one-size-fits-all approach may not be appropriate.

In Chapter $\mathbf{6}$ we determined the diagnostic yield (test uptake and rate of positive test results) of a combined public health and primary care birth cohort testing strategy in detecting hidden cases of $\mathrm{HCV}$ and HBV infections. We invited all patients aged between 40 and 70 years $(n=6,743)$ registered with 11 family practices serving $2 \mathrm{HCV}$ hotspots, in the south of the Netherlands. This best practice testing strategy was effective in achieving a high test uptake of $50.9 \%$. It completely failed, however, to detect hidden chronic HCV infections and is not recommended for countries with a low prevalence of the disease. The success factor of our high test uptake is the combination of a personal invitation accompanied by reminders, and the cooperation between public health care and primary care. Moreover, our findings informed the Dutch Health Council in their recommendation not to screen the general population for HCV and HBV infection.

In Chapter $\mathbf{7}$ we studied possible sexual transmission of HEV using a seroprevalence study as method to identify hidden hepatitis E infections. We compared the HEV prevalence in a Dutch sexual high-risk population with the prevalence in a general population while assessing sociodemographic and sexual risk factors. Overall prevalence of anti-HEV IgG of $18.9 \%$ ( $n=562$ ) was, adjusting for confounders, similar between the two populations. Prevalence was higher with each year's increase in age, among men and among individuals diagnosed with sexually transmitted infections. Our results only hint at the possibility of a sexual transmission route for HEV given higher rates in those with chlamydia and/or gonorrhoeal infections. Sexual transmission is not a dominant transmission route, as its prevalence was not higher for the sexual high-risk population than for the general population. Considering the limited clinical impact of HEV infections, we do not recommend increased HEV testing in sexual high-risk clinical settings, with the possible exception of patients who are immunocompromised.

In Chapter $\mathbf{8}$ the main findings of this thesis and recommendations for future policy and research on hidden infections are discussed. This is illustrated by recent studies on pertussis and hepatitis. In conclusion, several methodologies can be used to detect hidden infections. This thesis showed the value of the surveillance pyramid as a tool to determine the different levels in infectious disease control and factors influencing its accuracy. Epidemiological and geographical analyses compliment each other in identifying risk groups and estimating the prevalence of infectious diseases including hidden infections. However, there is no one-size-fits-all approach which can be applied to every infectious disease. Furthermore, this thesis demonstrates the importance of examining models and estimates in a real-life setting. 

Samenvatting 
De studies zoals gepresenteerd in dit proefschrift zijn gericht op het identificeren van verborgen infecties en evalueren de huidige preventie, surveillance en bestrijding van infectieziekten.

Surveillancedata zijn leidend voor het nemen van de juiste maatregelen en het voorkomen van morbiditeit en mortaliteit door kinkhoest bij zuigelingen. Hoofdstuk 2 geeft meer inzicht in de nauwkeurigheid van kinkhoest surveillance en de verschillende factoren in de (volks-)gezondheidszorg die het opsporen van verborgen infecties belemmeren. We analyseerden een unieke combinatie van databronnen in een regio met 1.1 miljoen inwoners, bestaande vit laboratoria data en GGD-meldingen. Deze grote surveillance studie (12,090 kinkhoest testen) onthulde mogelijke misdiagnoses, veel onderrapportage (18\%) en een grote vertraging tussen eerste ziektedag en de uiteindelijk melding aan de GGD (mediaan 34 dagen, IQR: 27-54). Aanvullend op het introduceren van maternale vaccinatie, adviseren we een hogere naleving van test richtlijnen, het standaardiseren van test interpretatie richtlijnen, het gebruik van geautomatiseerde meldingssystemen en het eerder nemen van preventieve maatregelen.

In Hoofdstuk 3 gebruikten we geografische analyses om clusters van kinkhoest infecties te identificeren. We analyseerden alle kinkhoest testen met postcodes van de laboratoria in Limburg. Sociaaldemografische kenmerken en gegevens over de infrastructuur werden gekoppeld aan deze geografisch-gecodeerde testdata. Het testen op kinkhoest wordt vooral bepaald door het hulpzoekgedrag van de patiënt, terwijl de kinkhoest incidentie vooral het resultaat is van testen. Meer testen verbeterd dus waarschijnlijk niet de kinkhoest bestrijding. Het detecteren van uitbraken is mogelijk met deze geografische analyses, maar er moet dan wel gecorrigeerd worden voor het testgedrag per regio.

Hoofdstuk 4 beschrijft, aanvullend op Hoofdstuk 2, factoren in de gezondheidszorg die het opsporen van verborgen kinkhoest infecties belemmeren. In totaal vulden 122 huisartsen (21\%) een online vragenlijst in over hun kinkhoest diagnostiek, bevorderende factoren, belemmerende factoren en de intentie om op kinkhoest te testen. In tegenstelling tot nationale richtlijnen rapporteren huisartsen vooral diagnostiek in te zetten voor kinkhoest bij patiënten met symptomen. Dit aanvraaggedrag komt overeen met de door de huisarts gerapporteerde bevorderende en belemmerende factoren om te testen op kinkhoest. Huisartsen zouden kinkhoest testen meer moeten richten op gezinsleden met nietof onvolledig gevaccineerde kinderen $<1$ jaar, vrouwen die $>34$ weken zwanger zijn en kinderen met ernstig onderliggend hart- of longlijden.

In Hoofdstuk 5 werden hotspots voor hepatitis $\mathrm{C}$ infecties en risicofactoren in kaart gebracht om gerichte, evidence-based test strategieën mogelijk te maken. We analyseerden 23,800 HCV testen in Zuid-Limburg. Bevolkingsgegevens werden aan deze testdata gekoppeld. Gebaseerd op geografische en epidemiologische analyses van deze laboratoria data is de geschatte HCV prevalentie $0.5 \%$ in ZuidLimburg met een oplopende prevalentie tot $1 \%$ in de gedetecteerde hotspots. De risicopopulatie bestond uit mannen van middelbare leeftijd, niet-westerse migranten en gescheiden personen. Sociaaleconomische determinanten waren éénpersoons huishoudens, personen met een laag inkomen en de gemiddelde woningwaarde. De associatie tussen deze demografische, sociaaleconomische determinanten en het risico op HCV verschilde echter sterk per regio en stadsdeel. Deze resultaten onderstrepen dat een one-size-fits-all aanpak niet van toepassing is. 
In Hoofdstuk $\mathbf{6}$ bepaalden we de diagnostische opbrengst (respons en percentage positief getest) van een geboortecohort test strategie. Dit was een samenwerking van publieke gezondheidszorg en eerstelijnszorg om verborgen HCV en HBV infecties te detecteren. Alle patiënten tussen de 40 en 70 jaar oud $(n=6,743)$ van 11 huisartspraktijken in twee HCV hotspots in Zuid-Limburg werden uitgenodigd. Deze teststrategie was effectief in het bereiken van een hoge respons van $50.9 \%$. Er werden daarentegen geen verborgen chronische HCV infecties opgespoord. Daarom wordt deze strategie niet aangeraden in andere landen met een lage HCV prevalentie. Succesfactoren van de hoge respons zijn de combinatie van een persoonlijke vitnodiging met herinneringen en de samenwerking van publieke gezondheidszorg en eerstelijnszorg. Onze bevindingen informeerden bovendien de Nederlandse gezondheidsraad in hun advies om niet de algemene bevolking te screenen op HCV en HBV infecties.

In Hoofdstuk 7 onderzochten we de mogelijke seksuele transmissie van HEV in een seroprevalentie studie om verborgen hepatitis $E$ infecties te identificeren. We vergeleken de HEV prevalentie tussen een populatie met een verhoogd seksueel risicogedrag en de algemene populatie en bepaalden sociaal-demografische en seksuele risicofactoren. De prevalentie van anti-HEV IgG $(18.9 \%, n=562)$ was gelijk in de twee onderzochte populaties na het corrigeren voor confounders. De prevalentie was wel hoger bij een hogere leeftijd, onder mannen en bij mensen met een chlamydia en/of gonorroe infectie. Onze resultaten geven daarom slechts een kleine indicatie voor de mogelijke seksuele transmissie route van HEV. Seksuele transmissie is geen dominante transmissieroute omdat er geen verschillende prevalentie werd gevonden tussen de twee onderzochte populaties. Gezien de beperkte klinische impact van $\mathrm{HEV}$ infecties raden we niet aan om meer te testen op HEV bij mensen met verhoogd seksueel risicogedrag, met uitzondering van immuun gecomprimeerde patiënten.

In Hoofdstuk 8 worden de belangrijkste resultaten van dit proefschrift en aanbevelingen voor toekomstig beleid en onderzoek naar verborgen infecties bediscussieerd. Dit is geïllustreerd aan de hand van studies naar kinkhoest en hepatitis. Samenvattend kunnen er verschillende methodes worden gebruikt om verborgen infecties op te sporen. Dit proefschrift laat zien dat de meldingspiramide een waardevolle tool is om de verschillende niveaus en beïnvloedende factoren van de infectieziekten bestrijding in kaart te brengen. Epidemiologische en geografische analyses vullen elkaar aan in het identificeren van risicogroepen en het schatten van de prevalentie van verborgen infecties. Er bestaat echter geen one-size-fits-all aanpak die kan worden toegepast op alle infectieziektes. Dit proefschrift toont bovendien het belang aan van het toetsen van modellen en schattingen in de praktijk. 

Valorisation 
Besides its scientific relevance this thesis also has implications for society as we identified and addressed hidden infections and evaluated current infectious disease prevention, surveillance and control. Based upon this thesis and recent literature we have several recommendations on how to improve current practice and policy. Overall, better insight into hidden infections allows for more targeted and effective testing practices in order to eventually protect the most vulnerable groups at risk. Several methodologies can be used to detect hidden infections. This thesis showed the value of the surveillance pyramid as a tool to determine the different levels in infectious disease control and factors influencing its accuracy. Epidemiological and geographical analyses compliment each other in identifying risk groups and estimating the prevalence of infectious diseases including hidden infections. However, there is no one-size-fits-all approach which can be applied to every infectious disease. Furthermore, this thesis demonstrates the importance of examining models and estimates in a real-life setting.

\section{Hidden pertussis infections}

We were able to give more insight into the factors that hamper the identification of hidden pertussis infections. These findings function as an important input for the discussion on how to reduce the workload of Public Health Service (PHS) and the debate on how to reduce the overall delay until notification to improve pertussis control. Overall, it is likely that the identified misdiagnosis, under-notification and overall delay in surveillance data are not unique for this area of the Netherlands and are generalizable to the rest of Europe. These countries are likely to encounter varying guidelines, difficulties in pertussis diagnostics and unexplained local differences in notification data too. Ideally, the accuracy of surveillance would be improved by focusing on the factors identified here. This contributes to optimisation of the surveillance system and more importantly, to improved pertussis control by preventing young infants from being infected with pertussis and avoiding morbidity and mortality in this young group.

First, to reduce misdiagnosis and the variation in pertussis diagnostics, we recommend laboratories and healthcare providers (HCPs) to improve adherence to national guidelines concerning timing and choice of test. For laboratories, a national uniform and standardised guideline on cut-off values in serology and the use of $\lg A$ and/or IgG is desirable. Testing all patients presenting with cough is not feasible, as only $3 \%$ of adult patients presenting with acute cough in primary care had evidence of an acute pertussis infection in Europe. Moreover, testing for pertussis follows to an extent the general healthcare seeking behaviour for common respiratory infections, whereas the current pertussis incidence is largely the result of testing. Increased testing would thus not necessarily improve pertussis control. Therefore, HCPs should focus pertussis testing on family members surrounding incompletely vaccinated infants $<1$ year of age, women $>34$ weeks pregnant and children with severe comorbidities such as heart or lung failure. In addition, they are advised to check whether patients with symptoms 
suggestive of whooping cough have vulnerable groups at risk in their household. As such, general practitioners (GPS) could play a more prominent role in contact tracing (now carried out by the PHS in the Netherlands) in order to minimise the disease burden in infants. We informed the GPs and laboratories in our region about our study results to remind them of the pertussis testing guidelines and to advise on possible preventive measures.

Second, to reduce under-notification, medical microbiology laboratories and HCPs could benefit from introducing automated notification systems. In an endemic situation with severe underreporting, the obligatory notification of pertussis is not effective for the protection of unvaccinated children. On the other hand, the notification of pertussis infections is of great value to national policy on pertussis surveillance and control although we showed the limitations of pertussis surveillance. Pertussis has to remain a notifiable disease as it is necessary to prohibit a pertussis-positive patient to go to work when he/she works with vulnerable young infants. In this thesis, we showed that the detection of pertussis outbreaks using space-time cluster detection is feasible and could help to facilitate an early and appropriate public health response. However, this approach has to be adjusted for the strong dependency to testing and is probably most efficient when using test-positivity as indicator.

Third, as public health is almost always too late to intervene, delays need to be reduced and we need earlier preventive measures by healthcare providers. Patient delays due to late presentation to healthcare may be unavoidable, however delays in reporting once a patient presents can be reduced. GPs, midwives and day nursery employees could play a major role here. Creating awareness among these professionals as well as patients themselves about taking timely preventive measures could lead to lower individual disease burden and to a higher cost-effectiveness of pertussis care.

At last, we also need additional preventive measures for the most vulnerable and susceptible group of unvaccinated infants, as the Dutch national vaccination program starts at the age of two months. In the first few months, young infants are unprotected as vaccination is only effective after at least three doses. The efficacy of pertussis vaccines has been debated because of waning immunity, incomplete protection of infants below 5 months, genetic changes in Bordetella pertussis and limited duration of protection. Currently, maternal immunisation provides good protection against infant disease, whilst no important side effects were observed, and has been recommended by the World Health Organisation and the European Centre for Disease Prevention and Control. The Dutch health council advised the introduction of maternal vaccination to the national vaccination program (December 2015) and pertussis vaccinations for healthcare workers (June 2017). Maternal vaccination will be executed at the child healthcare centres and introduced to the national vaccination program in 2019.

\section{Hidden hepatitis infections}

Lessons learned from our evidence-based practice to detect hidden hepatitis infections can be applied to future testing strategies and policy. The success factors of our high test uptake were the combina- 
tion of a personal invitation letter accompanied by reminder letters, the birth cohort testing, the hotspot approach and the cooperation between public health care and primary care.

At first, as no active hepatitis $\mathrm{C}$ virus (HCV) infections were found in the identified hotspots, the hotspot strategy would probably not work in other areas of the Netherlands as well as other countries with low HCV prevalence. Our findings partly informed the Dutch Health Council in their advice against screening of the general Dutch population for HCV and HBV (November 2016). This advice is part of the national hepatitis elimination plan, developed by specialists, doctors of the public health service and GPs, aimed at the prevention of transmission and reduction of hepatitis related disease burden and deaths. The committee recommends case finding by GPs for people in risk groups and by institutions who are responsible for delivering care to people in risk groups or for accommodating these people. The GP guidelines in the UK and the Netherlands advice to focus more on targeted HBV testing, especially among non-western migrants as they account for the largest proportion of HBV and HCV infections. This is in line with the recommendation of the Dutch Health Council on regional HBV screening programmes in areas with relatively large groups of first-generation migrants from high-endemic countries ( $\geq 2 \%$ chronic HBV infection). In the Netherlands, people who inject drugs (PWID) and HIV-positive men who have sex with men are tested for HBV and/or HCV as part of comprehensive health care programs (i.e., HIV treatment, HBV vaccination, and harm reduction programs for PWID). However, for migrants there are no structural screening programs. This may partly be caused by the heterogeneity of this population, in terms of ethnic origin, risk for infection and awareness of infection status. Some screening interventions in the Netherlands have targeted different migrant groups. These interventions, however, were limited in geographical coverage, and uptake was often low/moderate depending on the screening model. Structural screening programs for (subgroups of) migrants are needed to substantially reduce chronic viral hepatitis related morbidity and mortality among migrants, and the sustainability, linkage to care and access to treatment has to be ensured.

Additionally, our testing strategy could be applied to detecting HCV and HBV in high-endemic countries, to other infectious diseases and high-endemic settings. Higher positivity rates have been found in studies of countries with higher prevalence and in settings other than the general population with higher prevalence, such as the emergency department. An American study showed that HCV-infected individuals are more likely to use the emergency department (ED) for care than any other health care setting. Testing in this setting reveals hidden infections as this testing could reach those who do not respond to screening projects, do not feel at risk or avoid health care in general. Furthermore, test-uptake in this setting may be very high as tests can be offered and performed within routine diagnostic work-up. Several studies in the UK and US support routine testing on HCV in the ED setting with high test-uptakes and anti-HCV prevalence. In the context of applicability, it is shown that routinely offering $\mathrm{HCV}$ testing to patients who are undergoing laboratory testing had no effect on length of stay at the emergency department.

Consciousness of health care providers, for example to prompt viral hepatitis testing when people present with abnormal liver function, is needed to identify those infected who do not belong to one of 
the risk groups. Automated screening alerts for ALAT elevation (diagnostic liver enzyme) at the GP clinic can be a tool to detect hidden HCV infections, although this is a challenging process. The risk of $\mathrm{HCV}$ infection is substantially elevated in Dutch primary care patients with an ALAT elevation between $50 \mathrm{IU} / \mathrm{L}$ and $100 \mathrm{IU} / \mathrm{l}$, whereas the risk of HBV infection is not. Therefore, diagnostic follow-up for HCV is recommended in all these patients, particularly in those for whom no clear explanation for the ALAT elevation is found. Among HBV patients without an indication for referral, ALAT should be checked, both the GP and the patient should be reminded for these check-ups.

Future projects aimed at detecting chronic HBV and HCV infections hidden to care in the Netherlands should focus on retrieval projects. This includes retracing and evaluating patients previously diagnosed with HBV or HCV who are eligible for treatment. In the Netherlands, there is evidence for patients diagnosed with HBV or HCV who are eligible for treatment still remain untreated. These patients were lost to follow-up as they stopped treatment because of the side effects, were not able to start treatment because of contra-indications, or did not attend their follow-up appointments. The Health Council of the Netherlands recommend retracing people who have been diagnosed with HBV or HCV in the past but are no longer receiving care. This retracing should focus on giving patients the opportunity to make use of the new treatment options. Once they have been retraced, they must promptly be given appropriate care. Studies on detection of chronic hepatitis $B$ and $C$ patients who were lost to follow up, enables evaluation of the indication for current treatment options.

Currently, a national registry of all HBV and HCV infected patients is in development and will include patients characteristics and treatment data. HBV infections and recent HCV infections are notifiable diseases. Until now, chronic HCV infections are not notifiable. Therefore, there is no national surveillance system nor a database for chronic HCV infections. The surveillance of HCV could be improved by introducing chronic HCV infections into the notification policy. This would also make the current HBV and HCV estimated prevalence more precise.

We have provided scientific and societal relevance in the work presented. We identified and addressed hidden infections and evaluated current infectious disease prevention, surveillance and control. Based upon this work and recent literature we suggested on improvements of current practice and policy in hepatitis and pertussis control. Overall, better insight into hidden infections allows for more targeted and effective testing practices in order to eventually protect the most vulnerable groups at risk. Although, there is no one-size-fits-all approach we showed several methodologies that can be applied to the assessment of hidden infections in infectious diseases. 

Dankwoord 
Wie had dat gedacht? Van open sollicitatie naar werkervaringsplek en uiteindelijk het afronden van een promotietraject! Dit mooie boek is het resultaat van vier jaar hard werken, maar dit was er natuurlijk niet geweest zonder de hulp van vele anderen. ledereen die hieraan heeft bijgedragen wil ik daarom bedanken. De volgende mensen wil ik graag persoonlijk bedanken:

Om te beginnen mijn eerste promotor: Prof. dr. Hoebe. Christian, bedankt voor het vertrouwen en de kansen die jij me hebt gegeven. Van jouw expertise en enthousiasme heb ik veel geleerd in de afgelopen jaren. Van jou kreeg ik de vrijheid om veel zelfstandig te werken en met vragen kan ik ondanks je drukke agenda altijd bij je terecht.

Prof. dr. Cals, mijn tweede promotor, een aantal maanden geleden verraste je mij met het bericht dat je bent benoemd tot hoogleraar. In onze promotie-overleggen bespraken we vaak veel, jij dacht mee over de volgende stappen of andere mogelijkheden. Beste Jochen, bedankt voor de goede samenwerking met de verschillende huisartsen in Limburg, maar vooral bedankt voor jouw steun en waardering.

Mijn co-promotor, dr. Dukers-Muijrers, bedankt voor de vele uren die jij hebt geïnvesteerd in het lezen van mijn stukken en het beantwoorden van mijn vragen. Jouw scherpe blik, onderzoekservaring en ruime statistische en epidemiologische kennis vormden de basis van onze wekelijkse overleggen. Dankjewel Nicole, voor het delen van jouw kennis en voor jouw betrokkenheid.

Onderzoek doen is natuurlijk niet mogelijk zonder voldoende deelnemers en deskundige projectleden. Graag wil ik alle deelnemende patiënten, huisartsen, laboratoria-medewerkers, epidemiologen, psychologen, wijkverpleegkundigen, taalambassadeurs en buurtcentra bedanken voor hun medewerking. Ook alle co-auteurs wil ik bedanken voor hun bijdrage aan mijn artikelen in de vorm van data-verzameling, meeschrijven en/of het geven van feedback. With special thanks to Boris and Henriëtte.

Leden van de promotiecommissie, bedankt voor het beoordelen van mijn proefschrift en voor het plaatsnemen in de corona.

Bedankt fijne collega's van de GGD, afdeling Seksuele Gezondheid, Infectieziekten en Milieu voor jullie interesse en jullie enthousiaste inzet. De artsen en verpleegkundigen van het team IZB wil ik graag bedanken voor onze goede samenwerking en het geven van jullie advies. Collega's van Medische Microbiologie en in het bijzonder Inge, bedankt voor het meedenken en het vitvoeren van de testen in onze studies. Dames van het secretariaat, bedankt voor jullie ondersteuning en de gezellige lunchwandelingen. En natuurlijk de GGD-onderzoekers: Geneviève, Kevin, Lisanne, Jeanine, Juliën, Patricia, Mitch en Ymke. Dankjewel voor het delen van jullie kennis en ervaring, de lol op kantoor en de onvergetelijke teamuitjes. Wat fijn dat we nog een jaar collega's mogen blijven. 
Een speciaal woord van dank aan mijn paranimfen. Bedankt voor jullie luisterend oor. Steffi, gedeelde smart is halve smart. De afgelopen tien jaar hebben we veel gedeeld: collegebanken, een sollicitatie, ons kantoor, noem het maar op. Het is super dat we nu elkaars paranimf kunnen zijn en deze mooie tijd kunnen bekronen met twee promoties. Marlous, waar moet ik beginnen? Bedankt voor onze leuke weekendtrips, 'het misdragen', 'het sfeertje' en alle andere bijzondere tradities. Dankjewel voor jouw vriendschap en steun, wat ben ik blij dat jij achter mij staat bij mijn promotie.

Lieve vrienden en familie, jullie wil ik allemaal graag bedanken voor de afleiding, het aanhoren van mijn verhalen en het tonen van jullie interesse. Ward, bedankt voor alle bourgondische avonden, de onuitputbare drankvoorraad en jouw steun. Lieve Tessa en Lena, we go way back... Bedankt voor jullie gezelligheid! Bedankt volleybaldames en trainers van Fyrfad en VC Heerlen voor de adrenaline en ontspanning.

Frank, Monique en Daan, wat hebben wij samen al veel meegemaakt, bedankt dat ik zo welkom ben bij jullie. Bedankt lieve oma Elly, oma Pietje en oma Koenen voor jullie interesse in alles wat ik doe, ook al is het misschien lastig te begrijpen wat dat precies is. Papa, mama, Michiel, bedankt dat jullie mij altijd steunen. Ik ben trots op ons en dankbaar voor alles wat jullie voor mij doen. Jullie hoeven je geen zorgen meer te maken, het boekje is af!

Lieve Jeroen, zonder jou was dit boek er niet geweest. Dankjewel dat jij er altijd voor me bent. Wat hebben we het goed samen, bij jou is één blik genoeg. Laten we samen deze mijlpaal vieren, genieten van ons huis en de wereld blijven ontdekken. Ik hou van jou. 

Portfolio 


\section{Courses and training}

\section{6}

Analytic Story Telling

by Evert-Jan Kamerbeek

Workshop "Crafting the Valorisation Paragraph for your Doctoral Thesis"

by Ivo George

Presentation Skills

by John Rouvroye and Mabel Frumau

\section{5}

Online Academic Writing Skills (English for PHD Students)

by Neill Wylie

Heuvellandcursus (cursus schrijven en publiceren)

by Jochen Cals and Daniel Kotz

\section{Presentations}

\section{International}

European Scientific Conference on Applied Infectious Disease Epidemiology

Saint Julian's, Malta (2018)

European Scientific Conference on Applied Infectious Disease Epidemiology

Stockholm, Sweden (2017)

$26^{\text {th }}$ European Congress of Clinical Microbiology and Infectious Diseases

Amsterdam, the Netherlands (2016)

\section{National}

28e Transmissiedag Rijks Instituut Volksgezondheid en Milieu, Amersfoort (2018)

Annual Research Day Medical Microbiology, Maastricht (2016)

Nationale Hepatitis Dag, Amsterdam (2016) 
Annual CAPHRI researchday, Maastricht (2016)

Nederlandse Huisartsen Genootschap Wetenschapsdag, Amsterdam (2016)

26e Transmissiedag Rijks Instituut Volksgezondheid en Milieu, Amersfoort (2016)

Annual Research Day Medical Microbiology, Maastricht (2015)

Nationale Hepatitis Dag, Amsterdam (2015)

Nationale Hepatitis Dag, Amsterdam (2014)

\section{Grants}

\section{Travel grants}

Personal travel grant to the European Scientific Conference on Applied Infectious Disease Epidemiology (ESCAIDE), 6-8 November 2017, Stockholm, Sweden

Personal travel grant for the $26^{\text {th }}$ European Congress of Clinical Microbiology and Infectious Diseases (ECCMID), 9-12 April 2016, Amsterdam, the Netherlands

\section{Funding from industry}

$\mathrm{HCV}$ retrieval project in South Limburg. Retrieval of patients diagnosed with chronic hepatitis $\mathrm{C}$ in the past who were lost to follow-up

Period: October 2017 - September 2018

Project coordinator: Jeanne Heil/prof. dr. C.J.P.A. Hoebe/dr. N.H.T.M. Dukers-Muijrers

Funded by: Gilead Sciences Netherlands B.V. and MSD B.V.

\section{Memberships}

RIVM expert board on HCV/HBV prevalence estimations

Workgroup on health literacy at Public Health Service of South-Limburg 



\section{List of publications}




\section{8}

Dukers-Muijrers NHTM, Heijman T, Götz HM, Wolffs PFG, Zaandam P, Wijers J, Leenen J, van Liere GAFS, Heil J, Brinkhues S, Wielemaker A, Bruisten SM, van der Loeff MFS, Steenbakkers M, Hogewoning AA, de Vries $\mathrm{HJ}$, Hoebe CJPA. Participation, retention and associated factors in women recruited in a prospective multicentre study on Chlamydia trachomatis infections (FemCure) (in progress)

Heil J, Cals JWL, ter Waarbeek HLG, Hoebe CJPA, Dukers-Muijrers NHTM. Reasons for testing and non-testing for pertussis are not well know. Fam Pract 2018 (submitted)

Koopsen J, van Steenbergen JE, Richardus JH, Prins M, Op de Coul ELM, Croes EA, Heil J, Zuure FR and Veldhuijzen IK. Chronic hepatitis B and C infections in the Netherlands: estimated prevalence in risk groups and the general population. Epidemiology and Infection 2018 (submitted)

Heil J, Hoebe CJPA, van Loo IHM, Cals JWL, van Liere GAFS, Dukers-Muijrers NHTM (2018) Hepatitis E prevalence in a sexual high-risk population compared to the general population. PLOS ONE 13(1): e0191798.

Heil J, Hoebe CJPA, Cals JWL, ter Waarbeek HLG, van Loo IHM, and Dukers-Muijrers NHTM (2018) Detecting Hepatitis B and C by Combined Public Health and Primary Care Birth Cohort Testing. Ann Fam Med. 16(1):21-27; doi:10.1370/afm.2166.

\section{7}

Heil J, ter Waarbeek HLG, Hoebe CJPA, Jacobs PHA, van Dam DW, Trienekens TAM, Cals JWL, van Loo IHM, Dukers-Muijrers NHTM (2017) Pertussis surveillance and control: exploring variations and delays in testing, laboratory diagnostics and public health service notifications, the Netherlands, 2010 to 2013. Euro Surveill. 22(28): pii=30571.

Kauhl B, Heil J, Hoebe CJPA, Schweikart J, Krafft T, Dukers-Muijrers NHTM (2017) Is the current pertussis incidence only the results of testing? A spatial and space-time analysis of pertussis surveillance data using cluster detection methods and geographically weighted regression modelling. PLOS ONE 12(3): e0172383. 


\section{5}

Kauhl B, Heil J, Hoebe CJPA, Schweikart J, Krafft T, Dukers-Muijrers NHTM (2015) The Spatial Distribution of Hepatitis C Virus Infections and Associated Determinants-An Application of a Geographically Weighted Poisson Regression for Evidence-Based Screening Interventions in Hotspots. PLOS ONE 10(9): e0135656. 

"Winners... are not those who never fail, but... those who never quit"

\author{
Banksy
}




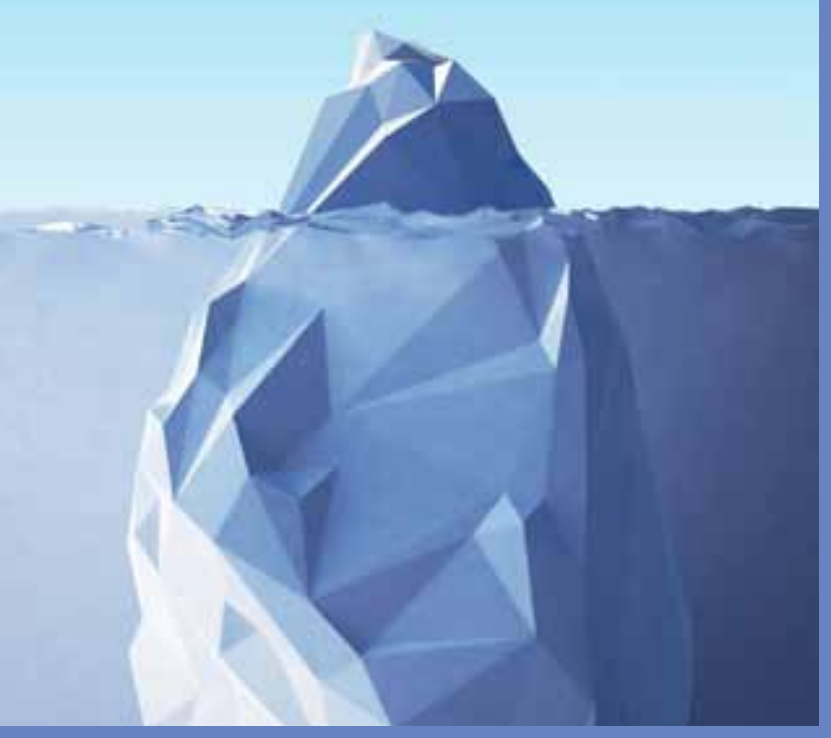

